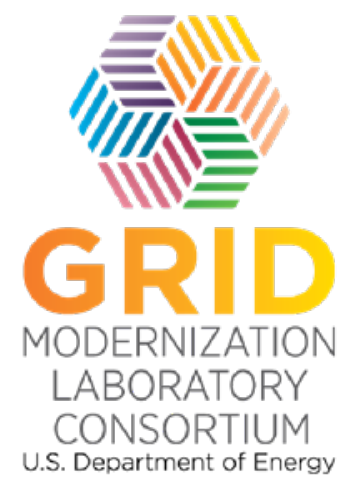

\title{
Research Priorities and Opportunities in United States Competitive Wholesale Electricity Markets
}

\section{May 2021}

Y Sun

T Levin

J Kwon

Q Xu

$N$ Singhal

E Ela

Z Zhou

C Crespo Montanes
B Frew

RB Hytowitz

AD Mills

$M$ Heidarifar

$P$ de Mello

A Botterud

BF Hobbs 


\section{Research Priorities and Opportunities in United States Competitive Wholesale Electricity Markets}

$\begin{array}{ll}\text { Y Sun }^{1} & \text { B Frew }^{1} \\ \text { T Levin }^{2} & \text { RB Hytowitz } \\ \text { J Kwon }^{2} & \text { AD Mills } \\ \text { Q Xu}^{5} & \text { M Heidarifar }^{3} \\ \text { N Singhal }^{3} & \text { P de Mello } \\ \text { E Ela }^{3} & \text { A Botterud }^{2} \\ \text { Z Zhou }^{2} & \text { BF Hobbs } \\ \text { C Crespo Montanes }\end{array}$

May 2021

\footnotetext{
${ }^{1}$ National Renewable Energy Laboratory

${ }^{2}$ Argonne National Laboratory

${ }^{3}$ Electric Power Research Institute

${ }^{4}$ Lawrence Berkeley National Laboratory

${ }^{5}$ Johns Hopkins University
} 


\section{NOTICE}

This work was authored in part by the National Renewable Energy Laboratory, operated by Alliance for Sustainable Energy, LLC, for the U.S. Department of Energy (DOE) under Contract No. DE-AC36-08GO28308. Funding provided by the U.S. Department of Energy Office of Electricity, the U.S. Department of Energy Office of Energy Efficiency and Renewable Energy Wind Energy Technologies Office and Water Power Technologies Office, and the U.S. Department of Energy Office of Nuclear Energy. The views expressed herein do not necessarily represent the views of the DOE or the U.S. Government.

U.S. Department of Energy (DOE) reports produced after 1991 and a growing number of pre-1991 documents are available free via www.OSTI.gov.

NREL prints on paper that contains recycled content. 


\section{Summary}

The power system is currently undergoing a number of changes, including a rapidly evolving resource mix, growth of distributed energy resources (DERs), more active consumer participation, increased deployment of energy storage and hybrid resources, and more advanced communication and control requirements. These changes in the power system present numerous technical, economic, implementation, and policy challenges and research opportunities for power system operators. To help address these challenges, a collaboration among five research institutions-Argonne National Laboratory, the National Renewable Energy Laboratory, Lawrence Berkeley National Laboratory, the Electric Power Research Institute, and Johns Hopkins University - has been established to provide technical assistance to the seven U.S. Independent System Operators (ISOs) and Regional Transmission Organizations (RTOs). The 3-year project aims to leverage the advanced methods, tools, datasets, and resources of the collaborators to provide robust analytical support to address the high-priority market challenges that will be faced in the 2to 10 -year time horizon.

This report, which is the first product of this collaboration, details six high-level topic areas related to challenges associated with wholesale electricity market design. These six topic areas, as well as specific subtopic market design challenges and opportunities, were identified through an extensive review of ISO/RTO publications, industry reports, and the academic literature. The project team then solicited feedback from representatives of the seven U.S. ISO/RTOs to quantitatively rank the priority of the six topic areas. The resultant ranking is as follows:

1. Incentivizing reliability services and operational flexibility;

2. Integrating new and emerging technologies in wholesale market operations;

3. Resource adequacy and system resilience;

4. Energy price formation;

5. Transmission-distribution coordination and wholesale-retail interactions; and

6. Transmission expansion planning and financial transmission rights.

The discussion of the six topic areas and their subtopics in this report proceeds in accordance with this prioritization. Each section corresponds to a topic area and includes a discussion of current market practices, relevant ISO/RTO market design initiatives, and major challenges and opportunities in wholesale market design that could benefit from development and application of analytical tools to support improved market procedures. This content is based on theoretical considerations, industry reports, the academic literature, technical capabilities of the project team, and ISO/RTO inputs.

In addition, ISO/RTO representatives were asked to rank specific market design challenges and research opportunities within each topic area. The following broad themes emerged:

First, the rapid growth of emerging technologies may motivate changes to current wholesale electricity market design in order to efficiently ensure both long-term and operational reliability. The deployment of these new technologies may have an impact on essential reliability service requirements, but such technologies also have an often underutilized ability to provide many of these services themselves. Market rule changes that enable variable renewable energy (VRE) resources, storage, hybrid systems and demand-side resources to participate in ancillary service markets can ensure that VRE and emerging technologies are able to provide the full range of essential reliability services. Furthermore, the development of new methods to accurately calculate the resource adequacy contribution of these emerging technologies is a crucial element of maintaining efficient long-term planning processes. 
Second, at an operational level, system resources must be appropriately incentivized to provide the grid services and operational flexibility needed to maintain system reliability in an economically efficient manner. Specifically, markets may benefit from introducing products and associated price signals for new reliability services, updating approaches to price formation to ensure that all resources are compensated in a fair and non-discriminatory fashion, adjusting definitions of existing products for reliability services, ensuring deliverability of capacity products, and considering multiday markets.

Third, a key challenge over planning horizons is ensuring that markets provide revenue sufficiency for the resources needed to guarantee long-term reliability, while also providing efficient price signals for market exit when appropriate. This is particularly the case in a world with an increasing amount of zero-marginal cost resources, which may suppress energy prices and revenues. Well-designed energy price formation mechanisms, especially scarcity and shortage pricing, possibly combined with additional resource adequacy constructs and clarity of responsibility for procuring and delivering adequate resources, are critical for generator cost recovery in power systems with high penetrations of zero-marginal cost resources.

Finally, enhanced transmission-distribution coordination will also help to support power systems with more active consumer participation at the distribution level. Enabling DERs to participate in wholesale markets for electricity and other grid services and improving ISO/RTO situational awareness of DERs are two primary challenges. Improving transmission planning processes to incorporate long-term uncertainties and to develop methods to co-optimize transmission and generation decisions are also important for future power system evolution.

In summary, this document serves to establish a broad research agenda by identifying gaps and research priorities related to evolving wholesale electricity market design, as guided by inputs from the seven U.S. ISO/RTOs for the targeted 2- to 10-year horizon. This report is not intended to be inclusive of broader policy, regulatory, industry, or inter-regional considerations, nor does it address longer-term issues. Future work could explore these additional factors and time scales; for example, coordination across multiple market regions to support transmission expansion for very-high-VRE futures and the role of improved VRE and load forecasts in such futures. Continued collaboration across a wide range of stakeholders is needed to support the ongoing and long-term transformation of the electrical power grid. 


\section{Acknowledgments}

This research was supported by the Grid Modernization Initiative of the U.S. Department of Energy (DOE) as part of its Grid Modernization Laboratory Consortium, a strategic partnership between DOE and the national laboratories to bring together leading experts, technologies, and resources to collaborate on the goal of modernizing the nation's grid. This work was authored in part by the National Renewable Energy Laboratory, operated by Alliance for Sustainable Energy, LLC, for the U.S. Department of Energy (DOE) under Contract No. DE-AC36-08GO28308. Funding was provided by the Office of Electricity, Office of Energy Efficiency and Renewable Energy Wind Energy Technologies Office and Water Power Technologies Office, and the Office of Nuclear Energy. The authors thank Michael DeSocio and Michael Swider (New York Independent System Operator), Dane Schiro (ISO New England), Anthony Giacomoni (PJM Interconnection), Mark O’Malley (Energy Systems Integration Group and University College Dublin), Rob Gramlich (Grid Strategies and Future Power Markets Forum), David Hill (Columbia University Center on Global Energy Policy and Future Power Markets Forum), and Daniel Bilello, Daniel Steinberg, Murali Baggu, Gian Porro, Jessica Lau, and Greg Brinkman (NREL) for feedback on the draft of this report. We also thank the U.S. DOE managers, Jian Fu, Melissa Pauley, and Alison Hahn, for their guidance throughout this project. Finally, we thank the seven U.S. ISOs and RTOs for their participation in this project, namely the California Independent System Operator, the Electric Reliability Council of Texas, ISO New England, the Midcontinent Independent System Operator, the New York Independent System Operator, PJM Interconnection, and the Southwest Power Pool. The views expressed in the report do not necessarily represent the views of the DOE or the U.S. Government. The U.S. Government retains and the publisher, by accepting the article for publication, acknowledges that the U.S. Government retains a nonexclusive, paid-up, irrevocable, worldwide license to publish or reproduce the published form of this work, or allow others to do so, for U.S. Government purposes. 


\section{Acronyms and Abbreviations}

AEMO

BRP

BSM

CAISO

CASPR

COG

CONE

CPUC

DA

DER

DFAX

DR

DSO

ECRS

ELCC

ELMP

EPRI

ERCOT

ERS

ES

FCM

FERC

FFR

FRR

FTR

GEP

IMM

ISO

ISO-NE

LMP

LODF

LOLE

LRE

LSE

MISO

MOPR

MWh

NERC
Australian Energy Market Operator Limited

Baseline Reliability Project

buyer-side mitigation

California Independent System Operator

Competitive Auctions with Sponsored Resources

constrained output generator

Cost of New Entry

California Public Utilities Commission

day ahead

distributed energy resource

distribution factor analysis

demand response

distribution system operator

ERCOT contingency reserve service

effective load-carrying capability

extended locational marginal pricing

Electric Power Research Institute

Electric Reliability Council of Texas

essential reliability services

energy storage

Forward Capacity Market

Federal Energy Regulatory Commission

fast frequency response

Fixed Resource Requirement

financial transmission right

generation expansion planning

independent market monitor

Independent System Operator

ISO New England Inc.

locational marginal pricing

line outage distribution factor

loss-of-load expectation

load responsible entity

load-serving entity

Midcontinent Independent System Operator, Inc.

Minimum Offer Price Rule

megawatt-hour(s)

North American Electric Reliability Corporation 


$\begin{array}{ll}\text { NREL } & \text { National Renewable Energy Laboratory } \\ \text { NYISO } & \text { New York Independent System Operator } \\ \text { ORDC } & \text { operating reserve demand curve } \\ \text { PFR } & \begin{array}{l}\text { primary frequency response } \\ \text { maximum power output }\end{array} \\ \text { PJax } & \text { PJM Interconnection LLC } \\ \text { PV } & \text { photovoltaics } \\ \text { QSGR } & \text { quick start generating resource } \\ \text { RBU } & \text { regional benefit upgrades } \\ \text { RT } & \text { real time } \\ \text { RTO } & \text { Regional Transmission Organization } \\ \text { RUC } & \text { residual unit commitment } \\ \text { SCED } & \text { Security Constrained Economic Dispatch } \\ \text { SPP } & \text { Southwest Power Pool, Inc. } \\ \text { TEP } & \text { transmission expansion planning } \\ \text { TSO } & \text { Transmission System Operator } \\ \text { VMP } & \text { Voluntary Mitigation Plan } \\ \text { VRE } & \text { variable renewable energy } \\ \text { W-DER } & \text { wholesale DER }\end{array}$




\section{Contents}

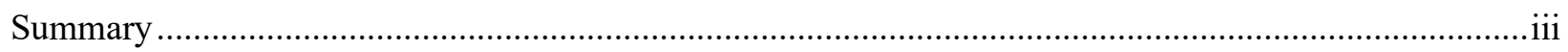

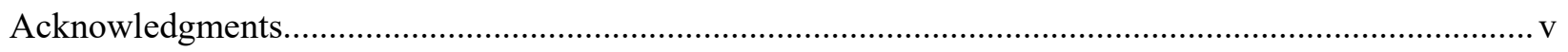

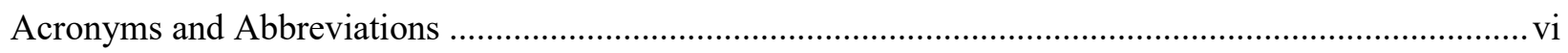

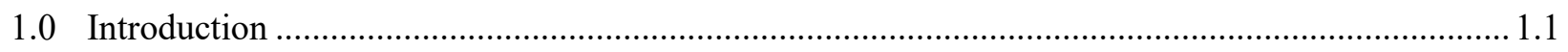

2.0 Incentivizing Reliability Services and Operational Flexibility................................................... 2.1

2.1 Current Market Practice for Incentivizing Reliability and Operational Flexibility ................. 2.2

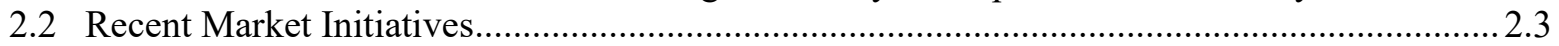

2.3 Key Challenges, Research Opportunities, and Findings from the Literature .......................... 2.4

2.3.1 New Reserve/Flexibility Products......................................................................... 2.5

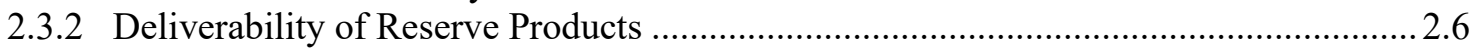

2.3.3 Structural Redesign of Ancillary Service Market ....................................................... 2.7

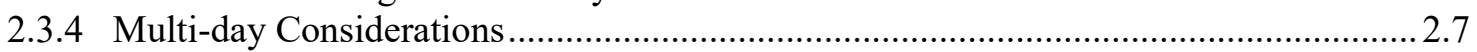

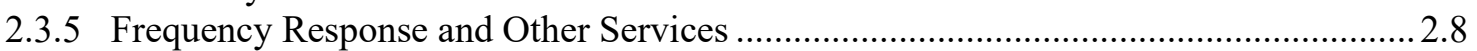

2.3.6 Cost Recovery and Incentive Structure during Emergencies ....................................... 2.8

2.3.7 Operating Reserve Demand Curve/Scarcity Pricing .......................................... 2.10

3.0 Integrating New and Emerging Technologies into Wholesale Market Operations ...........................3.1

3.1 Current Market Practice for Emerging Technologies .......................................................... 3.2

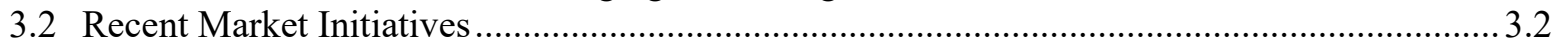

3.3 Key Challenges, Research Opportunities, and Findings from the Literature .............................. 3.4

3.3.1 Delivery of Sufficient Essential Reliability Services ................................................... 3.4

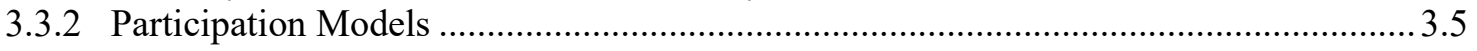

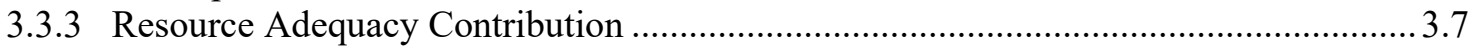

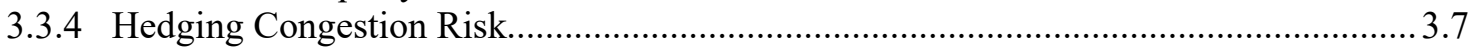

4.0 Resource Adequacy and System Resilience ............................................................................. 4.1

4.1 Current Market Practice for Resource Adequacy and Resilience Considerations .................... 4.2

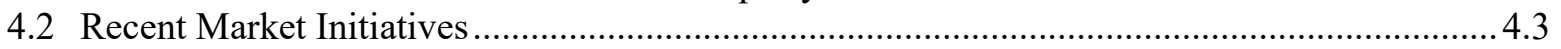

4.3 Key Challenges, Research Opportunities, and Findings from the Literature........................... 4.4

4.3.1 Enhance Reliability Assessment and Implementation .............................................. 4.5

4.3.2 Capacity Rating and Capacity Credit Calculation Method ........................................... 4.6

4.3.3 Accommodate State-Level Policies into Capacity Markets .......................................... 4.7

4.3.4 Shape and Parameters of Capacity Demand Curve..................................................... 4.8

4.3.5 Import Resources Capacity Contribution and Performance Evaluation...................... 4.10

4.3.6 Market Mechanism to Procure Sufficient Firm Capacity ............................................ 4.11

4.3.7 Participant Risk Mitigation in Capacity Markets and Bilateral Contracts ................... 4.12

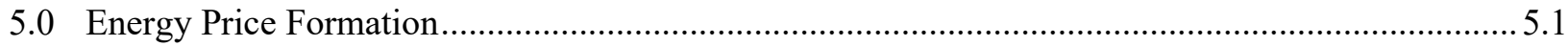

5.1 Current Market Practice for Energy Price Formation ....................................................... 5.2

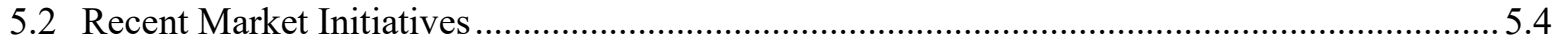

5.3 Key Challenges, Research Opportunities, and Findings from the Literature............................5.5

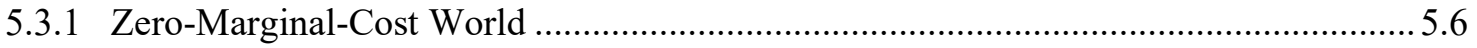

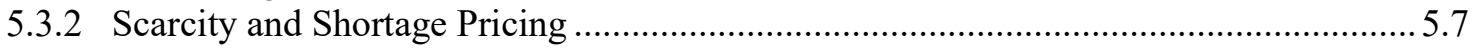

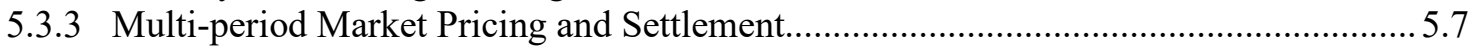

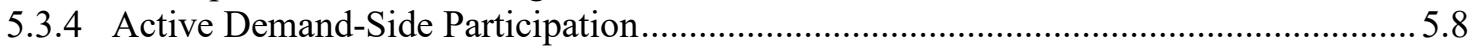

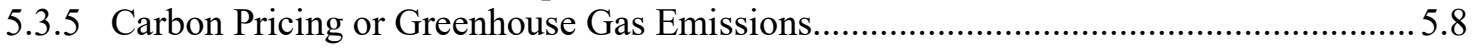


6.0 Transmission-Distribution Coordination and Wholesale-Retail Interactions ................................ 6.1

6.1 Current Market Practice for Transmission-Distribution Coordination.................................... 6.2

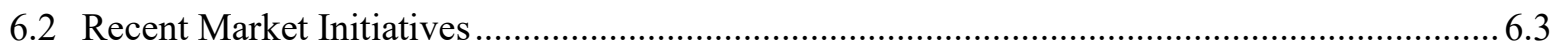

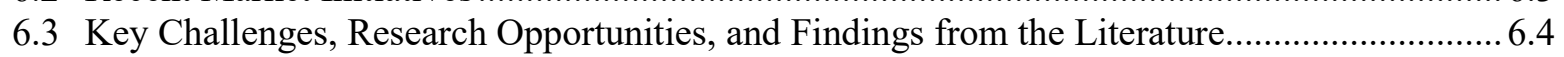
6.3.1 Market Design and Control Methods for the Provision of Grid Services from DERs ... 6.5

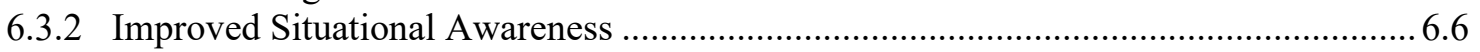

6.3.3 ISO-DSO Coordination Mechanisms and Concepts ................................................... 6.7

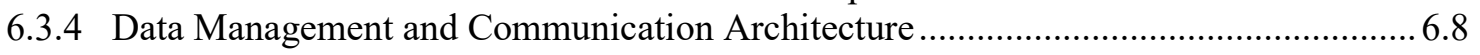

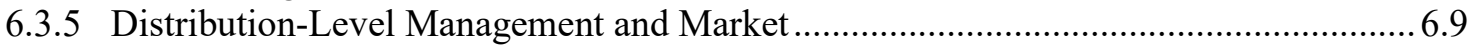

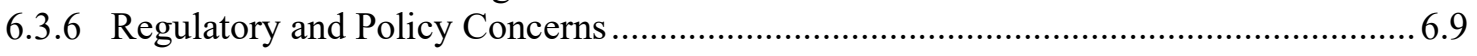

7.0 Transmission Expansion Planning and Financial Transmission Rights ....................................... 7.1

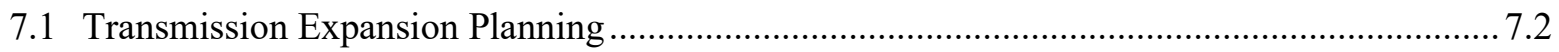

7.1.1 Current Market Practice for Transmission Expansion Planning .................................... 7.2

7.1.2 Key Challenges, Research Opportunities, and Findings from the Literature .................. 7.5

7.2 Financial Transmission Rights ....................................................................................

7.2.1 Current Market Practice for Financial Transmission Rights..................................... 7.10

7.2.2 Key Challenges, Research Opportunities, and Findings from the Literature ............... 7.12

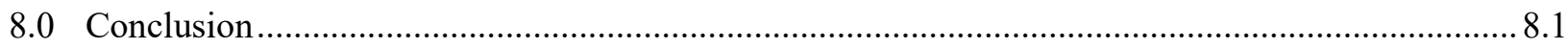

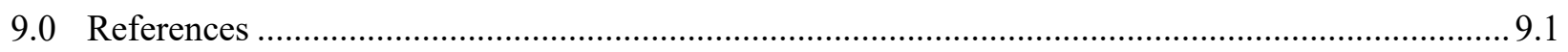




\section{Figures}

1. Prioritization ranking of aggregate topic areas provided by the ISO/RTOs .................................. 1.3

2. Priority ranking of market challenges in six market design areas from the ISO/RTO stakeholder meeting.

3. Priority ranking of market challenges related to incentivizing reliability services and operational flexibility from the ISO/RTO stakeholder meeting. .....

4. Priority ranking of market challenges related to integrating emerging technologies in market operations from the ISO/RTO stakeholder meeting

5. Priority ranking of market challenges related to resource adequacy and system resilience from the ISO/RTO stakeholder meeting

6. Illustration of a generic demand curve for a capacity market.

7. Priority ranking of market challenges related to energy price formation from the ISO/RTO stakeholder meeting

8. Challenges are emerging in the area of energy price formation

9. Priority ranking of market challenges related to transmission-distribution coordination and wholesale-retail interactions from the ISO/RTO stakeholder meeting

10. Priority ranking of market challenges related to transmission planning from the ISO/RTO stakeholder meeting.

11. General TEP cycle for ISO/RTOs.

12. Congestion Revenue Cash Flow without and with FTR markets

13. Composite cross-ranking of the 12 highest-priority market challenges and research opportunities across all six major topic areas from the ISO/RTO stakeholder meeting 


\section{Tables}

1. Operating reserves for active power control in each ISO/RTO

2. Recent market changes and proposed plans related to reliability and increased operational flexibility.

3. Major research questions and opportunities related to incentivizing reliability and operational flexibility.

4. Market prices during four extreme weather events......

5. Status of emerging technologies in the United States.

6. Recent market changes and proposed plans related to emerging technologies

7. Major research questions and opportunities related to emerging technologies in order of ISO/RTO stakeholder priority.

8. Current practice of resource adequacy programs and compensation in the United States

9. Recent market changes and proposed plans related to resource adequacy and system resilience

10. Major research questions and opportunities related to resource adequacy and system resilience

11. Existing characteristics of ISO and RTO auctions and energy price formation efforts.

12. Recent market changes and proposed plans related to energy price formation.

13. Major research questions and opportunities related to energy price formation.....

14. Key areas requiring greater transmission-distribution coordination, as identified by MISO

15. Recent market changes and proposed plans related to transmission-distribution coordination

16. Major research questions and opportunities related to transmission-distribution coordination

17. Comparison of ISO-DSO coordination models.

18. Current TEP practices of ISO/RTOs.

19. Major research questions and opportunities related to TEP for ISO/RTOs

20. Uncertainties in TEP considered by ISOs......

21. Review of current market practice of FTRs.

22. Major research questions and opportunities related to FTRs for ISO/RTOs 


\subsection{Introduction}

The power system is currently undergoing rapid changes. Wind, solar, and natural gas resources are continuing to grow at an increasing pace while many large coal and nuclear plants are retiring. Emerging technologies, such as distributed energy resources (DERs), energy storage (ES), and hybrid resources, are being deployed at ever-increasing rates, and more active customer participation is occurring in multiple electricity markets. These changes will likely require more advanced communication and control capabilities, as well as corresponding changes in market rules and participation models. Anticipated changes in both the magnitude and profile of electricity consumption through electrification will also introduce more opportunities for demand-side participation, further requiring a more holistic approach for energy system planning and operation to ensure system reliability and resilience.

These changes create new opportunities for wholesale electricity market design that explicitly fall under the purview of the Independent System Operators (ISOs) and Regional Transmission Organizations (RTOs) in the United States. While the market environment and related priorities differ across ISO/RTOs, many of the key challenges and research needs are similar across multiple markets. These common themes include but are not limited to the following: (1) how to efficiently incentivize the resources needed for long-term system reliability, while also providing efficient price signals for market exit when appropriate, within competitive power markets that are increasingly characterized by zero-marginal generation; (2) how to provide incentives for operational reliability and flexibility in an economically efficient manner; (3) how to integrate emerging technologies into market operations; and (4) how to improve transmission planning processes and enhance coordination between transmission and distribution systems to reflect grid needs.

These identified market challenges and research opportunities in wholesale electricity market design motivated a collaboration between five research institutions-Argonne National Laboratory, the National Renewable Energy Laboratory (NREL), Lawrence Berkeley National Laboratory, the Electric Power Research Institute (EPRI), and Johns Hopkins University - to provide technical support to the U.S. ISO/RTOs and their stakeholders. The seven U.S. ISO/RTOs engaged in this project are (in alphabetical order) the California Independent System Operator (CAISO), the Electric Reliability Council of Texas (ERCOT), ISO New England Inc. (ISO-NE), the Midcontinent Independent System Operator, Inc. (MISO), the New York Independent System Operator (NYISO), PJM Interconnection LLC (PJM), and Southwest Power Pool, Inc. (SPP). The three-year project aims to leverage the advanced methods, tools, datasets, and resources of the national laboratories and industry/academic partners to provide robust analytical support to address high-priority market research needs.

As the first task of this multi-year technical assistance project, this report identifies gaps and research priorities related to evolving wholesale electricity market design, as guided by inputs from ISO/RTOs and other relevant stakeholders obtained through a process that is described below. This report provides an indepth overview of current market practices and key market design challenges in U.S. electricity markets, with a focus on the challenges and research opportunities that can be addressed through technical assistance provided by the project team. The report targets a broad range of industry participants in this field, aiming to clearly identify and categorize the range of challenges and research needs currently faced by U.S. ISO/RTOs and motivate future discussion on these challenges and their potential solutions. We do not provide background materials on the basics of how competitive wholesale electricity markets operate and refer readers to Ela, Milligan, et al. (2014), Stoft (2002), Kirschen and Strbac (2004), FERC (2020b) and EPRI (EPRI 2016) for such background. Furthermore, since this report is based on input from the U.S. ISO/RTOs, we also do not provide discussion outside of the set of ISO/RTO-focused 
challenges in the targeted 2- to 10-year horizon. This report is not intended to be inclusive of broader policy, regulatory, industry, or inter-regional considerations, nor does it address longer-term issues; such factors could include coordination across multiple market regions to support transmission expansion for very-high-VRE futures. In addition, our focus is on highlighting - from a holistic perspective - the overarching themes across a diverse set of regions with varying resources, policies, and market design approaches. Future work could develop standard approaches to compare the incentive compatibility of each region's market design to provide a more consistent, analytically based comparison.

In April 2020, the project team held a stakeholder workshop on ISO and RTO Research and Development Prioritization to discuss and review high-level market design challenges and research opportunities related to ongoing power system evolution. The project team also polled representatives from all seven U.S. ISO/RTOs to prioritize six high-level market design topic areas and a set of respective subtopic market design challenges for each topic area. These topic areas and challenges were initially identified through a review of ISO/RTOs publications, industry reports, and the academic literature. The ISO/RTO representatives provided quantitative feedback through interactive polling to establish an ordered prioritization of these high-level topic areas and specific challenges, which is used to guide the research in this project. The resultant prioritization is as follows:

1. Incentivizing reliability services and operational flexibility;

2. Integrating new and emerging technologies in wholesale market operations;

3. Resource adequacy and system resilience;

4. Energy price formation;

5. Transmission-distribution coordination and wholesale-retail interactions; and

6. Transmission expansion planning and financial transmission rights (FTRs).

Each ISO/RTO participant was asked to rank all six topic areas in order of their perceived priority, particularly in respect to opportunities for the project team to provide the most assistance. The aggregate prioritization of each topic area was then quantified by ranking each response on a linear scale from $0 \%$ to $100 \%$; that is, a first-place ranking is allocated a value of $100 \%$; a second place vote $80 \%$; and so on, down to $0 \%$ for a sixth place ranking. In cases in which multiple individuals from a single ISO/RTO participated, these rankings were first averaged across all participants within each ISO/RTO to determine an average ranking score for each topic from each ISO/RTO. This was done to ensure that the input from each ISO/RTO was weighted consistently regardless of how many of its members participated in the poll. Then these average rankings were again averaged across the ISO/RTOs to arrive at a single composite ranking for each topic area. These quantitative prioritization results are shown in Figure 1. 


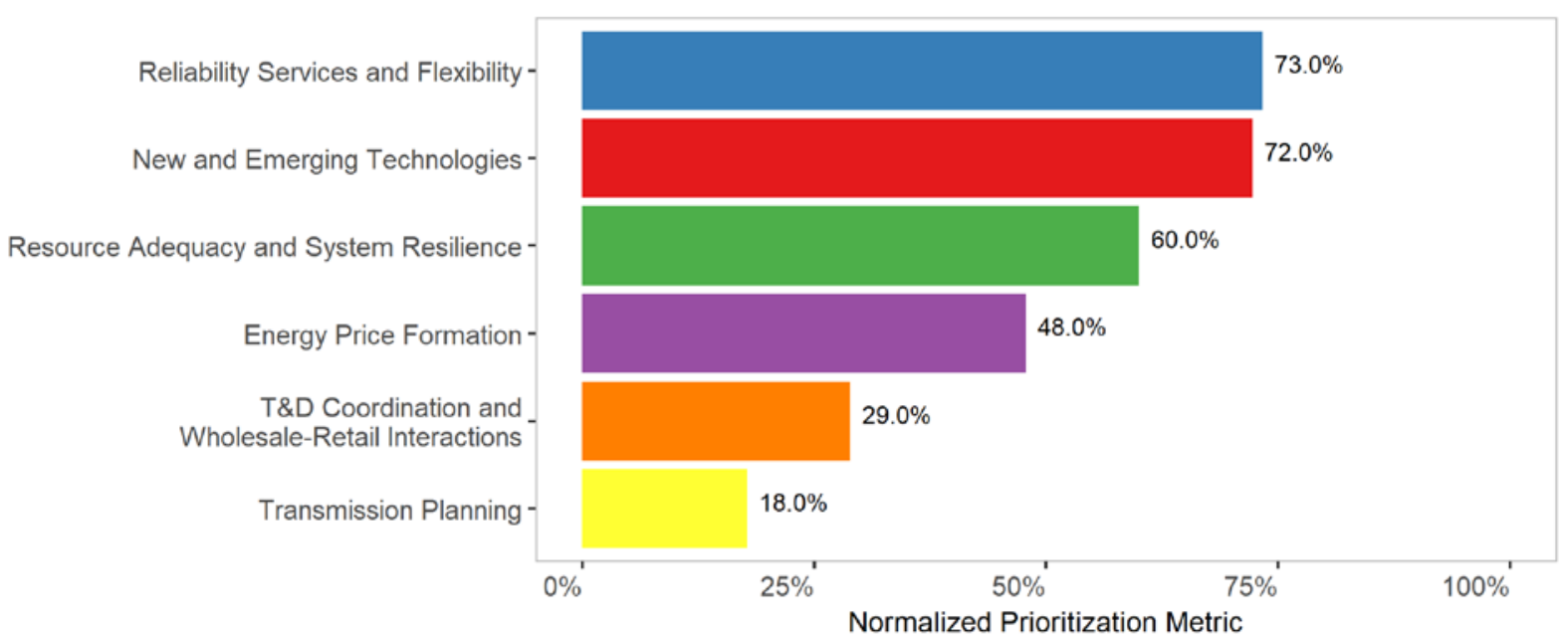

Figure 1. Prioritization ranking of aggregate topic areas provided by the ISO/RTOs

This same process was also applied to rank individual market challenges and research opportunities within each topic area; these are described in more detail in each section of this report. Figure 2 summarizes the resultant prioritization of both the topic areas (top to bottom) and their corresponding market challenges (left to right). We note that a number of overlaps exist between the challenges presented in this figure, and we highlight key ones throughout the document. For example, "ancillary service and market redesign" under the Reliability and Flexibility topic area and "scarcity and shortage pricing" under the Price Formation topic area clearly have many overlapping elements. Another overlap exists between "resource adequacy contribution of emerging resources" under Emerging Technologies and "capacity credit calculation" under Resource Adequacy. Overlaps are also present across the higherlevel topic areas; for example transmission planning is a key component of enabling system reliability and flexibility and also plays a crucial role in integrating emerging technologies. These inherent overlaps highlight a particularly notable aspect of electricity market design, namely, the fundamentally interconnected nature of different market products and design elements. Market objectives can often be achieved by implementing a number of different approaches, and any individual market changes can lead to cascading impacts across other areas of market design. These complex interactions make it inherently difficult to establish a universal and mutually exclusive list of research priorities, but also create opportunities in terms of devising novel approaches to address pressing market challenges and meet system objectives. 


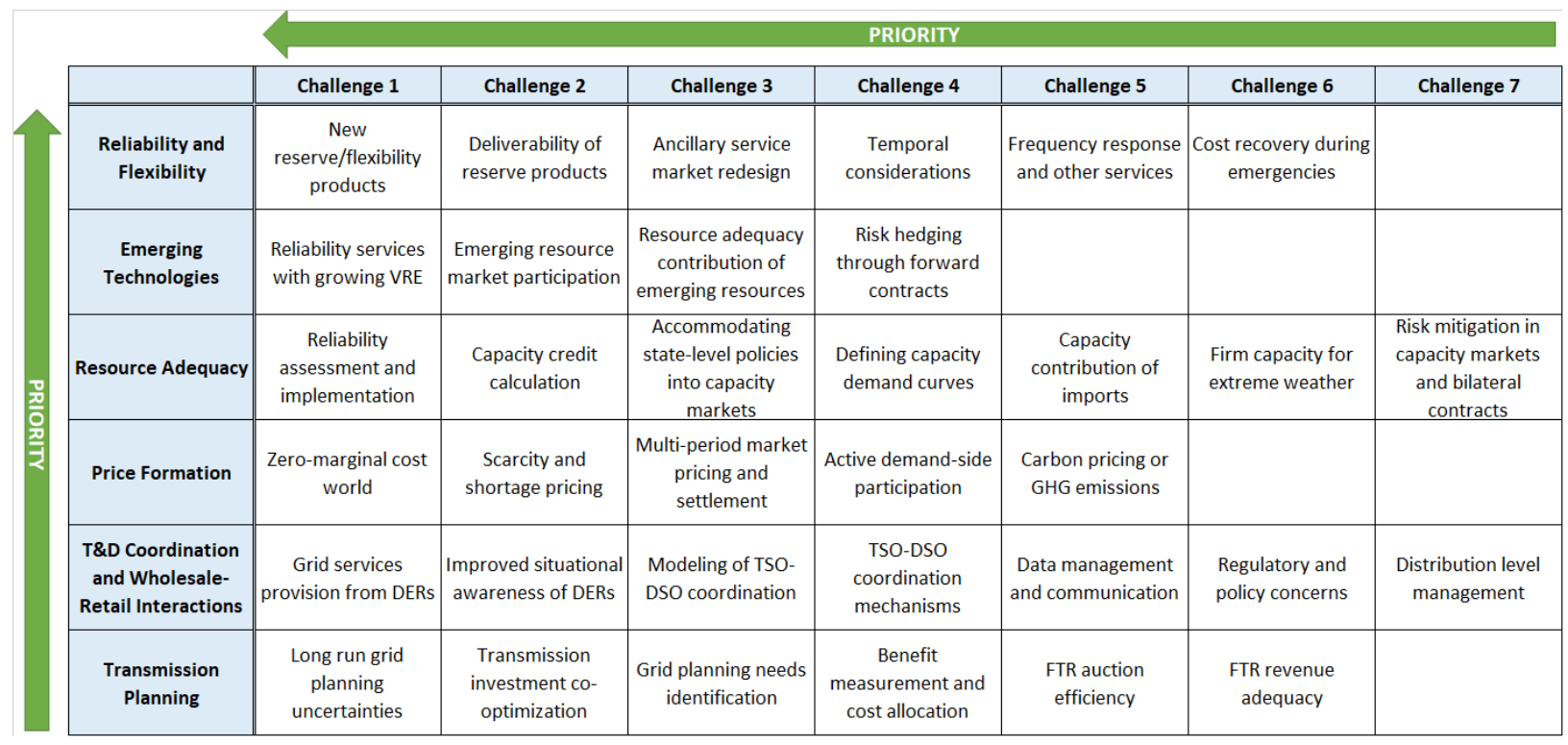

Figure 2. Priority ranking of market challenges in six market design areas from the ISO/RTO stakeholder meeting. The votes are normalized by the organization (i.e., one vote per ISO/RTO). The order of topic areas also reflects the priority ranking (from top to bottom).

This remainder of this report is organized as follows: sections 2 through 7 present detailed descriptions of each of the six challenge topic areas in the established order of prioritization, as shown in Figure 2. Within each section, the current market practice, industry trends, and recent ISO/RTO initiatives are summarized, followed by an in-depth discussion of specific challenges, research gaps, and insights from the literature. Each challenge is categorized as either a technical, economic, implementation, or policy challenge. ${ }^{1}$ Finally, section 8 summarizes the conclusions from this work.

1 Technical challenges refer to the challenges that can be resolved through engineering-based technical analysis, which are the focus of the project; economics challenges are the ones that touch underlying economic principles and require economic tools and methods to solve; implementation challenges are those that are relatively well understood in principle, but pose various implementation difficulties at the ISO/RTO level; and policy challenges are the challenges that are policy-related and rely heavily on political or regulatory decisions. 


\subsection{Incentivizing Reliability Services and Operational Flexibility}

Wholesale electricity markets operated by ISO/RTOs are used to ensure that operational reliability is maintained at all times. Products and designs are used alongside system operational procedures to ensure that the different services needed to maintain operational reliability are procured in sufficient quantities in locations where they are needed and at least cost. In addition to traditional reliability services and attributes such as voltage control, frequency control, and contingency reserves (Rebours et al. 2007), ISO/RTO regions may require additional operating flexibility to ensure reliability as the penetration of intermittent variable renewable energy (VRE), such as solar and wind, and behind-the-meter DERs increase (Ela et al. 2011). Resource flexibility is a broad concept that can depend on the needs of a specific system and may include attributes such as faster ramp rates, faster start-up/shutdown times, wider dispatchable range, and relaxed minimal commitment constraints (Nicholson 2019; Tuohy and Lannoye 2014). In addition, services that have traditionally been provided in ample amounts are becoming increasingly important, because the evolving fleet may lack some of the attributes that were inherently part of the existing fleet (Tuohy 2016). Many ISO/RTOs have modified or proposed to modify their operations and market rules to incentivize both supply- and demand-side resources and to provide the suite of services required to maintain operating reliability.

ISO/RTOs are evaluating how they can best enable sufficient system reliability services and operational flexibility through a variety of market and operational means. Doing so may require introducing new reserve and flexibility products, guaranteeing the deliverability of these products, redesigning ancillary service markets with new features and incentives, revising the current market structures to accommodate longer time horizons (e.g., multiday processes), enhancing or introducing frequency response and other reliability products that were traditionally inherent to the existing fleet, and ensuring cost recovery during emergencies. The prioritization of these market challenges is guided by ISO stakeholder inputs, with the ranking results shown in Figure 3.

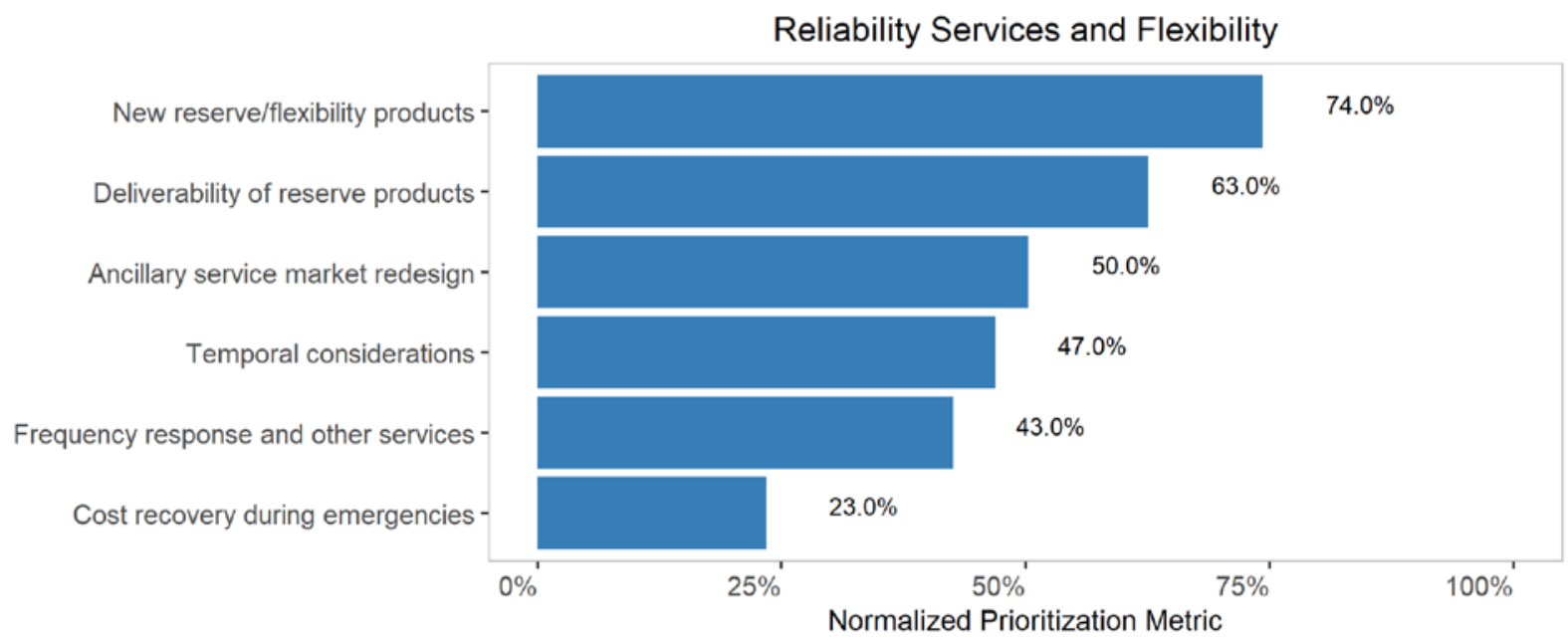

Figure 3. Priority ranking of market challenges related to incentivizing reliability services and operational flexibility from the ISO/RTO stakeholder meeting.

The rest of this section is organized as follows: section 2.1 highlights current market practices for supporting reliability and operational flexibility; section 2.2 summarizes recent market initiatives as well 
as potential modifications and proposals currently being discussed by ISO/RTOs, and section 2.3 provides detailed descriptions of the primary challenges and insights from the literature.

\subsection{Current Market Practice for Incentivizing Reliability and Operational Flexibility}

ISO/RTOs use a wide variety of methods to incentivize reliability services and ensure operational flexibility. These range from products to address a particular issue (e.g., ramping products in MISO and CAISO) to changes to bid structures (e.g., opportunity-cost adders in ISO-NE) to compensation for services (e.g., restoration energy compensation in MISO). Each ISO/RTO defines its own set of ERS; some ERS are paid for through market mechanisms, while others are covered by cost-based payments. Among those services are secondary contingency reserves (spinning reserve, non-spinning reserve), tertiary contingency reserves (replacement reserve, 30-minute operating reserve), regulating reserves, flexibility reserves (ramp capability), inertia service, primary frequency response (PFR), fast frequency response (FFR), voltage support and reactive power provision including reactive power reserve, and black start and restoration service. The product names used by ISO/RTOs for operating reserves for active power control are shown in Table 1; these products are all procured through associated auctions within each market. While the products within a category are similar, specific definitions and requirements differ across ISO/RTOs (EPRI 2019a).

Table 1. Operating reserves for active power control in each ISO/RTO

\begin{tabular}{|c|c|c|c|c|c|c|c|}
\hline Category & ISO-NE & NYISO & PJM & MISO & SPP & ERCOT & CAISO \\
\hline $\begin{array}{l}\text { Regulating } \\
\text { Reserve }\end{array}$ & $\begin{array}{l}\text { Regulation } \\
\text { (real time }[\mathrm{RT}] \text { ) }\end{array}$ & $\begin{array}{l}\text { Regulation } \\
\text { (DA [day } \\
\text { ahead], RT) }\end{array}$ & $\begin{array}{l}\text { Regulation } \\
\text { (RT) }\end{array}$ & $\begin{array}{l}\text { Regulation } \\
\text { (DA, RT) }\end{array}$ & $\begin{array}{l}\text { Regulation up, } \\
\text { down } \\
(\mathrm{DA}, \mathrm{RT})\end{array}$ & $\begin{array}{l}\text { Regulation } \\
\text { service } \\
\text { (DA) }\end{array}$ & $\begin{array}{l}\text { Regulation up, } \\
\text { down } \\
(\mathrm{DA}, \mathrm{RT})\end{array}$ \\
\hline $\begin{array}{l}\text { Spinning } \\
\text { reserve }\end{array}$ & $\begin{array}{l}\text { Ten-minute } \\
\text { spinning } \\
\text { reserve } \\
\text { (RT) }\end{array}$ & $\begin{array}{l}\text { Spinning } \\
\text { reserve } \\
(\mathrm{DA}, \mathrm{RT})\end{array}$ & $\begin{array}{l}\text { Synchro-nized } \\
\text { reserve } \\
\left(\mathrm{DA}^{\mathrm{a}}, \mathrm{RT}\right)\end{array}$ & $\begin{array}{l}\text { Spinning } \\
\text { reserve } \\
(\mathrm{DA}, \mathrm{RT})\end{array}$ & $\begin{array}{l}\text { Spinning } \\
\text { reserve } \\
(\mathrm{DA}, \mathrm{RT})\end{array}$ & $\begin{array}{l}\text { Responsive } \\
\text { reserve }^{\mathrm{b}} \\
\text { (DA) }\end{array}$ & $\begin{array}{l}\text { Spinning reserve } \\
(\mathrm{DA}, \mathrm{RT})\end{array}$ \\
\hline $\begin{array}{l}\text { Non- } \\
\text { spinning } \\
\text { reserve }\end{array}$ & $\begin{array}{l}\text { Ten-minute } \\
\text { non-spinning } \\
\text { reserve }\end{array}$ & $\begin{array}{l}\text { Non- } \\
\text { spinning } \\
\text { reserve }\end{array}$ & $\begin{array}{l}\text { Non- } \\
\text { synchronized } \\
\text { reserve }\end{array}$ & $\begin{array}{l}\text { Supplemental } \\
\text { reserve }\end{array}$ & $\begin{array}{l}\text { Supplemental } \\
\text { reserve }\end{array}$ & & $\begin{array}{l}\text { Non-spinning } \\
\text { reserve }\end{array}$ \\
\hline $\begin{array}{l}\text { Longer term } \\
\text { products }\end{array}$ & $\begin{array}{l}\text { Thirty-minute } \\
\text { operating } \\
\text { reserve }\end{array}$ & $\begin{array}{l}\text { Thirty- } \\
\text { minute } \\
\text { operating } \\
\text { reserve }\end{array}$ & & & & $\begin{array}{l}\text { Non- } \\
\text { spinning } \\
\text { reservec }^{c}\end{array}$ & \\
\hline $\begin{array}{l}\text { Flexibility } \\
\text { Reserve }\end{array}$ & & & & $\begin{array}{l}\text { Ramp } \\
\text { capability up, } \\
\text { down } \\
(\mathrm{DA}, \mathrm{RT})\end{array}$ & & & $\begin{array}{l}\text { Flexible ramping } \\
\text { product up, down } \\
\text { (RT) }\end{array}$ \\
\hline
\end{tabular}

a Day-ahead scheduling reserve is actually not completely aligned with the real-time products of synchronized and nonsynchronized reserves.

b ERCOT is in the process of disaggregating the current Responsive Reserve Service into three distinct products: ERCOT contingency reserve service (ECRS), PFR, and FFR. PFR and FFR are currently active as of early 2020; ECRS is anticipated to be in place by 2022 .

c ERCOT "non-spinning reserve" allows for 30-minute startup resources, whereas non-spinning products in other markets typically allow for 10-minute startup. ERCOT non-spinning reserve is therefore classified as a longer-term product similar to 30 -minute operating reserves in ISO-NE and NYISO. 


\subsection{Recent Market Initiatives}

Each ISO/RTO continues to improve and modify its existing products and services to support reliability, increase operational flexibility, and enable emerging technologies to provide these needed services. Initiatives related to these objectives can arise through the stakeholder process, from ISO/RTO staff, while others have also come from Federal Energy Regulatory Commission (FERC) orders or market monitor recommendations. The more significant changes are discussed in Table 2.

Table 2. Recent market changes and proposed plans related to reliability and increased operational flexibility

\begin{tabular}{|c|c|}
\hline & Recent and Proposed Market Changes \\
\hline PJM & $\begin{array}{l}\text { In response to FERC's price formation order (Docket No. EL18-34), PJM is proposing changes to its } \\
\text { ancillary services markets including making services consistent between DA and RT, removing the } \\
\text { distinction between tier } 1 \text { and tier } 2 \text { synchronized reserve categories, changing penalty prices of } \\
\text { reserves, and incorporating an operating reserve demand curve (ORDC) (PJM Energy Price } \\
\text { Formation Senior Task Force 2018). }\end{array}$ \\
\hline NYISO & $\begin{array}{l}\text { NYISO has recently proposed changes to ancillary service markets to include consideration of } \\
\text { increasing flexibility because of contingencies affecting transmission assets, a finer geographic } \\
\text { granularity for operating reserve in load pockets, and reevaluation of existing shortage pricing and } \\
\text { demand curves (Jain 2019). Among recently implemented changes to ancillary service products is the } \\
\text { creation of reserve zone J, which was implemented in June } 2019 \text {. The new zone is aimed at providing } \\
\text { operating reserves in New York City, and New York City-specific price signals. }\end{array}$ \\
\hline ISO-NE & $\begin{array}{l}\text { ISO-NE had proposed the procurement of new reserve services in the DA market (currently only } \\
\text { procured in RT), including generation contingency reserve, replacement energy reserve, and energy } \\
\text { imbalance reserve (ISO-NE 2019). The operator had also proposed a rolling multiday-ahead market } \\
\text { horizon to allow generators to appropriately procure fuel or contracts. However, the proposals were } \\
\text { rejected by FERC. }\end{array}$ \\
\hline MISO & $\begin{array}{l}\text { MISO implemented a "fast-first" approach to Automatic Generation Control regulation deployment } \\
\text { that requires fast ramping resources to address changes in regulation needs, while slow ramping } \\
\text { resources provide load-following (MISO 2017b). The operator has also proposed a new short-term } \\
\text { reliability reserve product, which allows both online and offline resources to offer capacity for } \\
\text { availability in } 30 \text { minutes (MISO 2018b). MISO is also aiming to reform scarcity pricing and improve } \\
\text { compensation for restoration energy. }\end{array}$ \\
\hline SPP & $\begin{array}{l}\text { SPP is proposing the implementation of two new products to handle forecast uncertainty: a ramp } \\
\text { product and an uncertainty product (SPP 2019b). The former is focused on RT impacts with a } 20 \text { - } \\
\text { minute horizon. The latter would account for forecast uncertainty over a longer term with several } \\
\text { possible time horizons being considered between } 30 \text { minutes and } 4 \text { hours. SPP has also begun to } \\
\text { convert the majority of its variable energy resources to be dispatchable after FERC approved SPP's } \\
\text { proposal. }\end{array}$ \\
\hline CAISO & $\begin{array}{l}\text { CAISO has proposed adding two products to its DA market. One is "imbalance reserves," which are } \\
\text { an extension of its existing flexible ramp product from its two RT markets to the DA market, with } \\
\text { ensured deliverability. The other is a reliability energy product to be incorporated into its DA market, } \\
\text { replacing residual unit commitment (RUC) (CAISO 2020c). The operator has also proposed a } \\
\text { mechanism for compensating and procuring PFR, although this initiative has been postponed and was } \\
\text { scheduled to restart in } 2020 \text {. }\end{array}$ \\
\hline
\end{tabular}


Table 2. (Cont.)

\begin{tabular}{|l|l|}
\hline ERCOT & \multicolumn{1}{|c|}{ Recent and Proposed Market Changes } \\
& $\begin{array}{l}\text { ERCOT is currently undergoing an ancillary service market redesign. In } 2020 \text { it introduced two new } \\
\text { products, namely, PFR and FFR service. These are triggered at certain frequency deviations, almost } \\
\text { immediately, and must be sustained for the next } 15 \text { minutes to stabilize frequency. In addition, a third } \\
\text { service has been proposed and approved, ERCOT contingency reserve service (ECRS), which must } \\
\text { respond within } 10 \text { minutes via dispatch directions to correct system frequency (ERCOT 2018a). } \\
\text { Responsive Reserve Service will remain in place as a 10-minute service until it is replaced by ECRS } \\
\text { in 2022. The operator also made several changes in the qualifications required of different resources, } \\
\text { including load resources, in order to provide these services. }\end{array}$ \\
\hline
\end{tabular}

\subsection{Key Challenges, Research Opportunities, and Findings from the Literature}

Table 3 lists important research topics that fall within the category of incentivizing operating reliability and flexibility in ISO/RTO markets. The questions and challenges focus on specific target areas or ideas that cover operational flexibility, ERS, or both. The last challenge, related to scarcity pricing, was not included in the prioritization ranking for this topic because a similar challenge is addressed in the Energy Price Formation topic. It is, however, listed in Table 3 for completeness because of its overlapping relevance to incentivizing reliability and operational flexibility.

Table 3. Major research questions and opportunities related to incentivizing reliability and operational flexibility

\begin{tabular}{|l|l|l|}
\hline \multicolumn{1}{|c|}{ Challenge } & \multicolumn{1}{|c|}{ Type } & \multicolumn{1}{c|}{ Research Questions and Opportunities } \\
\hline New reserve products & Technical & $\begin{array}{l}\text { Are existing reserve products sufficient for the future resource mix? } \\
\text { Are incentives and market products necessary for resources to } \\
\text { provide these new market products? }\end{array}$ \\
\hline $\begin{array}{l}\text { Deliverability of } \\
\text { reserve products }\end{array}$ & Technical & $\begin{array}{l}\text { Are there particular products and services that should ensure the } \\
\text { deliverability of reserve and to what level of granularity? Can this } \\
\text { be done during the auction, or after? }\end{array}$ \\
\hline $\begin{array}{l}\text { Ancillary service } \\
\text { market redesign }\end{array}$ & $\begin{array}{l}\text { Economics, } \\
\text { technical }\end{array}$ & $\begin{array}{l}\text { Should ancillary service markets as a whole be redesigned? Is there } \\
\text { a need to reassess their functionality? Do the increased number and } \\
\text { complexity of products interact in ways that meet system needs } \\
\text { cost-effectively while preserving transparency, or are there ways in } \\
\text { which that complexity interferes with market efficiency and } \\
\text { reliability, including coordination of neighboring systems? }\end{array}$ \\
\hline $\begin{array}{l}\text { Temporal } \\
\text { considerations } \\
\text { (markets, } \\
\text { commitments, or } \\
\text { forecasts) }\end{array}$ & $\begin{array}{l}\text { Technical, } \\
\text { economics, } \\
\text { implementation }\end{array}$ & $\begin{array}{l}\text { How would the } \text { multiday market be designed, and what are the } \\
\text { benefits? What about horizons for RT markets or resolution } \\
\text { changes (e.g., 15-minute DA markets)? What are the short- and } \\
\text { long-term incentives for new market entry with multiday markets? }\end{array}$ \\
\hline $\begin{array}{l}\text { Frequency response and } \\
\text { other services }\end{array}$ & Technical & $\begin{array}{l}\text { Is the existing requirement and procurement method for PFR } \\
\text { sufficient, and are other frequency response services or products } \\
\text { needed? Should there also be alternative procurement mechanisms } \\
\text { for other services such as inertia, voltage control, or short circuit } \\
\text { current? }\end{array}$ \\
\hline
\end{tabular}


Table 3. (Cont.)

\begin{tabular}{|l|l|l|}
\hline \multicolumn{1}{|c|}{ Challenge } & \multicolumn{1}{c|}{ Type } & \multicolumn{1}{c|}{ Research Questions and Opportunities } \\
\hline $\begin{array}{l}\text { Cost recovery and } \\
\text { incentive structure } \\
\text { during emergencies }\end{array}$ & Economics & $\begin{array}{l}\text { For cases in which reimbursement is not available, what } \\
\text { mechanisms can be used to ensure cost recovery during } \\
\text { conservative operations or emergencies? }\end{array}$ \\
\hline $\begin{array}{l}\text { Operating reserve } \\
\text { demand curves/scarcity } \\
\text { pricing }\end{array}$ & $\begin{array}{l}\text { Economics, } \\
\text { policy }\end{array}$ & $\begin{array}{l}\text { As we move into the future with varied resources mixes, are } \\
\text { scarcity and shortage pricing set appropriately? }\end{array}$ \\
\hline
\end{tabular}

\subsubsection{New Reserve/Flexibility Products}

There are many existing products and services that support reliability within the power system. With a changing resource mix, there may be different needs, reasons, or incentives for holding and deploying reserves. Examples include ensuring ramp capability, accommodating net load uncertainty, adding a FFR product, and returning transmission elements to their normal ratings shortly after a contingency event. MISO and CAISO both have recent products to accommodate the need for additional ramping, and other ISOs, such as SPP, are considering similar products. MISO developed a ramp capability model to ensure sufficient rampable capacity is available in RT to meet the net load (Navid and Rosenwald 2012; Gribik et al. 2012). MISO implemented a bidirectional ramp capability product in 2016, which is co-optimized with energy and other ancillary services (MISO 2016). CAISO's flexible ramping product was implemented in 2016 and modified in 2018 to improve uncertainty calculation and address implementation issues (Kyle 2018). Currently, the flexible ramping product in CAISO is procured in the 15-minute and 5-minute RT markets (Nicholson and Quinn 2019). CAISO has considered adding the ramp product to its DA market (CAISO 2020c).

The market-clearing price of both ramping products in MISO and CAISO is based on the opportunity cost of not selling energy or other ancillary services. This means that participants providing the product do not provide offers for the service because the prices are dependent only on the offers they provide for energy and, in some cases, other ancillary services. Prices for ramp products have been low since their inception, leading some researchers to question whether there is enough incentive for resources to maintain existing, or invest in new, ramping capability (Nicholson 2019). However, in practice, the products are primarily in place to ensure that existing resources have some incentive to save ramp capability for future time intervals.

Another ongoing issue with reserve products is that redispatch costs are not considered when reserve capacity is being procured. This is not a major issue with traditional reserves, such as spinning reserves, that have a relatively low probability of being dispatched for energy. But if the capacity has a significant probability of being dispatched, as in the case of ramp products, system costs can be inflated when highvariable-cost capacity is procured rather than low-variable-cost capacity. Wang and Hobbs (2016) demonstrate the inefficiency of ramping products in comparison with a stochastic RT unit commitment ${ }^{1}$ model, and attribute much of that inefficiency to the disregarding of dispatch costs when ramp is being scheduled. CAISO, for example, is considering assigning weights to dispatch costs in its DA market enhancements proposal for imbalance reserves (CAISO 2020c).

\footnotetext{
1 Stochastic unit commitment has been discussed primarily in the academic literature, since none of the North American ISO/RTOs have used it in their market management software. Much advancement has been made in speeding up the computational time for potential use in markets. For instance, see work by Sandia National Laboratory, including Rachunok et al. (2018).
} 
Lastly, the changing resource mix might increase the need for new types of products. At the same time, new technologies within future resource mixes might be able to address changing reserve needs and might be underutilized today. For instance, fast-frequency products might be provided by new technologies that can respond faster than traditional generation.

\subsubsection{Deliverability of Reserve Products}

Most reserve products and services in ISO/RTOs are procured without considering whether the reserve capacity could actually be delivered in RT operations if called upon, or, alternatively, deliverability is considered only at an aggregate (zonal) level. This practice leads to deliverability issues that may require manual intervention by system operators to relieve risk to system reliability. Given increasing uncertainty between DA and RT markets and continuing stress on the transmission system, ensuring reserve deliverability has become more important. This is a theoretical issue with all reserve products, and has proven to be a significant problem in CAISO. Products that are procured on a systemwide or zonal basis may in fact not be deliverable if needed because of local transmission congestion. This is because it is precisely those resources that are behind transmission constraints (and therefore have difficulty delivering energy) that have low energy prices and therefore low opportunity costs; consequently, the market software preferentially procures reserves from those resources (EPRI 2019b). Some ISO/RTOs have implemented limits on transfer capacity between zones (e.g., ISO-NE's Available Transfer Capability/Total Transfer Capability constraints); however, these methods are not as effective as modeling actual post-contingency reserve deployments.

A general solution is to include deployment constraints in market software that checks the feasibility of dispatching reserves under selected contingencies, such as a higher ramp than expected or a particular transmission contingency. While a contingency-constrained unit commitment model (Arroyo and Galiana 2005) explicitly incorporates power balance and transmission constraints under both pre- and postcontingency states, it is computationally expensive for large-scale power systems. In 2011, MISO proposed and implemented a computationally efficient approach to integrating zonal reserve deployment transmission constraints into its DA and RT energy and ancillary service market-clearing processes (Chen et al. 2014). CAISO proposed and implemented an enhancement to its Security Constrained Unit Commitment that incorporates loss of generator and Remedial Action Scheme operation in its dispatch (CAISO 2019a). In CAISO, such feasibility checks are proposed in the latest flexible ramp product initiative to ensure deliverability of up- and down-flexible ramp products (CAISO 2020c).

The growing penetration of renewables increases the complexity of predicting potential network congestion and further emphasizes the need to ensure deliverability. Wang and Hedman (2015) present a dynamic (daily probabilistic) geographic determination of reserve zones to improve reserve deliverability. PJM recently filed a proposal with FERC to enhance its reserve procurement and pricing methods, which, among other provisions, includes a more dynamic reserve subzone modeling approach (PJM Energy Price Formation Senior Task Force 2018). Cobos et al. (2018) ensure reserve offer deliverability using an adjustable robust optimization framework. Ye and Li (2018) introduce the concept of Deliverable Robust Ramping Products to address the deliverability issue of flexible ramping products. Park et al. (2020) develop a probabilistic zonal reserve requirement in the presence of several uncertainty sources, including wind power. Singhal et al. (2018) enhance the reliability of the market solution by modeling the projected post-contingency impacts of nodal reserve deployment and by incorporating reserve response-set policies. 


\subsubsection{Structural Redesign of Ancillary Service Market}

Many market design changes have been proposed for ancillary service markets. Some ancillary market redesign requests have come from FERC orders. In 2011, FERC Order 755 (FERC 2011) required a twopart compensation structure for regulation reserve providers, which included a capacity payment and a performance or "mileage" payment. Surprisingly, the price for mileage has been negligible since these systems were implemented; this is a cautionary tale for market designers who try to predict the impact of design changes. Some other proposals suggest using a strike price and treating a product as an energy call option (ISO-NE 2019). Others suggest incentivizing fast-responding regulation differently from slowresponding regulation (MISO 2017b).

Any market design proposal should consider whether the resources have the proper incentives to follow ISO/RTO instructions. If prices and schedules are inconsistent (i.e., prices are not "supporting" or prices are not determined at the same time as dispatch), resources have incentives to deviate from instructions, or distort their offers in order to obtain schedules or prices that they prefer; such deviations and distortions endanger reliability and efficiency of the system. Ela and O'Malley (2016) compare the performance of two market-clearing designs to meet net-load variability requirements, namely, the timecoupled multiperiod model and the ramp-capacity-constrained single-period model, in terms of efficiency, reliability, and incentive structure. While the former design achieves higher efficiency, it may lack proper incentives during ramping periods. Hua et al. (2019) demonstrate the incentive shortcomings of current ISO implementations of multi-interval RT market design formulated as look-ahead dispatch models and present two methods to mitigate the issues. Much of the research done to examine incentives focuses on current trends, where the majority of demand does not actively participate in markets. Load-serving entities (LSEs) need appropriate incentives to bid for supply in DA markets. Without proper exposure to real-time price volatility, LSEs have little motivation to hedge in their positions in the DA market, and real-time shortages could thus be reduced.

There is also a question regarding whether prices in the energy market sufficiently incentivize flexibility on their own, and how these energy prices interact with ancillary service markets (Ela, Gevorgian, et al. 2014). As the markets become more complicated, with more products and elaborate market rules, there is a potential for inefficient or surprising outcomes, and prices and schedules become less predictable and transparent to market participants. Fundamental questions arise about the need for and nature of ancillary services.

\subsubsection{Multi-day Considerations}

All U.S. ISO/RTOs operate a DA market with hourly resolution, but none have binding look-ahead periods beyond 1 day. Some systems provide advisory schedules beyond 1 day, but without financial consequences for deviating from them. Some existing resources with long start-up times have difficulty offering into the DA market, and others with multi-day fuel procurement needs also have difficulty offering in their total or opportunity costs. ISO-NE is considering replacing its existing single DA market with a multi-day ahead market on a rolling horizon (ISO-NE 2019) as part of its effort to enhance energy security in the presence of renewable and natural-gas-fueled resources and a growing frequency of extreme weather events that strain the natural gas network (discussed earlier in this section); however, this proposal was terminated by FERC, making its implementation highly uncertain. The SPP Market Monitoring Unit (SPP Market Monitoring Unit 2019) supports the Holistic Integrated Tariff Team's Reliability Recommendation of multiday optimization (SPP Market Design 2020) as it allows units to commit long-lead-time generators. The MISO Market Subcommittee (MISO Market Subcommittee 2018) estimates that a multi-day commitment process would reduce production costs by $\$ 30-\$ 45$ million per year. Meanwhile, many ISOs are evaluating look-ahead commitment as part of RT markets, with 
enhanced operation of storage being a catalyst. In addition, CAISO had at one point evaluated the feasibility of a 15-minute DA market (CAISO 2020c). These granularity options can help prepare the system for short-term variability.

\subsubsection{Frequency Response and Other Services}

All ISO/RTOs have the means to procure PFR. The exact eligibility requirements and procurement mechanism vary by region, and many are beginning to reassess what is needed and how best to procure it. Ela, Gevorgian, et al. (2014) present a market design capable of creating the right incentives for PFR. As the penetration of VRE increases and system inertia levels drop, arresting frequency deviation and the rate of change of frequency after a generator outage becomes a critical task. ERCOT is adding a FFR product with some characteristics different from those of PFR, which are intended to specifically accommodate battery storage, and under-frequency load shedding with nearly instant deployment capabilities (ERCOT 2020b). Using a 2000-bus test system representing the Texas power system under low-inertia conditions, Garcia and Baldick (2019) demonstrate that RT co-optimization of FFR and PFR decreases system costs. Meng et al. (2020) present a review of barriers and prospects for the participation of ES in FFR services. This addition of the FFR product in ERCOT is also an example of how markets can adapt to better accommodate the capabilities of emerging technologies.

Some ancillary services, such as black start and Volt/Var support, do not usually have competitive market mechanisms. For instance, ERCOT is the only independent system operator in the United States that procures the black-start service through a competitive market mechanism. Saraf et al. (2009) present improvements to ERCOT's annual black-start service selection analysis. Abdul-Rahman et al. (2011) evaluate the impact of including traditional voltage control and stability analysis in CAISO's energy market management system. A fundamental issue is whether the cost and complexity of a market mechanism for something like reactive power is justified by the efficiencies that potentially will be realized (O'Neill et al. 2008). It may be less expensive to take a regulatory approach, for example, by requiring photovoltaics $(\mathrm{PV})$ inverters to have reactive power generation capabilities.

\subsubsection{Cost Recovery and Incentive Structure during Emergencies}

Some actions taken by ISO/RTOs, requiring resources to operate conservatively or during emergencies, might not be compensated through traditional mechanisms, particularly during extreme events.

Depending on the action and the type of event, there might not be a mechanism for the generator to recover all costs. Examples include market suspension, islanding situations, or other out-of-market directions. In 2013, MISO completed a proposal on cost allocation for producers and consumers during islanding situations (MISO 2013). The operator has recently revisited the issue as a more concrete proposal. During islanding events or other restorative events that may follow widespread customer power interruptions, many parts of the existing power system operation and market operation are not applicable. Processes such as economic dispatch and communications with transmission providers may not be in place. This can lead to requests from the operator to generators (including black-start generators) that have no price associated with critical directions.

In response to this concern, a new design could include costs, in particular those that may be unusual given the event, as part of well-documented input prior to any type of event and to compensate participating resources by allocating the costs to reenergized load in the islanded region. MISO's recent FERC-approved proposal provides clear guidelines for compensation to generation resources and payment from load when it was previously done on a case-by-case basis. 
Other challenges may arise from the incentives that are in place during additional extreme events. As an example, it is not clear that incentives are aligned for different types of extreme events in a consistent manner (EPRI 2020). Table 4 shows the average and maximum prices during three extreme events occurring in ISO markets, as well as the percentage of intervals when prices were greater than $\$ 500 /$ megawatt-hour (MWh) during the event. While the prices during the extreme cold of the polar vortex in 2014 are undoubtedly high as a result of the supply shortages and other challenges associated with that event, prices during two other extreme events related to large-scale hurricanes were not so, even though these events caused customer interruptions while the polar vortex did not. The reasoning was that the polar vortex conditions primarily affected supply technologies, especially natural gas, whereas the other two storms affected transmission and distribution infrastructure, which led to lower perceived loads to serve (since there was no infrastructure for delivery) and thus lower prices.

Similarly, the 2021 Uri winter storm also caused many supply outages in Texas, including the loss of many natural gas plants due in part to supply shortages. The real-time Settlement Point Price in ERCOT averaged $\$ 6580$ /MWh between February 14 and February 19, 2021, with prices reaching or exceeding the administratively-set offer cap of $\$ 9000 / \mathrm{MWh}$ almost continuously over a three-day period (ERCOT 2021). Settlement Point Prices include impacts of congestion and can therefore exceed $\$ 9000 / \mathrm{MWh}$ (ERCOT 2020c). Other resource adequacy and system resilience considerations for extreme weather events are discussed in section 4.3.6.

Table 4. Market prices during four extreme weather events (EPRI 2020, ERCOT 2021)

\begin{tabular}{|l|l|l|l|l|}
\hline & \multicolumn{1}{|c|}{ Polar Vortex } & \multicolumn{1}{|c|}{$\begin{array}{c}\text { Superstorm } \\
\text { Sandy }\end{array}$} & \multicolumn{1}{|c|}{ Hurricane Harvey } & \multicolumn{1}{|c|}{ Winter Storm Uri } \\
\hline Location & NYISO Zone J & NYISO Zone J & $\begin{array}{l}\text { Houston Zone; South } \\
\text { Zone }\end{array}$ & $\begin{array}{l}\text { ERCOT Hub Average } \\
\text { Settlement Point Price }\end{array}$ \\
\hline Date & $\begin{array}{l}1 / 2 / 2014- \\
1 / 10 / 2014\end{array}$ & $\begin{array}{l}10 / 28 / 2012- \\
11 / 2 / 2012\end{array}$ & $8 / 25 / 2014-8 / 31 / 2014$ & $2 / 14 / 2021-2 / 19 / 2021$ \\
\hline Average Price & $\$ 184 / \mathrm{MWh}$ & $\$ 32 / \mathrm{MWh}$ & $\$ 23 / \mathrm{MWh} ; 37 / \mathrm{MWh}$ & $\$ 6580 / \mathrm{MWh}$ \\
\hline Maximum Price & $\$ 1422 / \mathrm{MWh}$ & $\$ 283 / \mathrm{MWh}$ & $\$ 175 / \mathrm{MWh} ; \$ 1594 / \mathrm{MWh}$ & $\$ 9052 / \mathrm{MWh}$ \\
\hline $\begin{array}{l}15-\text { minute } \\
\text { Intervals } \\
\text { above } \\
\$ 500 / \mathrm{MWh}\end{array}$ & $8 \%$ & $0 \%$ & $0 \% ; 1 \%$ & $90 \%$ \\
\hline
\end{tabular}

When all prescribed out-of-market actions are exhausted during an extreme event, the market may be suspended. Forced outages may initially occur according to forecasts and analyses, but then may proceed beyond studied cases. At this point, there may be no market response to support reliability, and automated protections and controls may disconnect or shut down resources, resulting in partial or full suspension of market operations. Each ISO documents its actions and procedures for market suspension. For instance, CAISO describes its actions in Procedure 2710, "Market Disruption-RTM [Real Time Market] Failure and Suspension" (CAISO 2019b, 4). After all resources are exhausted and voluntary load shedding is utilized, prices are set administratively until the market resumes. 


\subsubsection{Operating Reserve Demand Curve/Scarcity Pricing}

Approaches to scarcity and shortage pricing vary across the ISO/RTOs, but scarcity and shortage pricing are important indicators when the system is under stress. With occasional exceptions (e.g., reserve shortages in RT in CAISO), almost all ISO/RTOs use a single administratively set price or multistep curve for their reserve products, which may not adequately capture the value of reserve under all conditions. Many ISO/RTOs are considering alternatives such as the ORDC, which ERCOT has implemented (Hogan and ERCOT staff 2013), recognizing that their system derives value from procuring reserves beyond the minimum requirement. An ORDC approach provides a more transparent marketbased framework to procure and reward additional flexibility. Such mechanisms can in theory provide sufficient revenues to make up for "missing money" in the energy market and can incentivize efficient capital investment (Stoft 2002).

PJM proposes replacing its current demand curves for 10-minute synchronized reserves, primary (nonsynchronized) operating reserves, and 30-minute reserves with downward-sloping ORDCs. PJM's proposal includes improvements to ORDCs by increasing the maximum penalty point from $\$ 850 / \mathrm{MWh}$ to $\$ 2,000 / \mathrm{MWh}$ to enhance shortage pricing and minimize out-of-market operator intervention (PJM Energy Price Formation Senior Task Force 2018). Hogan and Pope (2019) identify PJM's proposal as a market design advancement that contributes to just and reasonable energy and ancillary service pricing. Future ORDC implementations may require dynamic determination of parameters for a more appropriate reserve valuation (Nicholson 2019). 


\subsection{Integrating New and Emerging Technologies into Wholesale Market Operations}

An overarching challenge faced by ISO/RTOs is how to ensure that their market designs continue to achieve the objective of operating economically efficient markets that maintain reliability during a time with a rapidly changing resource mix. Changes in the resource mix include greater participation from the demand side through flexible demand or customer-sited generation, increase in nonsynchronous generation including ES, new types of VRE like offshore wind, and increasingly hybrid resources with co-located VRE and storage. These emerging technologies differ from conventional technologies prevalent during the initial designs of modern power markets. Economic principles that underpin efficient market designs can serve as a foundation for adapting markets for emerging technologies (Conejo and Sioshansi 2018; Newberry et al. 2017; Cramton 2017).

Ensuring economically efficient market design while maintaining reliability requires delivering sufficient ERS to maintain secure operations (discussed in more detail in section 2), developing participation models for new resources, ensuring resource adequacy with weather-dependent and energy-limited resources, and enabling market participants to hedge against energy and congestion risk through forward contracting. The prioritization of these market challenges is guided by ISO stakeholder inputs, with the ranking results shown in Figure 4.

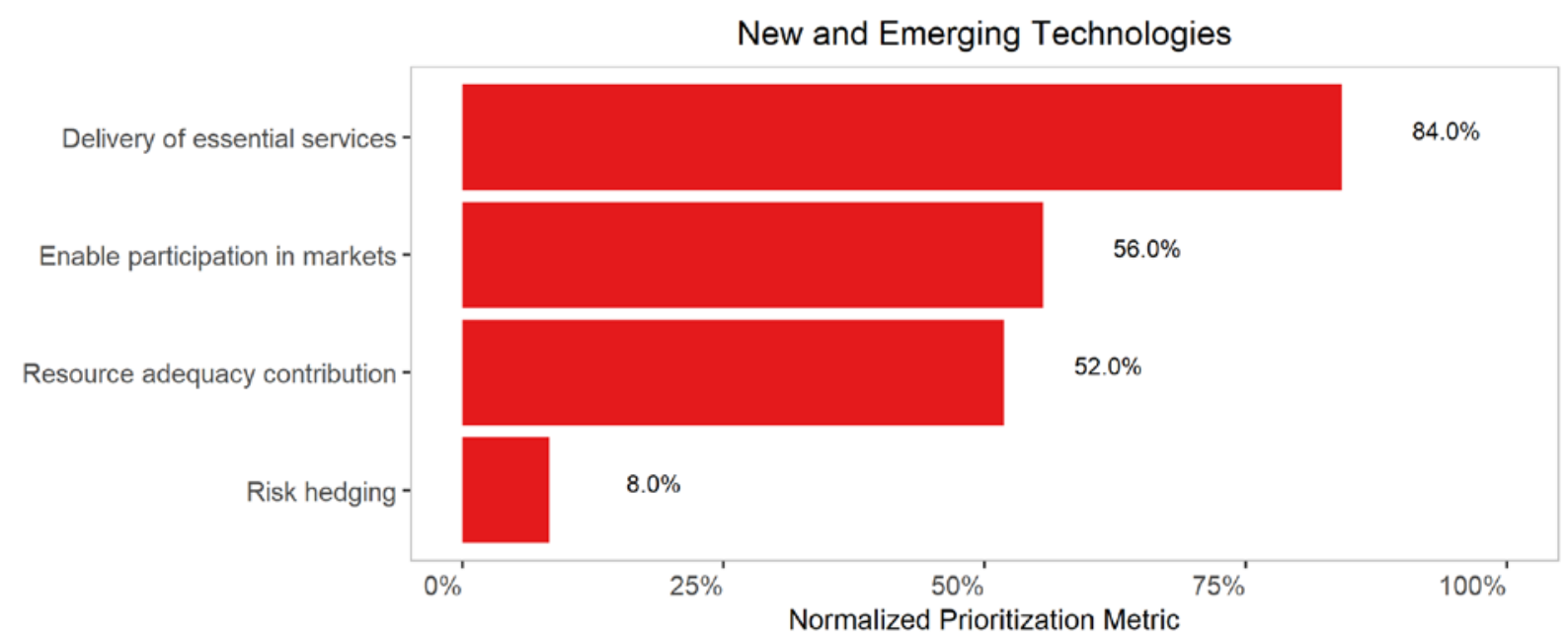

Figure 4. Priority ranking of market challenges related to integrating emerging technologies in market operations from the ISO/RTO stakeholder meeting

Responses during the ISO/RTO stakeholder meeting to an open-ended question about challenges posed by emerging technologies further highlighted the need for algorithms for multi-interval optimization problems with multiple DERs, storage and hybrids; efficient approaches to storage state-of-charge management; and inclusion of new technologies in the energy management system and market management systems. Decisions about managements systems are particularly important, as these decisions are the responsibility of the ISO/RTOs but have long-standing implications for available options in market design and operations. These additional issues, along with the challenge of enabling emerging resources to participate in markets, are grouped as a separate item below. 
The rest of this section is organized as follows: section 3.1 highlights current market practices for emerging technologies; section 3.2 summarizes recent market initiatives and proposals discussed by ISO/RTOs; and section 3.3 provides detailed descriptions of the four primary challenges, with insights from the literature.

\subsection{Current Market Practice for Emerging Technologies}

Deployment of emerging technologies varies by ISO/RTO. To illustrate this point, Table 5 summarizes the deployment of wholesale demand response (DR), ES (including pumped storage hydropower), and VRE (including distributed photovoltaics) by ISO/RTO region.

MISO has the largest amount of DR capability, although the majority is from interruptible load programs in regulated utilities' customer-sited generators that participate in the forward capacity market (MISO 2019a). Nearly all the storage capacity in the United States is pumped hydro storage (94\%). Of the roughly $800 \mathrm{MW}$ of battery storage, by the end of 2019, 39\% of the capacity was in the PJM region, $26 \%$ in CAISO, and $15 \%$ in ERCOT. Three ISO/RTO regions have more than $20 \%$ of their annual energy provided by VRE: SPP, CAISO, and ERCOT. In SPP and ERCOT, almost all the VRE generation is wind (>94\%), whereas in CAISO, $72 \%$ of the VRE is solar.

Table 5. Status of emerging technologies in the United States

\begin{tabular}{|l|c|c|c|}
\hline ISO/RTO & $\begin{array}{c}\text { Demand Response } \\
\text { Capability in 2018 }(\% \\
\text { Peak Demand Capacity) }\end{array}$ & $\begin{array}{c}\text { Storage Capacity in } \\
\mathbf{2 0 1 9}(\% \text { Peak Demand } \\
\text { Capacity) }^{\mathbf{b}}\end{array}$ & $\begin{array}{c}\text { Variable Renewable Energy in 2019 } \\
\text { (Including Distributed PV, \% Annual }_{\text {Energy) }}^{\mathbf{c}}\end{array}$ \\
\hline CAISO & $5.2 \%$ & $4.0 \%$ & $24.3 \%$ \\
\hline ERCOT & $4.4 \%$ & $0.2 \%$ & $21.3 \%$ \\
\hline SPP & $0.0 \%$ & $0.5 \%$ & $28.1 \%$ \\
\hline MISO & $10.6 \%$ & $1.7 \%$ & $8.7 \%$ \\
\hline PJM & $6.3 \%$ & $3.7 \%$ & $3.9 \%$ \\
\hline NYISO & $4.5 \%$ & $4.0 \%$ & $4.0 \%$ \\
\hline ISO-NE & $1.4 \%$ & $7.3 \%$ & $7.0 \%$ \\
\hline
\end{tabular}

${ }^{a}$ FERC 2019a.

${ }^{\mathrm{b}}$ EIA 2020.

${ }^{\mathrm{c}}$ Lawrence Berkeley National Laboratory calculations using methods and data described by Wiser et al. (2017).

\subsection{Recent Market Initiatives}

Several FERC initiatives over the past decade have established requirements related to participation of emerging technologies in ISO/RTO markets. FERC Order 719, issued in October 2008, requires ISO/RTOs to eliminate barriers to DR by accepting bids from DR resources in ancillary service markets and allowing retail customer aggregators to fully participate in the market (Cappers et al. 2013). FERC Order 825, issued in June 2016, requires coordinated market prices with resource dispatch instructions, in order to ensure that appropriate incentives are provided for resources' operations and performance (FERC 2016a). The order highlights the importance of adequately defining how resources participate in wholesale power markets to ensure fair competition. Extrapolating to other emerging resources, these FERC initiatives encourage ISO/RTOs to develop definitions and market participation rules that capture the full potential of resources in terms of the different services they can provide and reward their flexibility and dispatchability accordingly. 
FERC Order 841, issued February 2018, directly addresses the need for ISO/RTOs to ensure efficient participation of ES in U.S. wholesale electricity markets (FERC 2018a). The order mandates that ISO/RTOs establish participation models that enable ES resources to qualify as an eligible asset in the provision of capacity, energy, and ancillary services, when technically capable. The ruling also stipulates how storage should participate in setting the wholesale market-clearing price as both a wholesale seller and buyer; and defines the price for charging a storage resource as the wholesale locational marginal price (as long as that energy is intended for later sale of wholesale services). FERC Order 2222, issued in September 2020, builds upon Order 841 by requiring ISO/RTOs to provide participation models for aggregators of DERs to provide energy, capacity, and ancillary services (FERC 2020c). Individual ISO/RTOs are also undertaking a number of independent market initiatives related to emerging technologies, as outlined in Table 6 .

Table 6. Recent market changes and proposed plans related to emerging technologies

\begin{tabular}{|c|c|}
\hline ISO/RTO & Recent and Proposed Market Changes \\
\hline PJM & $\begin{array}{l}\text { As an illustration of challenges associated with incorporating emerging technologies into market } \\
\text { management systems, PJM formed a senior task force to look for ways to improve modeling } \\
\text { representation of complex resources such as combined-cycle units, coal units with multiple mills, } \\
\text { and pumped storage hydropower in PJM's market-clearing software. Many of the proposed } \\
\text { solutions depend on development of PJM's next-generation energy market, which will require } \\
\text { several years to complete (PJM Interconnection 2019d). }\end{array}$ \\
\hline NYISO & $\begin{array}{l}\text { NYISO is building on its DER aggregation rules and procedures to accommodate hybrid storage } \\
\text { resources. Stakeholders approved a "co-located" model that allows the ISO to dispatch the storage } \\
\text { and renewable generator individually within the limits set by a shared point of interconnection. In } \\
2021 \text {, NYISO will be developing an "aggregation" model in which a single schedule will be set for } \\
\text { all resources behind the point of interconnection. Finally, NYISO is studying the types of grid } \\
\text { services that renewable generators with adequate control capabilities could provide. }\end{array}$ \\
\hline ISO-NE & $\begin{array}{l}\text { ISO-NE's price-responsive demand project aims to integrate DR into its market structures in a } \\
\text { manner comparable to other resources. Through full market integration, DR can participate in the } \\
\text { DA and RT energy markets, provide operating reserve, and participate in the forward capacity } \\
\text { market in a way that is comparable to other dispatchable resources (ISO-NE 2017). }\end{array}$ \\
\hline MISO & $\begin{array}{l}\text { Building from prior work on storage, MISO created its Hybrid Resource Participation Model } \\
\text { (IR086). This model is meant to address questions regarding the role of hybrid resources in ensuring } \\
\text { resource adequacy, sizing interconnection capacity relative to the capacity of constituent } \\
\text { components, and options for treatment of hybrids in market operations. }\end{array}$ \\
\hline SPP & $\begin{array}{l}\text { SPP is increasingly considering new approaches to treat wind generation on par with other } \\
\text { conventional resources. One recommendation from a Holistic Integrated Tariff report was to } \\
\text { evaluate whether VRE resources should be required to offer a specific amount of capacity relative to } \\
\text { their forecasted generation in the DA market. Because negative offers from wind resources are } \\
\text { driving congestion in some constrained areas, the report further recommends a study of approaches } \\
\text { to mitigate unduly low offers that create uneconomic dispatch. Mitigation would allow the low offer } \\
\text { to be automatically replaced by a cost-based offer (SPP 2019b). }\end{array}$ \\
\hline CAISO & $\begin{array}{l}\text { CAISO initiated a "Hybrid Resources Initiative" in July } 2019 \text {, largely focused on renewable } \\
\text { generators and storage. The initiative allows for different configuration and technology } \\
\text { combinations in CAISO's definition and treatment of hybrids in the markets. }\end{array}$ \\
\hline
\end{tabular}


Table 6. (Cont.)

\begin{tabular}{|l|l|}
\hline ISO/RTO & \multicolumn{1}{c|}{ Recent and Proposed Market Changes } \\
\hline ERCOT & $\begin{array}{l}\text { ERCOT, not subject to FERC requirements, is identifying changes needed to accommodate DER } \\
\text { and storage. ERCOT is working to map all DERs to transmission loads, provide a locational } \\
\text { marginal price (LMP) signal to registered DERs rather than a zonal load price, and improve } \\
\text { representation of DER capabilities in planning models. ERCOT's Battery Energy Storage initiative } \\
\text { is systematically addressing 15 different key topics that will increase system operator awareness of } \\
\text { storage device operation and limitations and adapt the system models to facilitate integration of } \\
\text { storage (ERCOT 2018b). }\end{array}$ \\
\hline
\end{tabular}

\subsection{Key Challenges, Research Opportunities, and Findings from the Literature}

On the basis of a review of ISO/RTOs initiatives, stakeholder positions, technical reports, and academic literature, four key research questions for emerging technologies were identified and are summarized in Table 7. Each research question is presented in Table 7, and later discussed in more detail, in the priority order identified by ISO/RTO stakeholders.

Table 7. Major research questions and opportunities related to emerging technologies in order of ISO/RTO stakeholder priority

\begin{tabular}{|l|l|l|}
\hline \multicolumn{1}{|c|}{ Challenge } & \multicolumn{1}{|c|}{ Type } & \multicolumn{1}{c|}{ Research Questions and Opportunities } \\
\hline $\begin{array}{l}\text { Deliver sufficient ERS } \\
\text { with growing share of } \\
\text { variable and non- } \\
\text { synchronous generation }\end{array}$ & $\begin{array}{l}\text { Technical, } \\
\text { economic }\end{array}$ & $\begin{array}{l}\text { What resources can provide ERS? How substitutable } \text { are ERS } \\
\text { (e.g., can PFR substitute for inertia)? How can ERS be priced } \\
\text { in wholesale markets? }\end{array}$ \\
\hline $\begin{array}{l}\text { Enable emerging resources } \\
\text { to participate in markets }\end{array}$ & Implementation & $\begin{array}{l}\text { How can participation models balance participant flexibility in } \\
\text { bidding and scheduling with system operator requirements to } \\
\text { optimize the system while maintaining reliability? Are the } \\
\text { designs and software able to also capture characteristics of new } \\
\text { technologies that may limit their contribution to reliability } \\
\text { services? }\end{array}$ \\
\hline $\begin{array}{l}\text { Determining the resource } \\
\text { adequacy contribution of } \\
\text { emerging resources }\end{array}$ & $\begin{array}{l}\text { Technical, } \\
\text { implementation }\end{array}$ & $\begin{array}{l}\text { How does the resource adequacy contribution of variable and } \\
\text { energy-limited resources change with changes in the mix of } \\
\text { resources? How should those changing contributions be } \\
\text { reflected in forward capacity markets? }\end{array}$ \\
\hline $\begin{array}{l}\text { Enable participants to } \\
\text { hedge risk through } \\
\text { forward contracting, } \\
\text { including congestion risk }\end{array}$ & Economic & $\begin{array}{l}\text { Are FTR products created by ISO/RTOs capable of hedging } \\
\text { basis risk for emerging technologies such as variable wind and } \\
\text { solar? Can merchant transmission be proposed to enable } \\
\text { interconnection of future resources? }\end{array}$ \\
\hline
\end{tabular}

\subsubsection{Delivery of Sufficient Essential Reliability Services}

High penetrations of emerging technologies introduce challenges for maintaining reliability because of the nonsynchronous character of inverter-based generation and the distance of the resources from loads, particularly for wind. MISO's Renewable Integration Impact Assessment ${ }^{1}$ and the Australian Energy Market Operator Limited's (AEMO’s) Renewable Integration Study (AEMO 2020) comprehensively

1 Summary slides available at https://www.misoenergy.org/planning/policy-studies/Renewable-integration-impactassessment/ 
evaluate the magnitude of the issues caused by growing penetrations of VRE. With high shares of nonsynchronous generation, one challenge is maintaining frequency stability during contingencies as the inertia in the system decreases. In the United States, this challenge is most pressing in ERCOT, because of its limited interconnection capacity with the rest of the United States. Johnson et al. (2020) use a unit commitment model with inertia constraints in ERCOT to evaluate various strategies for enabling renewable energy penetrations in excess of $90 \%$ of annual energy demand. Incorporation of a system inertia constraint can enable $80 \%$ VRE penetration scenarios, although with additional costs associated with changing commitment decisions relative to the unconstrainted dispatch. Price signals associated with the provision of synchronous inertial response, changing traditional grid operational practices, plant retirements, and FFR from synthetic or virtual inertia might all support stable operation with more than $90 \%$ penetration. Trade-offs between options need to be managed thoughtfully.

Wind and solar plants can be a source of ERS (Milligan 2018), and various demonstrations show that wind and solar have this capability (Loutan et al. 2017; Loutan and Gevorgian 2020; Rebello et al. 2020). Some balancing authorities have multiple years of operating experience integrating wind into automatic generation control (Chernyakhovskiy et al. 2019). Experience with Kauai's island grid demonstrates the feasibility of operating with 100\% instantaneous renewable penetration. For 25 minutes in February 2019, the utility met all demand with a combination of PV (80\%), hydropower, biomass, storage, and a gas turbine running as a synchronous condenser. A turbine running in synchronous-condenser mode can help ensure system security by contributing inertia, voltage support, and fault current (Lew et al. 2019). In ISO/RTO markets, a primary consideration beyond the capability of wind and solar to provide ERS is the opportunity cost of curtailing VRE to provide these services (Denholm et al. 2019). Even if VRE has the capability, whether it should provide a service depends on the economic trade-offs between different services.

ERCOT has shown how demand-side resources can participate in providing PFR. The operator developed market mechanisms for pricing and procuring this service in RT dispatch ( $\mathrm{Li}, \mathrm{Du}$, and $\mathrm{Lu} 2018)$ and in DA markets that account for unit commitment. As described in more detail in section 2.3, load resources on under-frequency relays are eligible to provide responsive reserves in ERCOT's recently redesigned ancillary service market (Du et al. 2020).

\subsubsection{Participation Models}

In the near term, absent major structural reforms to power markets, existing markets can become more efficient by enabling participation of emerging technologies through development of effective participation models. Enabling participation of emerging resources requires that several important issues be addressed, including accurate representation of combined-cycle units; algorithms for multi-interval optimization problems with multiple DERs, storage and hybrids; efficient approaches to storage state-ofcharge management; and inclusion of new technologies in the energy management system and market management systems.

Many resources might not be able to offer their full flexibility to the market because of modeling limitations. For instance, although combined-cycle power plants provide faster ramping capabilities than traditional thermal units and can support the grid under high-VRE conditions, their complicated operating characteristics prevent them from offering their actual parameters because ISO/RTOs often use simplified models (Dai et al. 2019). Many ISO/RTOs are updating their combined-cycle models in order to provide them with more opportunities to bid their actual cost and performance parameters and to reduce overall production costs. MISO performed significant research and development studies to develop enhanced and computationally efficient representation of combined-cycle units in its models, showing a potential annual 
benefit of \$14-\$34 million from an improved model (MISO 2018c). In 2018, MISO performed a conceptual design for the development of a hybrid combined-cycle model described by configurations, components, and transitions with an anticipated implementation date in 2020 (MISO 2018d). The edgebased model (Fan and Guan 2016) is another recently proposed combined-cycle modeling approach that accurately represents the transition between different configurations. An enhanced edge-based model was described by Fan et al. (2019). Even with the capability to represent operating characteristics in bidding parameters, generators may still choose to offer in a highly inflexible manner. Market tests may be required to ensure that this behavior is not due to generators exercising market power.

PJM (PJM Interconnection 2017a) outlines a vision for enabling active participation of demand-side resources in the electricity market during a period with demand for a more resilient system and with increased customer adoption of behind-the-meter generation. The long-term direction includes fostering demand elasticity, expanding participation of DR resources in ancillary service markets, and aligning wholesale market prices with retail market prices or incentives. Additional details on participation models for DERs are included in section 6.3.

Storage participation models vary across U.S. markets, although recent FERC 841 orders establish common requirements (Sakti et al. 2018). From an implementation perspective, increased penetration of storage assets and VRE raises the possibility of multiple potential market equilibria (Grübel et al. 2020; Schmalensee 2019). Grübel et al. (2020) find that computation of market equilibria is much more challenging with storage because of the interlinkage of trading events over time, and develop computational methods to quickly solve such optimization problems using the alternating direction method of multipliers. More generally, current U.S. markets differ in how and if they manage intertemporal constraints for ES and demand-side resources. As reported by Zhao et al. (2020), researchers from ISO-NE have developed a new multiperiod model to enhance efficiency of markets with increased participation of VRE, storage, and other energy-limited resources. Alternatively, Siddiqui et al. (2019) find that a charge on ramping between on-peak and off-peak periods can induce socially efficient investment in storage by decentralized decision makers.

Many open questions and challenges remain regarding participation models for hybrid VRE and storage resources, with rapidly increasing commercial activities suggesting an increased urgency to resolve these questions (Gorman et al. 2020). One option for hybrid participation models is to give the ISO/RTO control of the dispatch and scheduling of hybrid plants, through the constant update of operational parameters such as forecasts and the state-of-charge of storage. Asking the ISO/RTO to control the hybrid requires a mechanism to manage state-of-charge along with respecting specific limits on number of cycles per year to maintain battery lifetime warranties (Gorman et al. 2020). These and other technical constraints can place a significant computational burden on centralized optimization systems.

An option at the other end of that spectrum would make hybrid operation the responsibility of the owners, where hybrids would dispatch into the markets as conventional resources. In this case owners would optimize their own dispatch strategies on the basis of anticipated market outcomes and therefore take on additional risk. The lower burden on ISO/RTO operators would likely ease integration with market operation, although it might also lead to reliability risks from the ISO/RTO perspective because of the lack of visibility into the state of the hybrid resources. Implementation of this participation model in market software may also be easier, owing to the similarity with the existing model for conventional resources.

Underpinning a major challenge to managing increased influence of customer choice on system planning decisions is the question of whether ISO/RTOs should procure capacity on behalf of all loads or whether 
organized capacity markets should be residual markets that supplement decisions by customers, utilities, and states (Glazer et al. 2017).

\subsubsection{Resource Adequacy Contribution}

Ensuring reliability requires adequate resources to meet demand in all time periods. The method for determining the resource adequacy contribution of many emerging technologies, often called the capacity credit, differs from methods for conventional resources because of the variability in production or energy limits. As discussed in greater detail in section 4, methods for estimating the capacity credit of VRE, using probabilistic effective load-carrying capability (ELCC) estimates, are increasingly used by system planners and can be applied to new VRE resources like offshore wind (Beiter et al. 2020). A variety of approaches to calculating the capacity credit of energy-limited resources are being developed for storage, including an approach proposed by PJM (Muzhikyan et al. 2019), DR (Klem and Stephen 2019; Parks 2019), and hybrids (Mills and Rodriguez 2019). Analysis by MISO highlights the challenge created by the fact that increasing penetration of VRE changes the risk profile (or distribution of loss-of-load probability) of systems (Pickering et al. 2019). Muzhikyan et al. (2019) similarly find that shifts can occur with increases in energy-limited resources although there is less literature on that aspect. This shift causes changes in the capacity credit with increasing penetration (Heath and Figueroa-Acevedo 2018; Parks 2019) and allows for potential synergies between multiple technologies (Byers and Botterud 2019; Mills and Rodriguez 2019). In practice, capacity markets vary in the methods used to calculate capacity credits of emerging technologies (Byers et al. 2018), and deviations between capacity credits assigned in practice versus those estimated with state-of-the-art methods can lead to inefficient market signals (Bothwell and Hobbs 2017). Economic efficiency of capacity markets also depends on the degree to which the demand side is enabled to participate (Liu 2017). This challenge is also discussed further in section 4.3.

\subsubsection{Hedging Congestion Risk}

Efficient markets enable participants to hedge risks. In many cases these hedges are bilateral financial arrangements that do not require ISO/RTO participation. Hedging congestion risk, through FTR or merchant transmission, does involve market design decisions by ISO/RTOs. Fixed-volume FTRs pay out the difference in prices between two nodes multiplied by the capacity of the FTR. One challenge for emerging technologies, particularly wind, is that the fixed-volume nature of FTRs may make them an inadequate mechanism for hedging the congestion risk of resources with variable generation (Bartlett 2019). More generally, FTRs that do not have a volume that matches the rate of production may lead to imperfect hedging of price risks (Biggar and Hesamzadeh 2014). Additional details on the role of FTRs in transmission planning and cost allocation are presented in section 7.2. 


\subsection{Resource Adequacy and System Resilience}

Recent changes in the electricity grid and ISO/RTO market operations have brought new challenges to the resource adequacy and resilience planning aspects of ISO/RTO market design. While various resource adequacy paradigms have been adopted across the different ISO/RTOs, some consistent issues have been recognized across many of these market areas. For example, the evolving nature of the grid resource mix requires a more comprehensive review of reliability requirements, including efficient incentives for resources to provide the necessary grid services across all hours of the year. Increasing penetration levels of VRE resources and the emergence of new technologies not only require advanced calculation methods to quantify their contribution to reliability requirements, but also necessitate more differentiated design of capacity requirements to reflect the temporal-, locational-, and service-specific values that the system needs. In addition, more frequent extreme weather events, especially cold winter events, also motivate ISO/RTOs to assess the impacts of potential resilience and fuel security issues and develop new approaches to incentivize fuel deliverability and storage capability.

We identify seven particular challenges and research needs related to resource adequacy and system resilience that could benefit from development of analytical tools or market procedures. These challenges include revising reliability assessment, updating capacity credit calculation methods, incorporating state policies into capacity markets, updating capacity demand curve shapes, improving and crediting import resources capacity delivery, developing long-term market mechanisms for firm capacity provision under extreme weather events, and mitigating participant risks in resource adequacy programs. The ranking of these market challenges according to input from ISO/RTO stakeholders is shown in Figure 5.

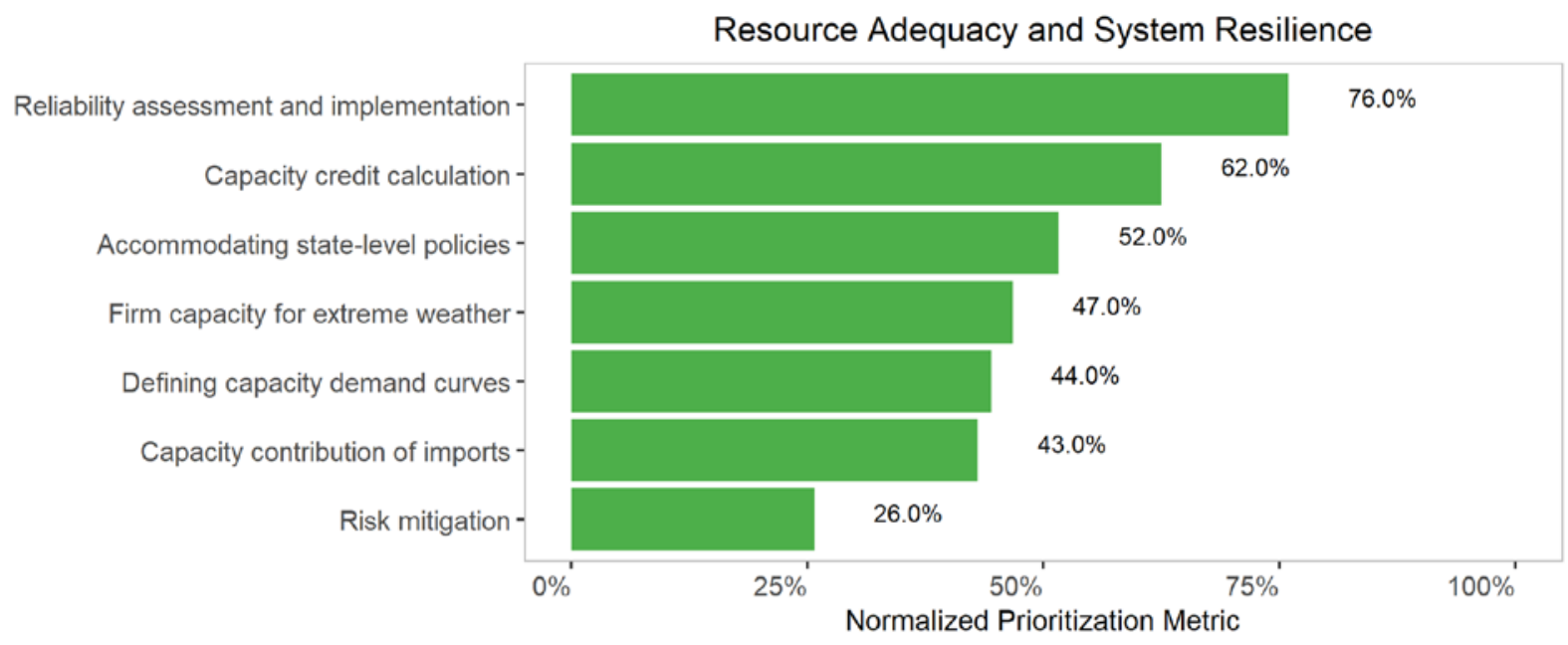

Figure 5. Priority ranking of market challenges related to resource adequacy and system resilience from the ISO/RTO stakeholder meeting

The rest of this section is organized as follows: section 4.1 documents current market practice for resource adequacy; section 4.2 summarizes recent market initiatives and proposals discussed in ISO/RTOs; and section 4.3 provides detailed descriptions of the seven resource adequacy challenges and insights from the literature. 


\subsection{Current Market Practice for Resource Adequacy and Resilience Considerations}

The ISO/RTOs in the United States have historically adopted three different types of resource adequacy paradigms to guarantee long-term reliability and incentivize investments in generation resources: (1) a centralized capacity market; (2) LSE resource adequacy requirements with some ISO/RTO or state regulatory requirements; and (3) an energy-only market with no regulatory requirement. These three paradigms can overlap when implemented in resource adequacy programs. Table 8 summarizes the current practice of resource adequacy programs across ISO/RTOs in the United States.

Table 8. Current practice of resource adequacy programs and compensation in the United States

\begin{tabular}{|c|c|c|}
\hline $\begin{array}{l}\text { Resource } \\
\text { Adequacy } \\
\text { Paradigm }\end{array}$ & ISO/RTO & Description \\
\hline \multirow[t]{3}{*}{$\begin{array}{l}\text { Centralized } \\
\text { mandatory } \\
\text { capacity market }\end{array}$} & PJM & $\begin{array}{l}\text { PJM runs a reliability pricing model annually, three years before the delivery date } \\
\text { of capacity resources using a downward-sloping demand curve, and the market } \\
\text { clears in each of the } 27 \text { locational deliverability areas. Incremental auctions are } \\
\text { held } 20,10 \text {, and } 3 \text { months prior to delivery (PJM Interconnection 2019a, 2020b). }\end{array}$ \\
\hline & NYISO & $\begin{array}{l}\text { NYISO conducts seasonal (strip auction, every six months), monthly, and spot } \\
\text { installed capacity market auctions using downward-sloping capacity demand } \\
\text { curves for each of the four capacity zones (NYISO 2020e). }\end{array}$ \\
\hline & ISO-NE & $\begin{array}{l}\text { ISO-NE calculates the installed capacity requirement annually and uses a forward } \\
\text { capacity market to procure resources three years in advance for system and zonal } \\
\text { needs through a downward-sloping capacity demand curve. Annual and monthly } \\
\text { reconfiguration auctions are also held prior to the final delivery month (ISO-NE } \\
\text { 2019). }\end{array}$ \\
\hline \multirow[t]{3}{*}{$\begin{array}{l}\text { LSE resource } \\
\text { adequacy } \\
\text { requirements }\end{array}$} & MISO & $\begin{array}{l}\text { MISO identifies the planning reserve margin requirement obligation (i.e., vertical } \\
\text { demand curve) for each LSE annually, and LSEs need to meet the requirements } \\
\text { through self-supply, bilateral contracting, or market-based acquisition via the } \\
\text { voluntary capacity auction (i.e., planning resource auction) (MISO 2020d). }\end{array}$ \\
\hline & SPP & $\begin{array}{l}\text { SPP establishes resource adequacy requirements annually for each load } \\
\text { responsible entity (LRE), and LREs need to meet these requirements through } \\
\text { self-supply or bilateral contracts with resources counted by SPP. The planning } \\
\text { criteria define the planning reserve margin to be } 12 \% \text { for each LRE, unless the } \\
\text { LRE's capacity is at least } 75 \% \text { hydro-based generation (SPP } 2018 \mathrm{~d} \text { ). }\end{array}$ \\
\hline & CAISO & $\begin{array}{l}\text { CAISO establishes system, local, and flexible resource adequacy requirements for } \\
\text { LSEs, and LSEs need to meet these requirements through self-supply or bilateral } \\
\text { contracts in both annual and monthly filings. CAISO procures backstop capacity } \\
\text { via auction (also known as capacity procurement mechanism) as needed (CAISO } \\
\text { 2020d). }\end{array}$ \\
\hline $\begin{array}{l}\text { Energy-only } \\
\text { Market }\end{array}$ & ERCOT & $\begin{array}{l}\text { ERCOT does not have specific reserve margin reliability requirements for LSEs, } \\
\text { nor any capacity payment mechanism. Instead, ERCOT relies primarily on } \\
\text { scarcity pricing mechanisms (e.g., ORDC price adder) in the energy and ancillary } \\
\text { service markets, as well as some voluntary bilateral contracting, to incentivize } \\
\text { capacity investment. LSEs (competitive retail suppliers) must procure sufficient } \\
\text { resources to meet load or else purchase energy on the spot market at scarcity } \\
\text { prices. However, ERCOT calculates a reserve margin for informational purposes } \\
\text { in its seasonal resource adequacy assessments (ERCOT 2020a). }\end{array}$ \\
\hline
\end{tabular}




\subsection{Recent Market Initiatives}

Each ISO/RTO has identified key market challenges related to resource adequacy and resilience in its long-term initiatives and through its stakeholder processes. The identified issues and priorities cover all key market design elements for resource adequacy programs, including resource adequacy requirement quantification, demand curve design in centralized capacity markets, capacity product design (including resource qualification), timeline of program implementation, performance requirements, and market power mitigation. Resource adequacy-related market challenges that have resulted in recent and proposed market design changes are summarized in Table 9.

Table 9. Recent market changes and proposed plans related to resource adequacy and system resilience

\begin{tabular}{|c|c|}
\hline ISO/RTO & Recent and Proposed Market Changes \\
\hline PJM & $\begin{array}{l}\text { PJM is exploring fuel and resource security through its Fuel Security Senior Task Force, and the } \\
2018 \text { Fuel Security Analysis study suggests that there are no immediate threats related to fuel } \\
\text { security in PJM (PJM Interconnection 2018c). PJM is also working with FERC to implement } \\
\text { changes to its Minimum Offer Price Rule (MOPR) to accommodate state-subsidized electric } \\
\text { generation resources into the capacity market. }\end{array}$ \\
\hline NYISO & $\begin{array}{l}\text { In its Strategic Plan 2020-2024, NYISO identifies Grid Reliability and Resilience, Efficient } \\
\text { Markets for a Grid in Transition, and Integration of Public Policy, among others, as key initiatives } \\
\text { (NYISO 2020a). Specifically, NYISO is conducting a comprehensive mitigation review to evaluate } \\
\text { its buyer-side mitigation (BSM) rules and ways to accommodate state policies such as the Climate } \\
\text { Leadership and Community Protection Act. NYISO is also considering revising its resource } \\
\text { capacity ratings for renewables and storage to reflect their reliability contribution. Other capacity } \\
\text { market- related activities include LMP of capacity, seasonal (winter and summer) procurement } \\
\text { requirements, and a capacity demand curve reset study (NYISO 2019c). NYISO also conducted a } \\
\text { fuel security analysis to evaluate the risks associated with fuel and energy availability during the } \\
\text { winter season (Hibbard and Wu 2019). }\end{array}$ \\
\hline ISO-NE & $\begin{array}{l}\text { ISO-NE is exploring longer-term market-based approaches to align multi-day energy needs with } \\
\text { market price signals through the Energy Security Improvements Key Project to ensure fuel security, } \\
\text { together with the Interim Compensation Treatment Key Project and Forward Capacity Market: } \\
\text { Retain Resources for Fuel Security Key Project for near-term solutions such as winter-season } \\
\text { resource compensation and incorporating Forward Capacity Market (FCM) Fuel Security Reliability } \\
\text { Review methodologies. ISO-NE also implemented the Competitive Auctions with Sponsored } \\
\text { Resources (CASPR) to efficiently accommodate state policies in its forward capacity market cost. }\end{array}$ \\
\hline MISO & $\begin{array}{l}\text { The availability and flexibility needs identified in MISO's forward report are both related to MISO's } \\
\text { resource adequacy program (MISO 2019b). MISO also identifies the need to improve reliability } \\
\text { requirements to reflect reliability needs across all hours of the year, and to better accredit resource } \\
\text { contributions towards resource adequacy in its Resource Availability and Need issue tracking task. }\end{array}$ \\
\hline SPP & $\begin{array}{l}\text { SPP identifies security resilience, regional resource needs, and grid resilience initiatives as priorities } \\
\text { in its strategic plan initiatives (SPP 2017). The operator also proposes to adopt ELCC methodology } \\
\text { to determine accreditation of wind and solar resources (SPP 2019c, d). }\end{array}$ \\
\hline CAISO & $\begin{array}{l}\text { CAISO's Resource Adequacy Enhancements Initiative proposes multiple changes to its resource } \\
\text { adequacy program, including full consideration of forced outage rates in reliability requirements and } \\
\text { net qualifying capacity calculation, to develop a new flexible resource adequacy framework, to } \\
\text { update rules for resource adequacy import provisions, and to improve resource deliverability } \\
\text { through updated must-offer obligations (CAISO 2020). CAISO also proposed to develop a } \\
\text { methodology to calculate unforced capacity value for use in resource adequacy requirements and } \\
\text { assessments on top of its current net qualifying capacity calculation to reflect the impacts of high } \\
\text { forced outage rates in resource adequacy (CAISO 2018a). }\end{array}$ \\
\hline
\end{tabular}


Table 9. (Cont.)

\begin{tabular}{|l|l|}
\hline ISO/RTO & \multicolumn{1}{c|}{ Recent and Proposed Market Changes } \\
\hline ERCOT & $\begin{array}{l}\text { ERCOT does not have specific resource adequacy requirements and programs. Instead, it uses } \\
\text { ORDC updates and refinements to incentivize investments and achieve reliability targets. Detailed } \\
\text { discussion is presented in section 5. ERCOT also keeps monitoring drought-related risks affecting } \\
\text { cooling water for thermal generation resources. }\end{array}$ \\
\hline
\end{tabular}

\subsection{Key Challenges, Research Opportunities, and Findings from the Literature}

From a review of ISO/RTOs initiatives, stakeholder positions, technical reports, and academic literature, seven challenges and research needs in resource adequacy and system resilience were identified; they are summarized in Table 10. Each challenge presented in Table 10 is discussed later in more detail, in the priority order identified by ISO/RTO stakeholders.

Table 10. Major research questions and opportunities related to resource adequacy and system resilience

\begin{tabular}{|c|c|c|}
\hline Challenge & Type & Research Questions and Opportunities \\
\hline $\begin{array}{l}\text { Enhance reliability } \\
\text { assessment and } \\
\text { implementation }\end{array}$ & $\begin{array}{l}\text { Technical, } \\
\text { implementation }\end{array}$ & $\begin{array}{l}\text { Options to revise engineering-based reliability assessment methods, } \\
\text { develop more granular temporal and spatial reliability } \\
\text { requirements, and incorporate economic-based reliability } \\
\text { assessment for comparison. }\end{array}$ \\
\hline $\begin{array}{l}\text { Capacity rating and } \\
\text { capacity credit } \\
\text { calculation method }\end{array}$ & $\begin{array}{l}\text { Technical, } \\
\text { implementation }\end{array}$ & $\begin{array}{l}\text { Approaches to probabilistic-based methods to calculate capacity } \\
\text { credits for VRE technologies, revise capacity accreditation rules, } \\
\text { and develop rules to quantify emerging technology capacity } \\
\text { contribution, including battery storage, DR, and hybrid resources. }\end{array}$ \\
\hline $\begin{array}{l}\text { Accommodate state- } \\
\text { level policies in capacity } \\
\text { markets }\end{array}$ & \begin{tabular}{|l|} 
Economics, \\
policy/regulatory
\end{tabular} & $\begin{array}{l}\text { Explore ways to accommodate state-subsidized resources in capacity } \\
\text { markets to correctly value their clean attributes and comply with } \\
\text { FERC orders, and understand the potential impacts of different } \\
\text { proposals on technology development and consumer cost. }\end{array}$ \\
\hline $\begin{array}{l}\text { Shape and parameters of } \\
\text { capacity demand curve }\end{array}$ & $\begin{array}{l}\text { Technical, } \\
\text { economics, } \\
\text { implementation }\end{array}$ & $\begin{array}{l}\text { Evaluate the market impacts of underlying parameters that define } \\
\text { the shape of demand curves on the basis of current design principles, } \\
\text { and explore new demand curve designs to better reflect the } \\
\text { economics of procuring a cost-minimizing and efficient quantity of } \\
\text { capacity. }\end{array}$ \\
\hline $\begin{array}{l}\text { Import resources } \\
\text { capacity contribution } \\
\text { and performance } \\
\text { evaluation }\end{array}$ & $\begin{array}{l}\text { Technical, } \\
\text { implementation }\end{array}$ & $\begin{array}{l}\text { Options to revise qualification rules for import resources adequacy } \\
\text { resources in the planning phase to increase assurance of supply, and } \\
\text { revise import resources must-offer obligations to ensure firm energy } \\
\text { delivery during operation, while treating all resources comparably. }\end{array}$ \\
\hline $\begin{array}{l}\text { Market mechanism to } \\
\text { procure firm capacity for } \\
\text { extreme weather }\end{array}$ & $\begin{array}{l}\text { Technical, } \\
\text { economics, } \\
\text { implementation } \\
\end{array}$ & $\begin{array}{l}\text { Explore whether new markets and/or updated market rules are } \\
\text { needed to incentivize fuel supply arrangement months ahead of } \\
\text { delivery. }\end{array}$ \\
\hline $\begin{array}{l}\text { Participant risk } \\
\text { mitigation in capacity } \\
\text { markets and bilateral } \\
\text { contracts }\end{array}$ & $\begin{array}{l}\text { Economics, } \\
\text { implementation }\end{array}$ & $\begin{array}{l}\text { Explore whether and how market design can be improved to } \\
\text { mitigate asymmetric effects of different technologies' risk profiles } \\
\text { and provide technology-agnostic incentives for investment, and } \\
\text { identify key factors in bilateral contract-based resource adequacy } \\
\text { program design that can reduce uncertainties for both LSEs and } \\
\text { investors. }\end{array}$ \\
\hline
\end{tabular}




\subsubsection{Enhance Reliability Assessment and Implementation}

Well-designed resource adequacy assessment methods and requirement calculations are the first step in ensuring system reliability while also avoiding unnecessary capacity investments. Three challenges and research questions can be summarized from both the assessment and implementation perspectives: (1) to revise and update engineering-based reliability assessment methods; (2) where applicable, to develop more granular temporal and spatial reliability requirements to more accurately signal for firm capacity in the times and locations that it is needed; and (3) to incorporate economic-based reliability considerations in the broader resource adequacy assessment.

First, most ISO/RTOs conduct a loss-of-load expectation (LOLE) analysis, for example, based on a 1day-in-10-years metric, to assess system reliability. In centralized capacity markets, the resulting planning reserve margin level is used in defining the reference capacity requirement level in the demand curve. ${ }^{1}$ In other cases in which reliability requirements are specified, these resulting values serve as the reliability obligations for LSEs to fulfill. While LOLE-based requirements can better reflect system reliability needs than an administratively-set planning reserve margin target (Milligan et al. 2016), studies also suggest that additional considerations may be needed in LOLE analysis. For instance, the traditional assumption that outages are independent and uncorrelated may no longer be valid due to the rise in disruptive events and common mode outages (EPRI 2021). To help address this gap, Murphy et al. (2018) and Murphy et al. (2020) suggest including correlated generator-forced outage rates and temperature-dependent outage rates in reliability assessments. The interpretation of reliability standards also requires caution. Pfeifenberger et al. (2013) show that even with the same 1-day-in-10-years reliability standard (i.e., 0.1 LOLE), differences in the reliability event definition, system size, intertie level, and other factors can result in very different reserve margin values, and the 0.1 LOLE standard does not represent a uniform level of reliability. Finally, metrics other than LOLE, such as expected unserved energy and loss-of-load hours, should be considered to indicate the magnitude and duration of loss of load events.

Second, to fully capture the reliability needs across the whole year and procure sufficient resources across subregions, ISO/RTOs with mandatory reliability requirements are proposing updates to these requirements with more granular temporal and spatial resolution. More specific reliability requirements will likely better attract resources with appropriate characteristics. For example, NYISO is considering different amounts of capacity procurement during the summer and winter capability periods to reflect underlying seasonal capacity needs. It is also investigating LMP of capacity with more geographical granularity (NYISO 2019c). Furthermore, transmission constraints can have a significant impact on the deliverability of capacity. For example, when zonal reliability requirements are considered together with system-wide ones, the level of the reliability targets and the construction of corresponding capacity demand curves require careful investigation to capture the dynamics for intra- and inter-regional reliability needs considering transmission constraints (Zhao et al. 2018).

Finally, a stronger linkage between engineering and economics in reliability assessment is also needed to help justify the selected reliability targets and requirements. Current engineering-based reliability calculations do not take into account economic impacts and consumers' willingness to shed load. Evolving market practice may consider incorporating economic considerations in resource adequacy requirements to complement pure engineering-based calculation. For example, although ERCOT does not have any mandatory reliability requirements, the operator assesses market equilibrium reserve margin and economically optimum reserve margin periodically (Newell, Spees, et al. 2014; Newell, Carroll, et al. 2018), and it also estimates reliability impacts of these economics-driven reserve margin levels.

1 This is also the $x$ axis of the reference point in the capacity demand curve. An illustration of capacity demand curves can be found in section 4.3.4. 
Pfeifenberger et al. (2013) calculate the economically optimal reserve margin from both cost-of-service and societal perspectives for different system configurations, finding that the resulting economic planning reserve margin levels are generally lower than the reserve margin calculated from an engineering-based 0.1 LOLE standard. These results suggest that desired planning reserve margins can be different, depending on whether an economic-based or engineering-based assessment method is used. Other markets may also consider an assessment of reliability requirements from an economic perspective, which could help support the development of demand curves in the capacity market.

\subsubsection{Capacity Rating and Capacity Credit Calculation Method}

Recent grid changes highlight the need to develop and adopt new methods to calculate the firm capacity contribution (i.e., capacity credit) of different technologies in meeting reliability requirements, while being adaptive to evolving resource mixes. Almost all ISO/RTOs have identified that revising and updating their capacity accreditation calculation method is a near-term market enhancement priority (NYISO 2019c; Rocha-Garrido 2020; SPP 2019c, d). Specifically, research needs and potential market changes in this area can be summarized in three categories: (1) to adopt probabilistic-based methods to calculate capacity credit for VRE; (2) to revise existing capacity accreditation rules to precisely capture resource contribution to resource adequacy; and, (3) to develop rules to quantify emerging technology capacity contributions, including battery storage, DR, and hybrid resources.

Current capacity credit calculation methods for VRE are based on either a probabilistic approach or some approximation-based methods (Keane et al. 2011; NERC 2011). The probabilistic approach considers key system components and a wide range of possible operating states across many time steps to quantify the firm capacity contribution of VRE (Milligan, Frew, Ibanez, et al. 2017). One accurate capacity credit metric is the ELCC, which is calculated using a system LOLE target or another probabilistic reliability metric (Holttinen et al. 2014; Keane et al. 2011; NERC 2011). Because of the uncertain and variable nature of VRE generation, as well as the dependence of the firm capacity contribution of VRE on the system resource mix (Mai et al. 2018; Milligan, Frew, Ibanez, et al. 2017), probabilistic approaches can provide a more accurate valuation of VRE capacity credits than alternative approximation methods that may miss critical system events that could lead to loss of load. Currently, only CAISO and MISO (for wind) conduct ELCC analysis to calculate the capacity credit for VRE in resource adequacy programs. A challenge ISOs are facing with determining ELCC is that the value of one resource is very dependent on the rest of the resource mix and it changes over time, though that challenge exists for any metric where there is a capacity construct. Other markets use a capacity-factor-based method to calculate an average capacity factor during "high risk" hours. Currently, PJM, NYISO (2019c), and SPP (2019c, d) are all considering adopting an ELCC method. Ideally, multiple years of historical data would be used to capture the inter-annual variability of load and VRE resources. In addition to adopting probabilistic approaches, ISOs may also consider applying reliability metrics other than LOLE to quantify capacity credits and more effectively capture the impacts of loss-of-load events. Other capacity credit metrics include equivalent firm capacity and equivalent conventional capacity (Soder and Amelin 2008).

Second, market operators may want to consider revisions to existing capacity accreditation rules so that they better reflect resource contribution to resource adequacy requirements considering system dynamics, especially for VRE. For example, one important consideration is whether to apply an average credit to all resources of a given technology type, or instead to differentiate between the average credit of existing resources and the marginal value of new resources (Bothwell and Hobbs 2017). This is especially important for VRE resources because their marginal capacity credit can decrease with higher resource penetration more rapidly compared to other technologies (Keane et al. 2011), and can change based on relative contributions of different resources (Denholm and Margolis 2018). 
Also, a fast-changing energy system landscape requires advanced quantification rules for emerging technology capacity contribution, including battery storage (Denholm et al. 2020; Sioshansi et al. 2013), DR (Parks 2019; Liu 2017), and hybrid resources (Mills and Rodriguez 2019; Byers and Botterud 2019). Additional research is needed to explore and capture the dynamics of capacity credits of these new technologies under different system configurations and market participation rules, and thereby to inform ISO market design. More detailed discussion of challenges associated with emerging technologies is presented in section 3 .

\subsubsection{Accommodate State-Level Policies into Capacity Markets}

As the number of states setting clean-energy goals and supporting renewable-energy development through subsidies continues to increase, the appropriate methods for ISO/RTOs to accommodate these state-level policies in capacity markets have become a major discussion topic. Some stakeholder groups are concerned that out-of-market payments to certain technologies allow these resources to submit artificially low bids and suppress the clearing capacity price (Briggs and Kleit 2013; Brown 2018; MJB\&A 2020), while state policymakers and clean energy proponents argue that regional electricity markets fail to value the specific attributes of low-carbon-emission technologies in their market design. Questions in two major areas have been discussed since these concerns were raised. First, what possible market designs could be adopted to accommodate state policies in capacity markets, and which of these is the most cost-effective? Second, given the possibility of new regulatory rules and order updates from FERC, what are the potential impacts of different market rule proposals on technology deployment and consumer cost, and how can unanticipated or undesired effects or market inefficiencies be mitigated?

For the first area, since March 2016, when a group of independent power producers filed concerns about the price distortion impacts of state policy-subsidized technologies in the PJM system with FERC (MJB\&A 2020), system operators like PJM, NYISO, and ISO-NE have been exploring market mechanisms to accommodate state policies in centralized capacity markets. ISO-NE has implemented CASPR, which introduces a substitution auction that runs immediately after the Forward Capacity Auction to pair the entry of state-sponsored resources with the exit of existing resources, intending to mitigate potential oversupply concerns (ISO-NE n.d.). Within PJM, a number of proposals have been discussed during iterations between PJM and FERC. The proposals either build on MOPR guidelines, which require a minimum capacity market bid price for certain technology types, or rely on Fixed Resource Requirement (FRR) obligations to incorporate subsidized resources through carveouts instead of central capacity auctions (PJM Interconnection 2018a, b; Gramlich and Wilson 2018).

The status of these capacity market-related rule changes and the direction of changes depend on FERC regulatory decisions. Recent key orders include one released on December 19, 2019, ${ }^{2}$ which directed PJM to expand its MOPR to any resources that receive or could receive any type of state subsidies, with certain exemptions (FERC 2019b). An additional order released on February 20, 2020, ${ }^{3}$ requires bidding price floors for new renewable and storage resources and some DR in NYISO's mitigated capacity zones (FERC 2020a). Market designers and the research community may need to adjust focus once FERC and/or the courts resolve the policy issue of whether broad application of MOPR is necessary in response to state policies.

In the second area, studies have also started to evaluate the impacts of FERC orders on technology development and consumer costs. For PJM, the recent FERC-mandated MOPR change may possibly raise

2 Dockets No. EL16-49-000 and EL18-178-000.

3 Dockets No. EL13-62-001, EL13-62-002, EL19-86-000, EL16-92-001, ER17-996-000, and ER16-1404-000. 
the capacity clearing price, thereby increasing consumer costs and resulting in over-supply. The estimated capacity price and consumer cost impacts of this update differ across studies. For example, Goggin and Gramlich (2020) and Kovanen et al. (2020) suggest that prices and costs would increase as a result of the new MOPR, while PJM's independent market monitor (IMM) finds no specific impact in the 2022/2023 auction (Monitoring Analytics 2020b). The actual impacts on technologies and costs will depend on the definitions of resource-specific price floors and technology exemption rules. The impact of the February 20, 2020, order on NYISO is likely less pronounced than the PJM MOPR order in the near term because of the limited size of mitigated capacity zones (Chaurey and Katsigiannakis 2020). However, the NYISO order may have long-term impacts, considering the New York's Climate Leadership and Community Protection Act goals, potential carbon pricing implementation, and the uncertainties of future order direction. Patterson (2019) finds that increased consumer costs due to stringent BSM rule changes can be mitigated by the carbon pricing proposal, since a carbon adder in energy markets can benefit renewable technologies by reducing their net cost of new entry (CONE), which can help them pass the exemption tests.

Moving forward, ISO/RTOs and researchers are continuing to explore ways to accommodate statesubsidized resources in capacity markets to correctly value both their clean attributes and capacity contributions while complying with FERC orders. For example, PJM and NYISO are evaluating the potential impacts of implementing a carbon price across their entire system (PJM Interconnection 2020a). States are also considering FRR alternatives to fulfill state goals in the context of current PJM capacity market rules (Farmer and Gramlich 2020). A fast-changing regulatory environment and the multistakeholder nature of the issue make it hard to identify a "perfect" solution unless and until larger policy questions are resolved by FERC and the courts. With these uncertainties in mind, additional research is still needed to evaluate the impacts of recent FERC orders as well as the ISO/RTO market design changes that are under consideration. In particular, it will be important to understand how market participants might respond to these changes and identify any potential side effects or unanticipated impacts.

\subsubsection{Shape and Parameters of Capacity Demand Curve}

In centralized capacity markets, downward-sloping demand curves help provide an economic rationale behind the reliability requirements and attempt to represent consumer willingness to pay for electricity reliability (FERC 2013; Hobbs et al. 2007; Newell, Oates, et al. 2018). NYISO, PJM and ISO-NE all adopt a downward-sloping demand curve in their capacity market design. An illustration of a representative capacity demand curve is shown in Figure 6. The underlying design principles for demand curves all rely on two key factors: (1) the net CONE and (2) the reference reliability level, usually shown as planning reserve margin values. Variations in other parameters, including multipliers for the price cap level, the zero-crossing point, and potential shifts of the overall curve, also result in different demand curve shapes across markets (Byers et al. 2018). Research is still needed to evaluate the market impacts of changes in the underlying parameters that define the shape of demand curves as currently designed, and to explore new demand-curve designs that better reflect the economics of procuring the quantity of capacity that minimizes total system costs. 


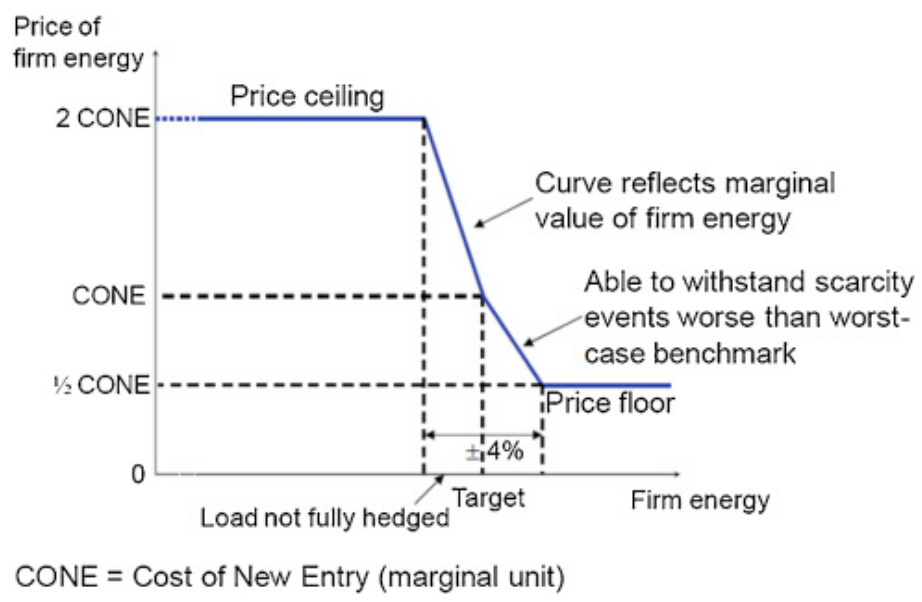

Figure 6. Illustration of a generic demand curve for a capacity market (Source: Cramton and Ockenfels 2012)

Both net CONE values and system reliability requirement levels must be reviewed and updated periodically. Both system operators and the corresponding IMMs review these values on a recurring basis (Newell, Hagerty, et al. 2018; Newell, Oates, et al. 2018; Pfeifenberger et al. 2014). NYISO also has an ongoing effort to examine the slope and shape of its demand curve (NYISO 2019c). The net CONE value serves as a reference value for the cost to build a new generator after energy and ancillary service revenues are accounted for; specifically, it is the operating margin that a new resource would need to earn in the capacity market, after netting margins earned in markets for energy and ancillary services (Newell, Hagerty, et al. 2014). Currently, all markets use a peaking plant, normally a combustion turbine unit, as the reference technology for their net CONE calculation, although Newell, Oates, et al. (2018) recommend that using a combined cycle plant can better incentivize investments without substantial overprocurement. The method used to calculate energy and ancillary service revenues also has an impact on the net CONE values and requires attention in methodological updates (Newell, Oates, et al. 2018). The reliability requirement levels are discussed in the section 4.3.1; the reference point requirement is usually based on reserve margin value calculated from probabilistic LOLE analysis using the 1-day-in-10-years metric. Evaluating the impacts of changes to other parameters, including multipliers for the price cap level (i.e., the horizontal portion of the curve), the level of zero-crossing point, and the percentage of curve shift, is also essential in determining a well-functioning demand curve. These administrative demand curves can be thought of as proxies for action demand valuation, which can be assessed with research to improve the estimate.

In addition to reviewing and updating the parameters that define the shape of current demand curves, efforts are also needed to investigate new demand-curve designs to better reflect a consumer's willingness to pay for reliability, while also considering system-level and zonal requirement interactions (Zhao et al. 2018). For example, Pfeifenberger et al. (2013) calculate a risk-neutral, cost-minimizing demand curve from both societal and cost-of-service perspectives, suggesting that they would result in lower prices compared to the demand curves currently implemented in ISO/RTO capacity markets, because the latter are developed with the objective of achieving reliability standards rather than economic efficiency. In terms of implementation, while still relying on some administratively set parameters, ISO-NE has transitioned to a full Marginal Reliability Impact demand curve to better reflect the declining incremental value of capacity after the reference reliability level has been achieved (Kotha 2019). 


\subsubsection{Import Resources Capacity Contribution and Performance Evaluation}

The qualification and deliverability of import resources to fulfill resource adequacy requirements can be essential for system reliability, especially in regions that rely heavily on imports to meet capacity needs. Reliability concerns may be raised if resource adequacy import rules are ineffectively set. For example, during the planning stage, if the import resources are not backed by physical resources or do not have a dedicated service requirement, the underlying resources may be double-counted in resource adequacy contributions across the source and destination regions. Also, during system operation, without welldesigned market rules, import resources may not be able to deliver during high-risk hours because of transmission constraints. Two key questions need to be considered carefully when rules for resource adequacy imports are being revised: (1) how to design qualification rules for import resources (or external resources) in the planning phase to ensure deliverability and exclude speculative supply; and (2) what rules are needed, including must-offer obligations, to ensure firm energy delivery as the system needs it during operation.

While most ISOs have developed relatively mature rules for resource adequacy imports, this remains a major concern in CAISO, which is having an ongoing discussion of possible rule changes. Specifically, CAISO is experiencing an increasing reliance on import resources adequacy resources to meet system resource adequacy requirements (CAISO 2020e). Current rules in CAISO for non-resource-specific resource adequacy imports may result in double-counting of resource adequacy import resources as well as rely on speculative supply during critical system conditions (CAISO 2018e; 2020e). CAISO is therefore actively working with the California Public Utilities Commission (CPUC) to revise California's resource adequacy import requirements to address these concerns in a cost-effective way (CAISO 2020e; CPUC 2020).

A first area of consideration when evaluating possible revisions of resource adequacy rules for import resources is related to resource eligibility and qualification rules. There are three major aspects to consider in the context of resource eligibility and qualification: (1) resource-specific resource adequacy provisions tied to physical resources (i.e., provision that is backed up by physical resources); (2) resource adequacy provisions that are not recallable or curtailable, especially under emergency conditions; and, (3) firm transmission requirement and deliverability demonstration. In general, resource-specific supply with demonstrated dedicated usage (e.g., not sold in other regions, not recallable or curtailable by an external control area) can provide more dependable and reliable resource adequacy compliance (CAISO 2019c). The deliverability under emergency conditions, especially when neighboring systems also face stressed conditions, is also suggested to be tested to ensure reliable delivery (Hibbard, Schatzki, and Bolthrunis 2017). To the third point, while not all markets require border deliverable demonstration, requiring some form of firm transmission service will likely help ensure operational deliverability. In addition to these three aspects, attention is needed to distinguish "external" resources with respect to local versus system resource adequacy requirements. For example, MISO modified its resource adequacy rule in 2018, incorporating External Resource Zones to better account for resources that support regionwide reserve requirements but do not count toward local requirements (MISO 2019f).

To ensure firm energy delivery during high-risk hours of operation, the must-offer obligation rules need to be well-designed. ISO-NE and PJM require import resources to bid in both DA and RT markets to ensure performance, while others require only DA provision with different rules for RT schedules (CAISO 2019c). In regions without RT obligations, resources may bid high prices close to the price cap in the DA market so that they do not clear in the market; therefore, they do not have further obligations in the RT market, resulting in potential speculative supply and performance concerns (CAISO 2018e; 
Hibbard, Schatzki, and Bolthrunis 2017). CAISO is proposing to modify its must-offer obligation rules to improve resource adequacy import deliverability (CAISO 2020e).

\subsubsection{Market Mechanism to Procure Sufficient Firm Capacity}

Energy security and system resilience under extreme system conditions, such as extreme weather events, have become increasingly important topics as system operators plan for long-term energy system transition. Among all potential weather hazards, extreme-cold winter events have been a significant threat in power system operation in recent years. For example, severe cold snaps, including the 2018 bomb cyclone and 2019 polar vortex events, led to record high electricity demand and natural gas prices in the Northeast and Mid-Atlantic (EIA 2019a, b). The more recent 2021 Uri winter storm also resulted in record high electricity demand, significant common-mode failures across a large portion of ERCOT's fleet, and unserved load (with the associated administratively set price cap of $\$ 9000 / \mathrm{MWh}$ ) for multiple days across large swaths of Texas (ERCOT 2021). These winter events are particularly challenging, as most systems have traditionally focused on summer peak-load periods in resource adequacy assessments; this fact highlights the need for evaluation across a broader set of hours. However, extreme hot and dry summer conditions have also resulted in unserved load, with additional threats to the integrity of the transmission system from multiple wildfires, such as those during summer 2020 in California (CAISO 2020f). Price statistics resulting from several extreme weather events are discussed in section 2.3.6. These extreme-weather-driven reliability concerns have underscored the need for ISO/RTOs to assess the reliability risks with respect to energy security and to explore whether new market rules are needed to incentivize sufficient fuel/resource supply for firm energy provision across all hours of the year (i.e., energy adequacy), especially during periods of heightened risk (NERC 2020a).

Ensuring the deliverability of firm capacity during extreme weather events requires the presence of both sufficient generation capacity and sufficient fuel and energy supply during the event period. Traditional resource adequacy studies usually assume that fuel is available when the capacity is needed, for example, through long-term contracts or on-site storage. However, recent extreme weather events and the resulting common-mode failures of system infrastructure have highlighted the importance of considering infrastructure interdependencies and fuel supply risks when determining system resource adequacy targets (EPRI 2021). Specifically, the market mechanisms employed by ISO/RTOs to ensure resource adequacy may evolve to include an assessment of both capacity adequacy and energy adequacy, which considers potential shortfalls in the conversion of capacity to energy, while also evaluating potential impacts across all hours of the year. North American Electric Reliability Corporation (NERC) has outlined some key considerations and research questions on fuel availability and energy adequacy with energy-constrained resources (NERC 2020b).

All northeastern ISOs-ISO-NE, NYISO, and PJM - have conducted fuel security analyses during the past two years to evaluate system reliability risks during extreme winter-weather events. Both the PJM and NYISO studies suggested that the risks associated with fuel and energy availability are low in the near term (PJM Interconnection 2018c; Hibbard and Wu 2019), while the fuel security report from ISONE suggested that significant levels of emergency actions were required in almost all cases evaluated (ISO-NE 2018b). The ISO-NE study finds that sufficient imports of LNG and electricity from neighboring regions and dual-fuel capability are the two key factors in maintaining reliable operation.

On the basis of the assessments of fuel security risks, ISO/RTOs and researchers from the industry have started exploring market design changes to address potential reliability risks due to lack of fuel security. Maintaining operational reliability under extreme weather events requires close monitoring of key system factors (across power supply, power demand, and fuel supply) to ensure operator awareness of risks, as 
well as sufficient financial incentives from both long-term and operational markets to support fuel supply arrangements during high-risk periods. When the overall fuel security risk is low in the near term, as shown by PJM and NYISO assessments, status quo operation with enhanced monitoring and periodic risk assessments is likely to be the most cost-efficient path to address the issue (Horger 2019). Close monitoring of key factors for fuel security, including dual-fuel generator capability, generator weatherization, generator outage due to lack of fuel, and gas pipeline capacity and availability, are essential to building operator awareness of potential risks. NYISO also plans to extend its weekly fuel inventory evaluation process to look 14 days into the future to better assess fuel adequacy (NYISO 2019a).

However, if the system starts seeing a high threat of fuel security issues as suggested by the ISO-NE study, which indicates that existing market rules are insufficient in incentivizing fuel supply arrangements during wintertime, then rule changes and/or new mechanisms are likely needed. For example, ISO-NE has identified several key problems for energy security, including the lack of incentive for additional energy supply arrangements, operational uncertainty during cold weather conditions, and inefficient scheduling of limited energy supplies (ISO-NE 2019). Suggested considerations to inform market changes in short-term market operation, including new DA ancillary service products and a voluntary multi-DA market, are discussed in sections 2 and 5.

Besides enhancing real-time price signals for the attributes needed for secure fuel supply, forward markets that allow generators to make energy supply or other reliability enhancement investments months and years ahead of delivery may also help provide incentives and risk-mitigation measures. Such a forward market could be developed as a new market platform, or it may leverage the existing FCM structure and be designed as add-on market rules. For example, ISO-NE suggested a voluntary seasonal forward auction as a potential solution to fuel security issues (ISO-NE 2019). Another approach, as proposed by the Brattle Group (Newell and Ruiz 2019), is to modify the existing FCM to incorporate energy security standards explicitly. This effort includes identifying a qualification standard for "energysecure demand" and an associated demand curve similar to a capacity market demand curve, and "fuelsecure resources" would also have to be rated with a metric similar to capacity credit calculation; both of these actions impose challenges in quantification. In summary, more work is needed to fully understand the interactions between forward markets and other energy- or fuel-security-focused market rule changes, as well as the potential market impacts of specific energy- or fuel-security market design proposals.

\subsubsection{Participant Risk Mitigation in Capacity Markets and Bilateral Contracts}

From a risk management perspective, centralized capacity markets and long-term bilateral contracts can also be viewed as tools for investors and consumers to hedge risk due to volatile spot-market prices. Centralized capacity markets have the same impacts as a call option, or a reliability option, with a strike price equal to the market price cap (Bidwell 2005; Cramton and Stoft 2008; Mays et al. 2019; Vázquez et al. 2002). With the obligations imposed on LSEs, such a call option helps stabilize generator revenues and reduce uncertainties due to price volatility, therefore incentivizing long-term investments (Deng and Oren 2006). Studies have shown that forward capacity markets can help correct the investment shortcomings compared to markets with no risk-trading mechanisms (De Maere d'Aertrycke et al. 2017), and they are relatively insensitive to investor risk aversion compared to other instruments (Abani et al. 2018). Similarly, bilateral contracts in resource adequacy programs serve similar roles for generation investors and consumers to hedge risks with LSEs that have fixed resource adequacy obligations.

However, there are also uncertainties and risks associated with capacity markets and bilateral contracts, jeopardizing their capability to incentivize investments and to provide a technology-agnostic framework 
for decision making. For example, a poorly calibrated reliability target and an ill-designed capacity demand curve may create highly volatile prices in capacity markets and reduce the economic efficiency of capacity markets in attracting investments (De Maere d'Aertrycke et al. 2017; FERC 2013). Also, existing capacity market structures have an asymmetric risk impact on different technologies, resulting in a less favorable environment for low-carbon technologies with high capital and low operating costs (Mays et al. 2019). In addition, LSEs face a variety of regulatory uncertainties in procurement requirements and resource qualification rules, especially in ISO/RTOs relying on bilateral contracts to achieve resource adequacy targets, that may lead to inefficiencies in contracting (CAISO 2020b). Finally, there exist normal uncertainties in future technology costs, electricity prices, and other varying factors in both paradigms that contribute to uncertainty and potential investment risk. As a result, additional financial instruments to hedge risk for both investors and LSEs may be needed.

Different market-related solutions have been discussed to reduce investor- and consumer-related uncertainties in resource adequacy programs. For centralized capacity markets, incorporating a downward-sloping demand curve, extending forward periods, and introducing additional financial instruments can all help reduce capacity price volatility. Studies have shown that a gentler slope of the capacity demand curve can reduce capacity price uncertainty (Bhagwat et al. 2017; FERC 2013). There also exist multiple financial instruments for capacity market risk trading, such as fixed-price capacity futures, to help investors hedge risks due to price uncertainties, especially in strip and spot auctions in NYISO. ${ }^{4}$ On the other hand, in regions with bilateral contracts, both clearer resource adequacy requirements and potentially longer contract times for certain resource types can provide more certainties to market participants. For example, CAISO is considering a multi-year maximum importing capacity rule and uses it as a starting point to implement a multi-year resource adequacy requirement to help provide more certainty to the LSEs (CAISO 2020b).

Overall, this risk mitigation issue remains a low-priority issue among all ISO market design challenges related to resource adequacy. Potential future research will focus on determining whether and how market design can be improved to mitigate asymmetric effects of different technologies' risk profiles and to provide technology-agnostic incentives for investment, and determining how bilateral contract-based resource adequacy program designs can be updated to reduce uncertainties for both LSEs and investors.

${ }^{4}$ Examples include secondary capacity future products from CME Group (https:/www.cmegroup.com/education/courses/introduction-to-energy/introduction-to-power/managing-risk-inthe-capacity-market.html), and capacity fixed-price futures (https://www.theice.com/products/FuturesOptions/Energy/Electricity). 


\subsection{Energy Price Formation}

Higher penetration of VRE resources with very low or zero variable costs, along with low natural gas prices and stagnant demand growth due to efficiency enhancements, have contributed to declining energy prices in recent years (Wiser et al. 2017). As more zero-variable-cost VRE generation sources are expected to enter the grid in the foreseeable future, and as specific attributes (e.g., lower emissions, reliability services, flexibility) are becoming more desirable, energy price formation practices may need to be updated to ensure that resources are incentivized appropriately to deliver the requested services and that they have the opportunity to recover their costs transparently within the market. In a recent report in collaboration with ISO/RTO staff, energy price formation was defined as follows (EPRI 2019c):

Price formation is the algorithm(s) and rules that set how energy and ancillary services prices and payments are calculated in ISO/RTO wholesale electricity markets and the design of relevant settlement rules.

In such an environment, scarcity-pricing approaches, such as the ORDC proposed by some ISO/RTOs, provide incentives for resources to enhance reliability with price signals reflecting true reliability needs (Hogan 2018). Another challenge faced by ISO/RTOs is that the LMP framework does not typically include start-up and no-load costs associated with the unit commitment problem, resulting in significant out-of-market uplift payments. Other issues include the inability of fast-start resources to set the price in many wholesale electricity markets because of their typical block-loaded characteristic and, in many cases, the inability or inefficiency of price-setting from demand-side resources. Underpinning all of these factors is a fundamental inefficiency in current wholesale electricity markets: most markets are highly one-sided, because demand is not incentivized to express its true price willingness (Cramton et al. 2013; Milligan, Frew, Clark, et al. 2017). As a result of poor incentives, prices in wholesale electricity markets are almost always set by the supply curve rather than the demand curve (Stoft 2002).

ISO/RTOs face several challenges in energy price formation. These include, but are not limited to, handling systems in which zero-marginal cost resources are on the margin the majority of hours, designing appropriate scarcity and shortage pricing mechanisms, and implementing multi-period market pricing and settlement, active demand-side participation mechanisms, and carbon pricing. The prioritization of these market challenges is guided by ISO stakeholder inputs; the ranking results are shown in Figure 7. 


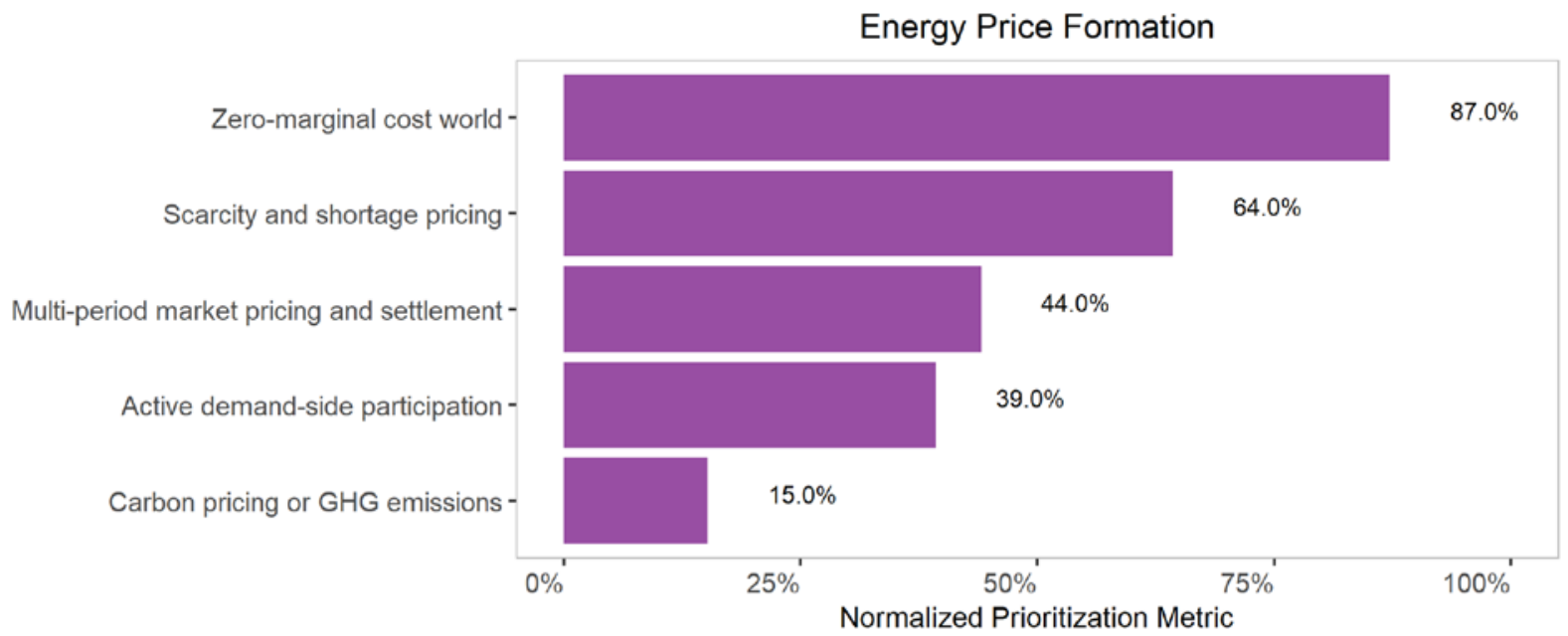

Figure 7. Priority ranking of market challenges related to energy price formation from the ISO/RTO stakeholder meeting

The rest of this section is organized as follows: section 5.1 highlights the market practices related to energy price formation; section 5.2 summarizes recent market initiatives discussed in ISO/RTOs; and section 5.3 provides detailed descriptions of primary challenges and insights from the literature.

\subsection{Current Market Practice for Energy Price Formation}

Energy price formation has been defined broadly depending on organization and use, and usually refers to pricing and settlement issues around electricity products. In recent years, there has been an increased focus on fast-start pricing, dealing specifically with nonconvex issues stemming partially from a 2014 FERC proceeding (FERC 2016c, 17-3-000). Nonconvexities arise because of three-part bidding (incremental costs, no-load costs, and start-up costs) and other aspects inherent in market clearing (e.g., minimum generation limits) (O’Neill et al. 2005; Gribik et al. 2007).

Since traditional pricing solely reflects incremental costs, many ISO/RTOs have incorporated aspects of no-load and start-up costs into prices for a subset of resources to minimize out-of-market uplift payments. Extended locational marginal pricing (ELMP) was introduced in 2007 as an optimal Lagrange multiplier of the dual-unit commitment problem, which inherently includes no-load and start-up costs. Wang et al. (2013) present a sub-gradient simplex cutting plane method to find ELMPs. MISO currently employs ELMPs as an alternative pricing method and continues improving its calculation method (MISO 2019c).

Table 11 summarizes current fast-start pricing characteristics across the ISO/RTOs, including RT market characteristics. The table includes these characteristics: whether the ISO/RTO has two separate market runs for physical scheduling and pricing, whether the market scheduling run is a single snapshot interval or a multiperiod horizon (and, if so, how long the horizon is), what resources are considered as modified for the pricing runs, how those resources' minimum generation level is relaxed to affect pricing, and to what extent commitment costs (nonconvex costs) are incorporated into price-setting. 
Table 11. Existing characteristics of ISO and RTO auctions and energy price formation efforts (Note: several ISO/RTOs are updating practice and rules, so some characteristics may be changing.)

\begin{tabular}{|c|c|c|c|c|c|c|}
\hline \multirow{2}{*}{$\begin{array}{l}\text { ISO/RTO } \\
\text { CAISO }\end{array}$} & \multirow{2}{*}{\begin{tabular}{|c|}
$\begin{array}{c}\text { Separation of } \\
\text { Scheduling and } \\
\text { Pricing }\end{array}$ \\
Integrated
\end{tabular}} & \multicolumn{2}{|c|}{$\begin{array}{l}\text { Length of RT Market } \\
\text { Horizon (final dispatch) }\end{array}$} & \multirow[b]{2}{*}{$\begin{array}{l}\text { Resource Subset } \\
\text { Online constrained } \\
\text { output generator } \\
\text { (COG) (block- } \\
\text { loaded) }\end{array}$} & \multirow{2}{*}{$\begin{array}{c}\text { Minimum } \\
\text { Generation Limit } \\
\text { Relaxation }\end{array}$} & \multirow[b]{2}{*}{$\begin{array}{l}\text { Commitment Cost } \\
\text { Minimum } \\
\text { generation cost } \\
\text { allocated over } \\
\text { maximum power } \\
\text { output (Pmax) }\end{array}$} \\
\hline & & $\begin{array}{l}\text { Multiple; } \\
13 \text { intervals }\end{array}$ & 1 hour ahead & & & \\
\hline ERCOT & Separate & Single & $\begin{array}{l}5 \text { minutes } \\
\text { ahead }^{\mathrm{a}}\end{array}$ & $\begin{array}{l}\text { RUC committed } \\
\text { resources }\end{array}$ & $\begin{array}{l}\text { In pricing run, } \\
\text { relaxed to zero }\end{array}$ & None $^{\mathrm{b}}$ \\
\hline IESO & Separate & Single & $\begin{array}{l}5 \text { minutes } \\
\text { ahead }\end{array}$ & $\begin{array}{l}\text { Block-loaded } \\
\text { resources }\end{array}$ & Relaxed to zero & $\begin{array}{l}\text { Included in } \\
\text { incremental energy } \\
\operatorname{cost}^{\mathrm{c}}\end{array}$ \\
\hline ISO-NE & Separate & Single & $\begin{array}{l}15 \text { minutes } \\
\text { ahead }\end{array}$ & $\begin{array}{l}30 \text {-minute and } \\
\text { faster start-up } \\
\text { resource }\end{array}$ & Relaxed to zero & $\begin{array}{l}\text { No-load allocated } \\
\text { over Pmax and } \\
\text { start-up cost } \\
\text { allocated over Pmax } \\
\text { and min. run time }\end{array}$ \\
\hline MISO & Separate & Single & $\begin{array}{l}10 \text { minutes } \\
\text { ahead }\end{array}$ & $\begin{array}{l}\text { 60-minute and } \\
\text { faster start-up } \\
\text { resources (ELMP } \\
\text { Ph. II), includes } \\
\text { DR }\end{array}$ & Relaxed to zero & $\begin{array}{l}\text { No-load and start- } \\
\text { up cost incorporated } \\
\text { into price based on } \\
\text { "unit status" } \\
\text { relaxation }\end{array}$ \\
\hline NYISO & Separate & $\begin{array}{l}\text { Multiple; } \\
5 \text { intervals }\end{array}$ & 1 hour ahead & $\begin{array}{l}30 \text {-minute and } \\
\text { faster resources } \\
\text { with a min runtime } \\
\text { of } 1 \text { hour or less }\end{array}$ & Relaxed to zero & $\begin{array}{l}\text { Start-up costs } \\
\text { included for all fast- } \\
\text { start resources }\end{array}$ \\
\hline PJM & Integrated & Single & $\begin{array}{l}10 \text { minutes } \\
\text { ahead }\end{array}$ & $\begin{array}{l}\text { Block-loaded } \\
\text { resources with a } \\
\text { start time and run } \\
\text { time of } 2 \text { hours or } \\
\text { less }\end{array}$ & $\begin{array}{l}\text { Relaxed to } 80 \% \text { of } \\
\text { minimum }\end{array}$ & None \\
\hline SPP & Integrated & Single & $\begin{array}{l}5 \text { minutes } \\
\text { ahead }\end{array}$ & $\begin{array}{l}\text { 10-minute start-up, } \\
\text { can follow } \\
\text { dispatch }\end{array}$ & $\begin{array}{l}\text { Relaxed for } \\
\text { screening run, but } \\
\text { not pricing }\end{array}$ & None $^{\mathrm{e}}$ \\
\hline
\end{tabular}

a Security Constrained Economic Dispatch (SCED) Base Points are effective immediately upon posting, and typically there is a SCED execution every 5 minutes. ERCOT also calculates and posts indicative pricing, which is nonbinding and provided for each 5-minute interval for 11 future intervals. Quick-start resources are relaxed to zero for dispatch (SCED). RUC-committed resource offer curves are the greater of $\$ 1,500 / \mathrm{MWh}$ or the resource's offer.

b The exception is as follows: quick-start generating resources (QSGR) resources and other resources with Voluntary Mitigation Plans (VMPs) may include start-up and no-load costs or other costs in their offers. For mitigation purposes, verifiable incremental costs are used. QSGRs are allowed to include start-up and no-load costs in their verifiable incremental costs. For resources with VMPs, the verifiable incremental costs are based on a filed agreement with the Public Utility Commission of Texas.

c Fast-start resources include commitment costs as part of their incremental energy offer.

d Offline resources have different criteria for start-up time and are also amortized differently.

e Registered quick-start resources can include an adder to their energy offer with start-up and no-load costs, which is amortized over the previous year's output, but not all quick-start resource commitment costs will set prices; minimum limits are relaxed to zero for a screening run but not the final dispatch or pricing run.

Source: modified from EPRI (2019c). 


\subsection{Recent Market Initiatives}

Although a broad FERC order on fast-start price formation was not implemented, many of the ISO/RTOs received individual orders to update their pricing mechanisms. FERC issued an additional three orders related to price formation more broadly to all markets under its jurisdiction: Order 825, 831, and 844 (FERC 2016a, b; 2018b). Order 825, "Settlement Intervals and Shortage Pricing in Markets Operated by RTOs and ISOs," was issued to accomplish two price formation goals dealing with deficiencies in the way markets were settled and how shortage prices were triggered (FERC 2016a). The issue was that prior to the order, hourly averaging was occurring for settlement earnings such that the resources would follow the average price over an hour rather than the individual dispatch price. Order 825 sought to reconcile this misalignment of incentives. Order 831, "Offer Caps in Markets Operated by RTOs and ISOs," allowed participants to offer costs at over $\$ 1,000 / \mathrm{MWh}$ as long as the offer cost is justified and capped the offer at $\$ 2,000 / \mathrm{MWh}$ for pricing purposes. This allowed for prices to be set on the basis of true marginal costs (capped at \$2000/MWh), particularly during extreme scenarios (e.g., when fuel prices are extremely costly due to natural-gas-heat demand competition). Last, Order 844, "Uplift Cost Allocation and Transparency in Markets Operated by RTOs and ISOs," established reporting requirements for uplift costs and other transparency measures.

Table 12 details recent and upcoming changes proposed to ISO/RTO pricing methodologies focused on fast-start pricing. All but ERCOT have planned or implemented changes related to the three FERC orders. There are many other initiatives at the ISO/RTOs that deal with pricing generally, such as cost-adders that affect prices (carbon or opportunity-cost adders) or scarcity pricing, which are mentioned in the challenges.

Table 12. Recent market changes and proposed plans related to energy price formation

\begin{tabular}{|c|c|}
\hline ISO/RTO & Recent and Proposed Market Changes \\
\hline PJM & $\begin{array}{l}\text { PJM currently has a form of alternative pricing narrowly applied to resources and has proposed } \\
\text { updates to its pricing methodology in accordance with a FERC order (Giacomoni 2018). Recent } \\
\text { filings focused on ancillary service pricing, including an ORDC with changes to the level of } \\
\text { shortage pricing for each of its reserve products. PJM has also been evaluating several carbon- } \\
\text { pricing leakage mitigation mechanisms in its region. }\end{array}$ \\
\hline NYISO & $\begin{array}{l}\text { Because of the large number of gas turbines in its system, NYISO has long used a hybrid- } \\
\text { pricing methodology that includes a physical and economic pass that relaxes minimum } \\
\text { operating limits to allow start-up costs of block-loaded units to be reflected in energy prices. } \\
\text { Following FERC orders, NYISO extended this pricing methodology to all fast-start units, } \\
\text { starting in December } 2020 \text {. NYISO also has issued a proposal to include additional carbon } \\
\text { pricing in its region. }\end{array}$ \\
\hline ISO-NE & $\begin{array}{l}\text { ISO-NE has implemented alternative modeling for fast-start resources and is currently } \\
\text { evaluating opportunity cost-adders and multi-day energy markets with strike prices and options } \\
\text { because of long-term energy security issues. }\end{array}$ \\
\hline MISO & $\begin{array}{l}\text { MISO was early to implement alternative pricing for fast-start units and continues to make } \\
\text { improvements to the calculation method behind its ELMP formulation (MISO 2019c). }\end{array}$ \\
\hline SPP & $\begin{array}{l}\text { SPP had no alternative pricing and has recently proposed new methods because of a FERC } \\
\text { order that creates a separate pricing run and sets fast-start eligibility requirements. }\end{array}$ \\
\hline CAISO & $\begin{array}{l}\text { Although CAISO offers a COG resource category with associated pricing, no resources have } \\
\text { opted to use this voluntary categorization. }\end{array}$ \\
\hline ERCOT & $\begin{array}{l}\text { ERCOT was not affected by the FERC ruling, and has implemented different adjustments over } \\
\text { time. The operator offers fast-start resources the ability to set prices based on the inclusion of } \\
\text { commitment costs. }\end{array}$ \\
\hline
\end{tabular}




\subsection{Key Challenges, Research Opportunities, and Findings from the Literature}

Issues around nonconvex pricing have been part of the academic literature since markets began. Many have proposed methods to incorporate commitment costs into prices or allocate the costs to participants through different side payments. While there is no consensus on the right way to price wholesale electricity, many questions around price formation have shifted from the fundamental algorithm to issues surrounding new or changing market designs. Questions about energy price formation can be categorized in a variety of ways and can be summarized into subtopics: pricing with nonconvex problems, incentivizing specific attributes, unique resource price setting, alternative scheduling software price calculation, and interaction with other products such as ancillary services (see Figure 8).

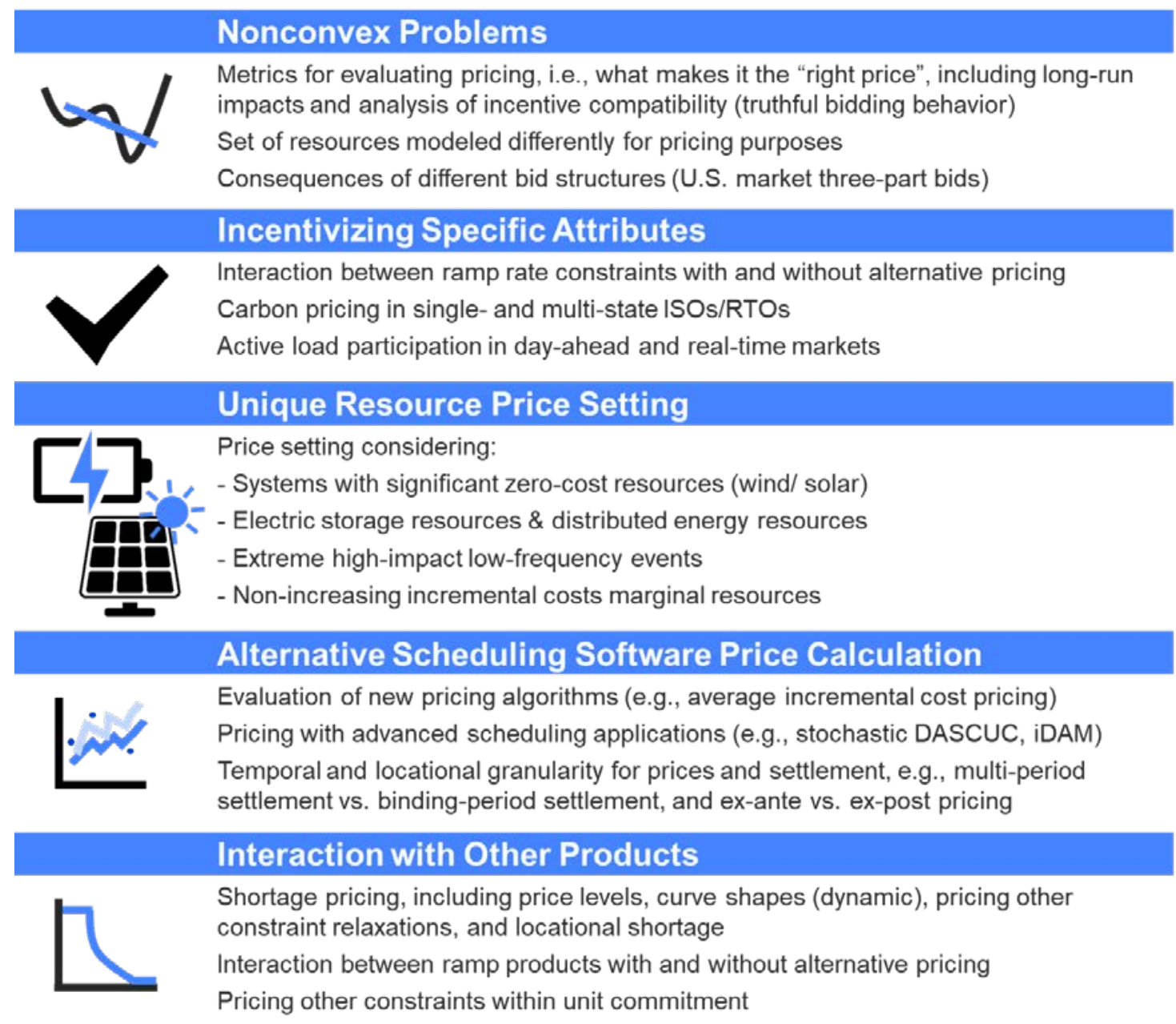

Figure 8. Challenges are emerging in the area of energy price formation (EPRI 2019c)

Table 13 lays out many research questions that have arisen on energy price formation topics. The relevance of each challenge depends on the region or operator, and interest in furthering research on them depends on many stakeholders, including ISO/RTO staff, boards of directors, federal agencies, state agencies, and the research community. Selected challenges relevant to most regions are described in Table 13 . 
Table 13. Major research questions and opportunities related to energy price formation

\begin{tabular}{|l|l|l|}
\hline \multicolumn{1}{|c|}{ Challenge } & \multicolumn{1}{|c|}{ Type } & \multicolumn{1}{c|}{ Research Questions and Opportunities } \\
\hline $\begin{array}{l}\text { Zero-marginal- } \\
\text { cost world }\end{array}$ & Economic, policy & $\begin{array}{l}\text { In a future in which the prices are set frequently by zero- } \\
\text { marginal-cost resources, are current pricing mechanisms } \\
\text { sufficient? How will or should the markets change in an } \\
\text { increasingly zero-marginal-cost world? }\end{array}$ \\
\hline $\begin{array}{l}\text { Scarcity and } \\
\text { shortage pricing }\end{array}$ & Economics, policy & $\begin{array}{l}\text { As we move into futures with varied resources mixes, is } \text { scarcity } \\
\text { and shortage pricing designed and set appropriately? }\end{array}$ \\
\hline $\begin{array}{l}\text { Multi-period } \\
\text { market pricing } \\
\text { and settlement }\end{array}$ & $\begin{array}{l}\text { Technical, economics, } \\
\text { implementation }\end{array}$ & $\begin{array}{l}\text { Is multi-period pricing and settlement possible, and do the } \\
\text { benefits outweigh the complexities? In RT, how many periods } \\
\text { should be included? How should settlement occur when multi- } \\
\text { period optimization is employed? }\end{array}$ \\
\hline $\begin{array}{l}\text { Active demand- } \\
\text { side participation }\end{array}$ & Implementation, policy & $\begin{array}{l}\text { How will markets change with } \text { active demand-side } \\
\text { participation? Are current modeling, pricing, and settlements } \\
\text { sufficient? }\end{array}$ \\
\hline $\begin{array}{l}\text { Carbon pricing } \\
\text { or greenhouse } \\
\text { gas emissions }\end{array}$ & Economics, policy & $\begin{array}{l}\text { With new policies being introduced, how can wholesale markets } \\
\text { efficiently incorporate carbon pricing } \text { or emission-reducing } \\
\text { incentives into prices? }\end{array}$ \\
\hline
\end{tabular}

\subsubsection{Zero-Marginal-Cost World}

If a region has a resource mix with a large share of VRE that has variable costs equal or close to zero, the market could become convex, alleviating the need for alternative pricing to address nonconvexities created by unit commitment. In a future scenario in which the prices are more frequently set by these resources, the current pricing mechanism may not be sufficient for resources to recover their costs. This might be especially true if out-of-market subsidies resulted in negative offers and many periods of negative pricing. In particular, a key uncertainty is whether energy prices alone, with potential for greater volatility, will be enough to secure financing of high-capital projects, or whether additional long-term mechanisms will be required to ensure a functioning and efficient market for investment.

Leslie et al. (2020) explore the impacts of an increasing penetration of VREs on electricity market outcomes and demonstrate the importance of adequately pricing scarcity and all network constraints and services under such a scenario. The role of ORDCs in price formation is emphasized by Hogan (2018). Aggarwal et al. (2019) review challenges faced by future wholesale electricity markets because of increasing penetration of zero-marginal-cost VREs and present two market design proposals, namely, a centralized spot market with decentralized forward procurement (Gramlich and Hogan 2019), and a centralized forward market working with more robust short-term energy and ancillary services markets (Corneli et al. 2019).

Schäfer and Altvater (2019) use an analytical study to make the case that capacity markets will play an increasingly important role in efficient markets with growing shares of renewables. Kraan et al. (2019) use an agent-based model to argue that capacity markets are necessary to achieve fully renewable, reliable systems. In contrast, Riesz et al. (2016) use scenario analysis of the Australian system to argue that by setting higher price caps or enabling the demand side to choose the desired level of reliability, the energyonly market design can continue to function with high shares of VRE. More generally, the role and need for capacity markets may depend on how well short-run prices incentivize flexible operation and 
investments (Botterud and Auer 2020). Increasing penetrations of storage resources may interact with VRE to lessen the price reduction effect (Shahmohammadi et al. 2018). Ambec and Crampes (2019) evaluate market design requirements to achieve socially efficient outcomes with VRE and storage, finding that the need for capacity payments depends on whether externalities are included in markets. While this research has advanced our collective understanding of market options under high-VRE scenarios, more work is needed to fully understand the potential impacts and anticipated prices resulting from these future scenarios.

\subsubsection{Scarcity and Shortage Pricing}

As discussed generally in section 2, approaches to scarcity and shortage pricing vary across the ISO/RTOs, but all shortage-pricing options are important indicators of when the system is under stress. Appropriate price signals during these times can incentivize short-term reliability but also support longterm revenue adequacy by providing rent for the peaking supply resources to recover capital costs. Scarcity pricing reflects the economic phenomenon that when supply is scarce in a market, the price is set by the demand curve, not the marginal cost of supply. In electricity markets, demand is not highly incentivized to submit competitive offers, so scarcity pricing serves as an administrative proxy for the actual demand side as it would be bid by consumers. Almost all ISO/RTOs use a single administratively set price or multistep curve when reserve levels are not sufficient to meet the requirement, which may not adequately capture the value of reserves under all conditions, particularly the value of reserves above the minimum requirement. Like ERCOT (Hogan and ERCOT Staff 2013), other ISO/RTOs are considering alternatives such as the ORDC, recognizing there is value to reserves beyond the requirement. An ORDC provides a transparent market-based framework to procure and reward additional flexibility.

PJM has proposed replacing the current demand curves for 10-minute synchronized reserves, primarily (non-synchronized) operating reserves, and 30-minute reserves with downward-sloping ORDCs. The PJM proposal includes changing the shortage-pricing level by increasing the maximum penalty point from $\$ 850 / \mathrm{MWh}$ to $\$ 2,000 / \mathrm{MWh}$, which the operator says minimizes out-of-market operator intervention (PJM Energy Price Formation Senior Task Force 2018). Hogan and Pope (2019) identify PJM's proposal as a market design advancement that contributes to just and reasonable energy and ancillary service pricing. Future ORDC implementations may require dynamic determination of parameters for a more appropriate reserve valuation (Nicholson 2019).

\subsubsection{Multi-period Market Pricing and Settlement}

Although some ISOs run multi-period models in RT, none settle on future prices; that is, settlement occurs for the first period and the remaining prices are nonbinding and advisory. This approach may lead to inappropriate price signals when resources are backed down in the binding interval to provide ramp in the future. These signals do not allow the market to incorporate the costs of intertemporal constraints into prices or allocate start-up costs to the period that caused the unit to start up. While further information about costs and constraints on the system will be reflected in prices, the difficulty in implementing settlement across the multiple periods could be significant. Ela and O'Malley (2016) compare the performance of two market-clearing designs to meet net-load variability requirements, namely, the timecoupled multi--period model and the ramp capacity-constrained single-period model. While the former design achieves higher efficiency, it may lack proper incentive during ramping periods, and the authors thus propose using dual variables capturing the opportunity costs of ramping as separate prices without the need to use multi-interval settlement. Hua et al. (2019) demonstrate the incentive shortcomings of current ISO implementations of multi-interval RT market design formulated as look-ahead dispatch 
models and present two methods to mitigate the issues using multi-interval pricing and dualizing systemwide constraints and intertemporal constraints.

Additional designs are proposed for ensuring that opportunity costs are priced for even longer horizons. As discussed in section 2, ISO-NE has discussed the possibility of a multi-day DA market, such that the opportunity costs of procuring or reserving fuel for use several days in advance are captured in financial settlements. By allowing the multi-day market to have financially binding settlements, similar to the multi-period (multi-hour) markets in RT, the opportunity costs can be more explicitly captured. The ISONE proposal also includes a new feature including a strike price for DA reserve products, set before suppliers provide offers having an impact on the price formation of these reserve products as well as energy.

\subsubsection{Active Demand-Side Participation}

Traditionally, the demand side of electricity markets has been inactive or perfectly inelastic. This can be thought of as a vertical demand curve such that prices are set only by the marginal cost of suppliers rather than the marginal value of energy that is implied by demand. There have been programs encouraging DR, but few resources that actively bid in and get dispatched by the market outside of emergency conditions.

Retail consumers typically do not see or pay RT prices and thus have no incentive to change behavior on the basis of the changing cost of energy across the day or year. As more technology permeates both residential and industrial loads, offering ways to curb demand for a price (i.e., automation, demand aggregators, transactive energy markets, DERs), more opportunities for active participation will arise. When greater participation from demand occurs, ISO/RTOs will need to reflect this in price formation through aggregated bids or other means. Barriers and prospects of DR participation in wholesale electricity markets are reviewed by Dupuy and Linvill (2019), who list geographical restrictions and high minimum capacity for DR participation as barriers in some regions. Another problem is that some jurisdictions may limit the direct participation of DR aggregators in wholesale electricity markets for regulatory reasons (Gramlich, Goggin, and Burwen 2019).

\subsubsection{Carbon Pricing or Greenhouse Gas Emissions}

More U.S. states are beginning to implement policies or initiatives to reduce emission of carbon dioxide and other greenhouse gases. California already has a cap-and-trade program that affects the CAISO market, and many states in the Northeast participate in the Regional Greenhouse Gas Initiative. Both NYISO and PJM have been evaluating potential carbon-pricing initiatives in their respective regions. The details of the NYISO proposal have been laid out with many of the key challenges regarding leakage and allocation discussed and addressed to a degree (NYISO 2019c). The carbon price would be set by New York State; the emitting generators pay for the carbon dioxide they release into the atmosphere; and the additional revenues from the carbon price are then allocated back to customers. Whereas NYISO benefits from being contained within a single state, PJM must consider an additional challenge in that it would be unlikely for all states in its region to agree on one carbon price. This lack of uniformity could cause significant leakage issues, and PJM and other stakeholders have begun to consider border adjustment approaches to mitigate such effects (PJM Interconnection 2019c).

If done properly, pricing carbon through competitive electricity markets could provide an efficient way of reducing carbon emissions in the power sector, as it reflects the value of the avoided emissions and enables the most cost-effective resources to reduce emissions (Levin et al. 2019). As new state-level policies are developed that may impose positive or negative costs on certain resources, the ISO/RTOs must determine how to incorporate those costs into their wholesale markets (CAISO 2018d). Key issues 
related to this topic include whether it is a single or multistate ISO/RTO and how to manage trade at the seams as well as leakage issues. PJM has studied and compared both regional and subregional carbonpricing frameworks (PJM Interconnection 2017b). While the former achieves the maximum efficiency and eliminates emissions leakage concerns, it is challenging to make all states within the PJM footprint take collective policy action. The second framework is similar to the framework proposed by CAISO (CAISO 2018d), in which the PJM region would be partitioned into two subregions, one including states with a carbon price and the other including those without a carbon price.

The Analysis Group studied the implications of a carbon-pricing framework within NYISO's wholesale electricity market (Tierney and Hibbard 2019). The study showed that carbon pricing brings about several benefits, such as promoting clean energy generation and encouraging innovation and energy efficiency improvement in fossil fuel generators. It also concluded that the NYISO proposal could be implemented soon with the potential to mitigate emissions leakage issues. Butner et al. (2020) explore the legal requirements and economic considerations ISO/RTOs, states and FERC should take into account when implementing carbon-pricing frameworks.

In September 2020, FERC held a technical conference to discuss carbon pricing in wholesale markets. Panelists from ISO/RTOs, academia, and state governing bodies discussed both technical aspects of including carbon in wholesale markets and FERC's jurisdictional authority. Many pointed to the need for state-level policies in order to move forward with pricing carbon within any market. Subsequently, FERC issued a policy statement discussing its ability to review carbon-pricing proposals if they are submitted by ISO/RTOs as driven by state carbon goals (FERC 2020d). Because of testimony and discussion at the conference, FERC acknowledged the many benefits discussed by panelists. In the policy statement, the commission encouraged stakeholders or interested parties to examine proposals, while noting that each proposal will be reviewed separately. 


\subsection{Transmission-Distribution Coordination and Wholesale- Retail Interactions}

Traditionally, the power system was set up in a one-way direction, with generators supplying electricity to the transmission grid and end-users consuming electricity as passive loads in the distribution grid. So there has been limited coordination between transmission and distribution systems. However, this situation is changing rapidly as consumers are becoming more active participants in electricity markets and DERs are making up a significant share of the overall resource mix in many systems. DERs include a set of resources, such as solar PV, ES, and DR, located at the distribution level on the customer side (i.e., behind-the-meter) or utility side (i.e., front-of-the-meter). In some areas, the participation of DERs has increased to such an extent that resources are now also supplying electricity to the transmission grid analogously to conventional resources. The resulting shift toward more two-way interactions between transmission- and distribution-connected resources has impacts on power systems operations and economics, and the market-based transactions between entities at the wholesale and retail levels. From our initial literature review, we identified seven key market design challenges related to transmissiondistribution coordination. The prioritization of these challenges based on stakeholder feedback is shown in Figure 9.

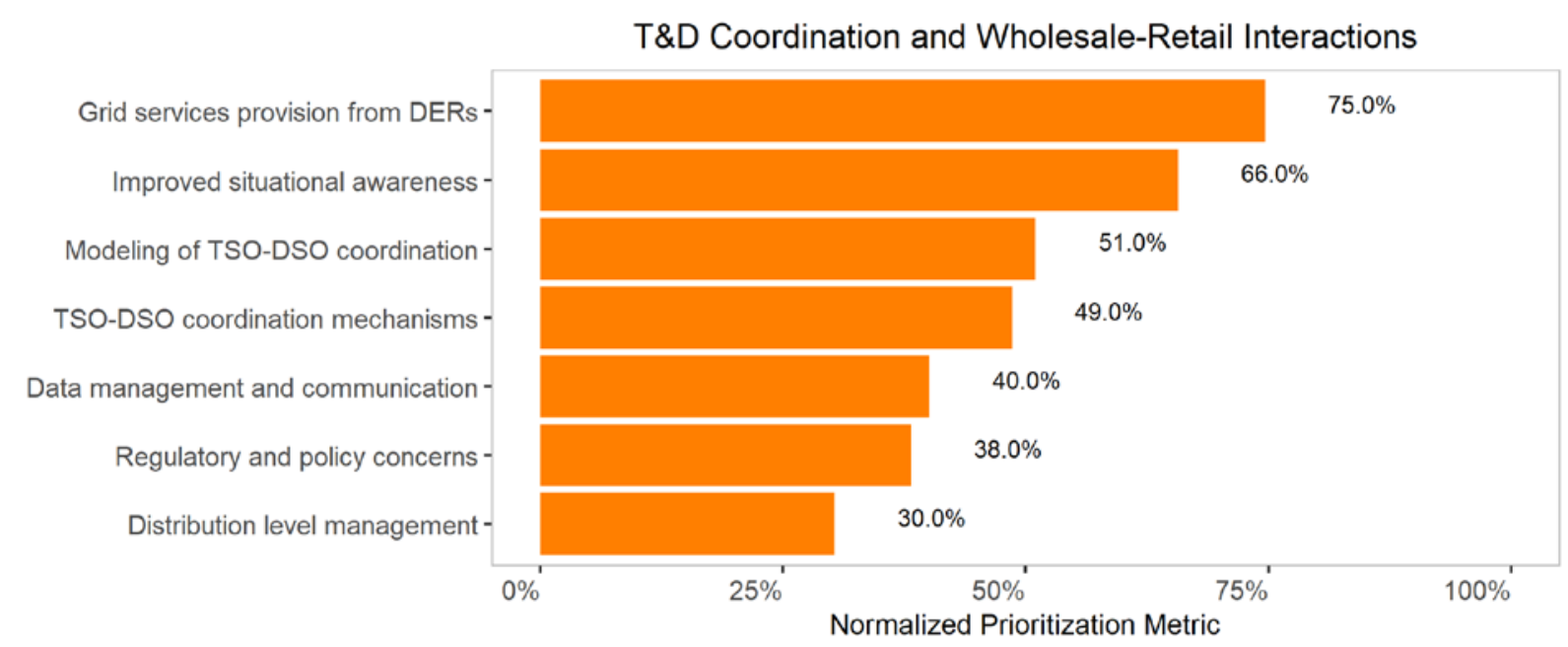

Figure 9. Priority ranking of market challenges related to transmission-distribution coordination and wholesale-retail interactions from the ISO/RTO stakeholder meeting

The three areas with the highest level of interest from the surveyed ISO/RTO stakeholder group are (1) provision of grid services from DERs; (2) improved situational awareness of DERs; and (3) modeling of TSO-DSO coordination (i.e., mechanisms and concepts for coordination between transmission and distribution system operators).

The rest of this section is organized as follows: section 6.1 briefly discusses the current market practice of transmission-distribution coordination and wholesale-retail interactions, and section 6.2 summarizes related recent market initiatives and proposals discussed within ISO/RTOs. A more detailed description of research challenges and related insights from the broader literature, with a focus on the highest-priority areas of the ISO/RTOs, is provided in section 6.3. 


\subsection{Current Market Practice for Transmission-Distribution Coordination}

The existing ISO/RTO operational frameworks are not designed to integrate and coordinate with a large number of flexible loads, microgrids, and other DERs that are connected to the distribution system for several reasons, as discussed below. A report prepared by CAISO, utility companies in California, and the More Than Smart Initiative (2017) describes the current state of coordination between the ISO/RTO, the utility distribution system operator (DSO), and the DER providers based on how DR works today. To summarize, the ISO market software models DERs in an aggregate manner at the transmissiondistribution interface (i.e., the point of common coupling between the transmission and distribution systems) with no visibility to distribution system topology or operating conditions. Furthermore, the utility/DSO and the ISO/RTO do not communicate or coordinate with each other regarding DER offers/bids, dispatch schedules, and network conditions. The report states that the lack of communication and coordination between these key entities could result in infeasible DER dispatch schedules and operational problems on distribution systems in a high-DER future. In addition, in 2019, MISO held the DER 300 T\&D interface coordination workshop (facilitated by the Regulatory Assistance Project and EPRI) to discuss potential impacts of increasing penetrations of DERs on the reliability of the bulk power system with transmission operators, distribution providers, and regulators (MISO 2019d). In the workshop, MISO identified six areas in which the gaps between the current state and the desired future state require greater collaboration and coordination at the transmission-distribution interface. The identified areas are (1) planning and modeling coordination; (2) distribution interconnection; (3) potential market implications; (4) under-frequency load shed and under-voltage load shed; (5) forecasting; and (6) seams and dispatchability. Table 14 summarizes the current state and possible future state for three selected areas, as described in the MISO workshop documents. These coordination areas are relevant to most ISO/RTOs and DSOs because they integrate more DERs into their systems.

Table 14. Key areas requiring greater transmission-distribution coordination, as identified by MISO

\begin{tabular}{|c|c|c|}
\hline Topic Area & Current State & Possible Future State \\
\hline $\begin{array}{l}\text { Planning and } \\
\text { modeling } \\
\text { coordination }\end{array}$ & $\begin{array}{l}\text { - Netting of behind-the-meter DERs and load } \\
\text { - Explicit modeling of DERs larger than 2-to 5- } \\
\text { MW capacity } \\
\text { - Little to no data exchange between distribution } \\
\text { and transmission }\end{array}$ & $\begin{array}{l}\text { - Separate data collection for DERs of any size and load } \\
\text { - Aggregate modeling of behind-the-meter DERs, for } \\
\text { example, via aggregate DER model } \\
\text { - Regular data exchange between distribution and } \\
\text { transmission }\end{array}$ \\
\hline $\begin{array}{l}\text { Distribution } \\
\text { interconnection }\end{array}$ & $\begin{array}{l}\text { - Little to no consideration of aggregate impacts } \\
\text { from DERs on bulk system, no ride-through } \\
\text { - Firm DER connection capacity but limited } \\
\text { hosting capacity } \\
\text { - Little to no telemetry for small-scale DERs }\end{array}$ & $\begin{array}{l}\text { - Consideration of aggregate impacts from DERs on } \\
\text { bulk system, requirement for ride-through } \\
\text { - Firm and nonfirm (flexible) DER connection capacity } \\
\text { and hosting capacity may be increased. } \\
\text { - Staged rollout of telemetry starting with mid-scale } \\
\text { DERs }\end{array}$ \\
\hline $\begin{array}{l}\text { Potential market } \\
\text { implications }\end{array}$ & $\begin{array}{l}\text { - Energy-only revenue for DERs: net metering, } \\
\text { fixed price per kilowatt-hour, and so on } \\
\text { - Little to no information exchange for } \\
\text { operations } \\
\text { - Challenges for DER aggregations to participate } \\
\text { in markets }\end{array}$ & $\begin{array}{l}\text { - Energy, ancillary service, and capacity markets } \\
\text { revenue for DERs facilitated by hierarchical control } \\
\text { - DER aggregators exchange information for operations } \\
\text { (e.g., registrations, reliability, time-varying distribution } \\
\text { factors) } \\
\text { - Consideration of distribution grid constraints in } \\
\text { forecasts and offers/bids } \\
\text { - Penalties for poor forecast and/or nonperformance of } \\
\text { resources }\end{array}$ \\
\hline
\end{tabular}

Source: MISO 2019d. 


\subsection{Recent Market Initiatives}

Although the ISO/RTO wholesale markets in the United States have been mainly designed around traditional generation technologies, the ISO/RTOs are opening up their wholesale markets to distributionconnected DERs by allowing them to provide all the services they are technically capable of providing, including capacity, energy, and ancillary services. FERC has guided this movement through multiple orders. In particular, FERC issued Order 841 in 2018, requiring ISO/RTOs to establish a participation model for ES, which recognizes the physical and operational characteristics of these unique grid resources, along with appropriate metering and accounting practices (FERC 2019a). In September 2020, FERC issued Order 2222, which expands the directive initially issued under Order 841 to cover all other classes of DERs - distributed generation resources, DR, energy efficiency resources, electric vehicles and other-in addition to ES. A number of efforts toward this end are underway across the ISO/RTOs. Table 15 summarizes a selection of recent market changes and proposed plans related to transmissiondistribution coordination for each ISO/RTO.

\section{Table 15. Recent market changes and proposed plans related to transmission-distribution} coordination

\begin{tabular}{|c|c|}
\hline ISO/RTO & Recent and Proposed Market Changes \\
\hline PJM & $\begin{array}{l}\text { PJM published a wholesale DER (W-DER) proposal in 2018. The W-DER proposal defines W-DER } \\
\text { as DERs that participate in wholesale (W) markets. The proposal sets the role of a DSO or electric } \\
\text { distribution company as central to the DER interconnection and operational coordination process. } \\
\text { The proposal enables aggregated market participants, in particular DERs with less than 0.1-MW } \\
\text { capacity, to participate in PJM's capacity, energy, and ancillary service markets through aggregation } \\
\text { (PJM Interconnection 2019b). }\end{array}$ \\
\hline NYISO & $\begin{array}{l}\text { The DER Roadmap initiative has developed a series of market enhancements since } 2017 \text { with the } \\
\text { key objectives of (1) integrating DER into the energy, ancillary services, and capacity markets, ( } 2) \\
\text { aligning with the goals of the state policies, ( } 3 \text { ) enhancing measurement and verification } \\
\text { methodologies, (4) aligning compensation with performance, (5) dual participation in wholesale and } \\
\text { retail markets, and (6) coordination with system planning, interconnection, and forecasting practices } \\
\text { (NYISO 2017a). }\end{array}$ \\
\hline ISO-NE & $\begin{array}{l}\text { A number of initiatives related to DERs are being considered to help enable participation in energy, } \\
\text { reserve, and capacity markets. Several initiatives related to forecasting DERs (short- and long-term), } \\
\text { including solar PV and energy efficiency impacts on loads, are also underway (ISO-NE 2020a). }\end{array}$ \\
\hline MISO & $\begin{array}{l}\text { MISO developed a series of workshops in } 2019 \text { to begin framing key challenges; in particular, the } \\
\text { DER } 300 \text { workshop focused on the transmission-distribution interface (MISO 2019e). Also, MISO } \\
\text { published a DER framing and discussion document in 2020. The Five-Year Plan of MISO states that } \\
\text { the planning and modeling processes will account for DER growth (MISO 2020b). }\end{array}$ \\
\hline SPP & $\begin{array}{l}\text { SPP's near term objective is to enhance the ISO's visibility into the distribution system. The long- } \\
\text { term objective includes enhanced control through market participation with relationships across } \\
\text { different jurisdictional layers (SPP 2018c). }\end{array}$ \\
\hline CAISO & $\begin{array}{l}\text { Together with distribution utilities, CAISO investigated the needs for transmission-distribution } \\
\text { coordination for a high-DER future in } 2016 \text {. In addition, CAISO enabled aggregation of DERs } \\
\text { connected to distribution systems in } 2016 \text { (More Than Smart 2017). }\end{array}$ \\
\hline ERCOT & $\begin{array}{l}\text { In 2018, ERCOT worked with stakeholders to develop a standard approach for obtaining the data } \\
\text { needed to map registered DER units to their appropriate transmission system loads. Mapping also } \\
\text { provides a foundation for enabling larger DERs to receive localized (nodal) price signals, to help } \\
\text { ERCOT manage congestion on the grid. Also, ERCOT lowered the limit for DER participation in } \\
\text { energy and ancillary services markets to } 1 \text { MW (ERCOT 2019c). }\end{array}$ \\
\hline
\end{tabular}




\subsection{Key Challenges, Research Opportunities, and Findings from the Literature}

In this section, we identify and provide a review of seven specific research questions and issues based on our review of ISO/RTO technical reports and initiatives. Table 16 summarizes the identified key challenges, along with corresponding research needs. The order of the list in Table 16 is based on the prioritization received through stakeholder feedback, as described at the outset of this section.

Table 16. Major research questions and opportunities related to transmission-distribution coordination

\begin{tabular}{|c|c|c|}
\hline Challenge & Type & Research Questions and Opportunities \\
\hline $\begin{array}{l}\text { Market design and control } \\
\text { methods for the provision of grid } \\
\text { services from DERs under } \\
\text { different ISO-DSO coordination } \\
\text { schemes }\end{array}$ & $\begin{array}{l}\text { Technical, } \\
\text { implementation }\end{array}$ & $\begin{array}{l}\text { - Wholesale market participation models for DERs that } \\
\text { capture their unique physical and operating } \\
\text { characteristics adequately regardless of regional } \\
\text { footprint } \\
\text { - Implementation of new market products (e.g., } \\
\text { reactive power, voltage support) } \\
\text { - Compensation methods aligned with performance } \\
\text { - Dual participation of DERs in retail and wholesale } \\
\text { markets } \\
\text { - Hierarchical control strategies for aggregated DER } \\
\text { resources providing multiple services }\end{array}$ \\
\hline Improved situational awareness & $\begin{array}{l}\text { Technical, } \\
\text { implementation }\end{array}$ & $\begin{array}{l}\text { - Advanced short-term forecasting of DERs with high } \\
\text { accuracy } \\
\text { - Assessment and monitoring of feasibility and } \\
\text { flexibility of the full range of services provided by } \\
\text { DERs connected at the distribution level }\end{array}$ \\
\hline $\begin{array}{l}\text { Modeling and assessment of } \\
\text { ISO-DSO coordination } \\
\text { approaches }\end{array}$ & $\begin{array}{l}\text { Technical, } \\
\text { implementation }\end{array}$ & $\begin{array}{l}\text { - Modeling of various ISO-DSO coordination schemes } \\
\text { - Assessment and comparison of different approaches } \\
\text { (e.g., cost-benefit analysis, feasibility and/or } \\
\text { reliability assessment) }\end{array}$ \\
\hline $\begin{array}{l}\text { ISO-DSO coordination } \\
\text { mechanism and concept }\end{array}$ & Technical & $\begin{array}{l}\text { - Review of potential ISO-DSO coordination } \\
\text { mechanisms } \\
\text { - New concepts for ISO-DSO coordination }\end{array}$ \\
\hline $\begin{array}{l}\text { Data management and } \\
\text { communication } \\
\text { architecture/concept }\end{array}$ & Technical & $\begin{array}{l}\text { - Metering, telemetry, and verification requirements } \\
\text { and methods } \\
\text { - Communication and data management protocol for } \\
\text { information exchange between entities }\end{array}$ \\
\hline Regulatory and policy concerns & Policy/regulatory & $\begin{array}{l}\text { - Coordination between multiple governing entities to } \\
\text { overcome jurisdictional issues } \\
\text { - Privacy and cybersecurity }\end{array}$ \\
\hline $\begin{array}{l}\text { Distribution level markets and } \\
\text { management }\end{array}$ & $\begin{array}{l}\text { Technical, } \\
\text { implementation }\end{array}$ & $\begin{array}{l}\text { - Review and modeling of DSO management systems } \\
\text { that interact with ISO/RTOs } \\
\text { - Market prices with full consideration of network } \\
\text { constraints (e.g., locational marginal prices at the } \\
\text { distribution level) } \\
\text { - Settlement methods of DERs located at the } \\
\text { distribution level }\end{array}$ \\
\hline
\end{tabular}




\subsubsection{Market Design and Control Methods for the Provision of Grid Services from DERs}

The most common approach implemented by ISO/RTOs for DER integration is to reduce the minimum DER size threshold for market participation, and to enable the aggregation of small DERs to meet the minimum size threshold. Many ISO/RTOs and utilities are currently allowing and testing DER aggregation, as reviewed by Cook et al. (2018). The aggregation of DERs enables small individual DERs to be combined and offered in an aggregated way to the wholesale market. The aggregation of DERs can be done by DER providers or aggregators. In a layered control structure, a DSO can aggregate and manage local assets and provide an aggregated bid to the ISO considering specific distribution-level operational constraints. The importance of aggregation is increasing with high penetration levels of DERs because the market engines for DA and RT market-clearing cannot efficiently optimize a large number of small resources (MISO 2020b). However, there is a trade-off between efficient DER participation and overall system reliability. In particular, as identified in the MISO and DER: Framing and Discussion Document (MISO 2020b), a broad aggregation may result in challenges from transmission flow errors, potential reliability risks, market inefficiency, and forecasting difficulties. One possible solution is limiting the granularity of DER aggregations to those resources connected to the same bulk transmission node for effective and efficient management of transmission system constraints and reliability (NYISO 2017b; PJM Interconnection 2019b). However, there are also ways to aggregate across multiple transmission nodes and account for the consequent impact of the aggregated DERs on the transmission system through other more complicated design means that warrant further research; for example, CAISO has proposed to allow for aggregation across multiple pricing nodes (CAISO 2018f).

Another challenge in market design is the so-called dual use of DERs. A dual-participation model allows DERs to participate in both the wholesale market and other distribution-level retail programs or markets simultaneously. This market participation model could provide benefits to DERs by enabling additional revenue streams. The dual-participation model could also include cost-based services, such as transmission services, that offer regulated cost-based financial incentives. However, there are multiple challenges in designing the dual-participation model. NYISO identified several issues that need to be addressed (NYISO 2017a), as follows:

- Operational control over DERs participating in multiple markets;

- Appropriate communication paths;

- Impact of conflicting dispatch signals from multiple markets on reliability and economics;

- Dual participation of an individual DER that is participating in wholesale markets as a part of an aggregated resource;

- Regulatory issues of sales for resale (e.g., a storage resource that charges in the wholesale market and discharges through a retail market); and

- Preventing double payments or dual compensation.

Last, designing an appropriate compensation mechanism considering the obligation and performance of DERs is one of the critical issues identified by the ISO/RTOs. In theory, in an efficient market, market prices and payments should be aligned with the value of services provided by individual assets. Therefore, it is essential to design a market settlement process considering efficient market prices and performance obligations. For instance, NYISO proposed three options for DER performance obligations based on the varying availability to deliver capacity over 24 hours and the corresponding degree of operational benefits: full-day service, on-peak service (i.e., available from early morning through late evening hours), and daytime peak service (i.e., available during daily peak hours) (NYISO 2017a). However, more research is needed to develop market designs and control methods that provide adequate 
compensation and performance obligations for DERs to provide services at both distribution and transmission levels.

\subsubsection{Improved Situational Awareness}

As DERs increasingly participate in wholesale electricity markets, several issues may arise that were not present when only large generators at the transmission level were used to provide grid services. The issues arise because of the lack of observability or visibility of DERs and their operational nature in distribution systems. At the same time, DERs often exhibit increasing variability, uncertainty, and unconventional net load profiles. Although the impact of an individual DER is small, the aggregated effects can create a transmission-level reliability concern with complications for the system's visibility and controllability (ERCOT 2019b). The ISO has limited information about the location, status, and output of DERs, as well as how DERs are affecting power flows on distribution systems. The ISO also does not have visibility into the distribution system network conditions, for example, distribution line switching.

The lack of situational awareness makes it difficult to ensure feasible DER dispatch schedules that do not compromise local reliability. In particular, today's distribution systems have typically been operated passively and were treated as pure electricity sinks without considering the possibility of bidirectional power flows between the transmission and distribution networks. Thus, local distribution network reliability could be affected if there are substantial changes in power flows caused by grid services from DERs. However, typically, utilities do not have an operational framework designed to integrate and coordinate with a large number of DERs and microgrids (Lawrence and Vrins 2019). Therefore, it is essential to investigate multiple options for improving situational awareness to ensure the interoperability of DERs by maintaining a proper level of interaction and communication. For instance, Mayorga Gonzalez et al. (2018) propose an approach to determine feasible interconnection power flows, and identify influencing factors that have a significant impact on the feasible operating region. Similarly, Silva et al. (2018) introduce an interval constrained power flow model that provides a set of DER flexibility maps. Riaz and Mancarella (2019) also propose a methodology for evaluating operating regions at the transmission-distribution interface. The regions considered include the feasible operating region and the flexibility operating region. The feasible operating region represents the set of all feasible dispatch setpoints of an aggregated virtual power plant. The flexibility operating region is a quantitative representation of the operating flexibility, which is defined as the availability of an aggregated virtual power plant to deviate from its dispatch setpoint.

Finally, another challenge is the difficulty in short-term forecasting of DER net generation or load profiles with sufficiently high accuracy. This is vital because DER participation affects net interchange and other operational characteristics at the transmission-distribution interface. In particular, the net interchange profiles at the transmission-distribution interface have an impact on transmission system unit commitment, economic dispatch, and ramping needs. However, the diverse array of technologies and variable characteristics of DERs, and their potential aggregation, challenge accurate short-term forecasting at the distribution level. Therefore, more research is required to develop and assess methods for short-term forecasting of DERs, considering its impacts at the transmission-distribution interface (Lawrence and Vrins 2019). 


\subsubsection{ISO-DSO Coordination Mechanisms and Concepts}

The increasing penetration of DERs providing grid services requires better coordination between the key entities in transmission and distribution networks. In its report on the coordination of transmission and distribution operations, CAISO identifies operational coordination needs in a high-DER future and defines three key entities: the ISO, the DSO, and the DER provider or aggregator (More Than Smart 2017). In addition, CAISO introduces two general coordination models between the key entities (Kristov 2017), as summarized and compared in Table 17. These two models lie at either extreme, but composite models that fall somewhere on the spectrum between them could be considered as well.

First, the Minimal DSO model proposes a direct integration of DERs with the ISO/RTO. In this model, the ISO directly manages all DERs considering both transmission and distribution system operating conditions. The DSO maintains the current distribution utility role with limited enhancements to accommodate high DER volumes as needed. This model has limited scalability because it requires a highdimensional central market optimization that incorporates the distribution system, which has a different structure, characteristics (e.g., unbalanced power flow), and operating principles.

Second, the Total DSO model proposes a layered hierarchy of optimizing subsystems. In this model, the DSO expands its role to manage all resources, including DERs and microgrids, within the distribution system and schedules power exchange with the ISO in the form of aggregated bids/offers at each transmission-distribution interface. Typically, the interface refers to substations at which transmission and distribution networks interconnect. Therefore, the ISO only needs to see the net interchange at the interface without needing DER and distribution system visibility. This layered control structure could also include third-party DER aggregators that communicate with both the ISO and DSO. The layered control structure is more scalable than the Minimal DSO model. Another benefit of such an architecture is the distributed multitier reliability responsibility and management. However, the hierarchical model requires a detailed design of coordination mechanisms between different entities. For example, a key question is which entity should be responsible for managing net interchange deviations at the transmissiondistribution interface. In addition, the required level of communication and visibility must be clearly defined for each coordination model. For instance, in the Minimal DSO model, in order for the DERs to provide bulk grid services, the ISO/RTO may need visibility via telemetry in RT for situational awareness to ensure and confirm the ability of the DER to provide the corresponding service.

Table 17. Comparison of ISO-DSO coordination models

\begin{tabular}{|l|l|l|}
\hline \multicolumn{1}{|c|}{ Design Element } & \multicolumn{1}{|c|}{ Minimal DSO } & \multicolumn{1}{c|}{ Total DSO } \\
\hline Market structure & $\begin{array}{l}\text { Central market optimization by ISO with } \\
\text { large numbers of participating DERs }\end{array}$ & $\begin{array}{l}\text { DSO optimizes local markets at each } \\
\text { transmission-distribution substation; ISO } \\
\text { market sees a single virtual resource at each } \\
\text { transmission-distribution interface. }\end{array}$ \\
\hline $\begin{array}{l}\text { Distribution-level } \\
\text { energy prices }\end{array}$ & $\begin{array}{l}\text { Based on the wholesale LMP plus a } \\
\text { distribution component that would be } \\
\text { determined by the ISO }\end{array}$ & $\begin{array}{l}\text { Based on the value of DER services in a } \\
\text { local market, wholesale LMP may set the } \\
\text { price if imports/exports are used to meet } \\
\text { demand. }\end{array}$ \\
\hline $\begin{array}{l}\text { Resource/capacity } \\
\text { adequacy }\end{array}$ & $\begin{array}{l}\text { As is done currently, based on system } \\
\text { coincident peak plus load pocket and } \\
\text { flexibility needs; opt-out allowed for } \\
\text { microgrids }\end{array}$ & $\begin{array}{l}\text { Layered resource adequacy framework: DSO } \\
\text { responsible for each transmission- } \\
\text { distribution interface area; ISO responsible } \\
\text { only for meeting net interchange at each } \\
\text { interface, does not need insight into } \\
\text { distribution system resources }\end{array}$ \\
\hline
\end{tabular}


Table 17. (Cont.)

\begin{tabular}{|l|l|l|}
\hline \multicolumn{1}{|c|}{ Design Element } & \multicolumn{1}{|c|}{ Minimal DSO } & \multicolumn{1}{c|}{ Total DSO } \\
\hline $\begin{array}{l}\text { Grid reliability } \\
\text { paradigm }\end{array}$ & Similar to today & $\begin{array}{l}\text { Layered responsibilities: DSO takes a load- } \\
\text { based share of PFR. }\end{array}$ \\
\hline $\begin{array}{l}\text { Multiple-use } \\
\text { applications of } \\
\text { DERs }\end{array}$ & $\begin{array}{l}\text { DERs subject to both ISO and DSO } \\
\text { instructions. Rules must resolve dispatch } \\
\text { priority, multiple payments, } \\
\text { telemetry/metering issues }\end{array}$ & $\begin{array}{l}\text { DERs subject only to DSO instructions, as } \\
\text { DSO manages DER response to ISO dispatch } \\
\text { instructions and ancillary service provision }\end{array}$ \\
\hline $\begin{array}{l}\text { Regulatory } \\
\text { framework }\end{array}$ & $\begin{array}{l}\text { Federal-state jurisdictional roles similar to } \\
\text { today }\end{array}$ & $\begin{array}{l}\text { New frameworks may be needed to regulate } \\
\text { distribution-level markets }\end{array}$ \\
\hline
\end{tabular}

Source: Kristov 2017.

Several different transmission-distribution coordination models have also been proposed in the broader research literature. For instance, Sebastian, Marti, and Lang (2008) analyze the impacts of two DER aggregation models, which are similar to the Minimal DSO and the Total DSO models, on grid operations. Liu et al. (2018) propose a coordinated decision-making framework for integrated transmission and distribution network using a stochastic bilevel hierarchical model. Mezghani et al. (2018) compare the efficiency of the centralized and decentralized coordination schemes based on a generalized Nash equilibrium approach. Edmunds et al. (2020) also propose a market-based coordination scheme that allows both the ISO and the DSO to access the flexibility provided by DERs, while giving priority to the DSO in using DERs for local operations. Last, Rahimi and Albuyeh (2016) discuss the similarities and differences between the wholesale market systems and the retail transactive energy systems, and identify tools and methods developed for wholesale market systems that can be applied to distribution systems.

Prior studies also have investigated the role of transmission-distribution coordination in ancillary services. For instance, Zipf and Möst (2016) investigate the economic implications of transmissiondistribution coordination schemes and show that a higher degree of coordination leads to significant cost savings in providing ancillary services. Gerard, Rivero, and Six (2016) propose several coordination schemes focusing on the activation of distributed reserves to manage net interchange deviations, including (1) a centralized ancillary service market model, (2) a local ancillary service market model, (3) a shared balancing responsibility model, (4) a common ISO-DSO ancillary service market model, and (5) an integrated flexibility market model. Papavasiliou and Mezghani (2018) then propose mathematical models that can be used to assess the performance of the various coordination schemes proposed by Gerard, Rivero, and Six (2016). In addition, Le Cadre et al. (2019) extend the work of Papavasiliou and Mezghani (2018) by presenting a game-theoretic framework for assessing coordination models.

\subsubsection{Data Management and Communication Architecture}

Integrating a large number of DERs into the wholesale market requires enhanced measurement and verification methodologies. Furthermore, the increased communication between multiple entities with a large volume of data requires advanced communication architecture and data management protocols. Prior studies have investigated data exchange methodologies between ISOs and DSOs. Lambert et al. (2018) provide a review of use cases for TSO-DSO data exchange supported by information communications technology and present an opportunity for using Internet of Things technology for data exchange in power systems. In addition, NYISO investigates whether new telemetry technology may be available to help facilitate DER integration and determines that a public-internet-based Software-Defined Wide Area Network is a viable alternative that meets the NYISO's operational needs (NYISO 2019b). 


\subsubsection{Distribution-Level Management and Market}

The proliferation of DERs may require revisiting traditional distribution utility business models and the operational framework. Prior studies have proposed a concept of distribution markets (Bahramirad et al. 2016), the key role of DSOs with new market mechanisms for DERs (Salon, Huet, and Blanc 2013), and methodologies for calculating distribution locational marginal prices (Huang et al. 2015).

\subsubsection{Regulatory and Policy Concerns}

Integrating DERs located on state-jurisdictional distribution systems into the wholesale market, which is under federal regulation, poses jurisdictional issues because of the many jurisdictional layers, as stated by multiple ISO/RTOs (SPP 2018c; MISO 2020b). 


\subsection{Transmission Expansion Planning and Financial Transmission Rights}

This section addresses the market challenges identified in the topic area of transmission expansion planning (TEP) and FTRs. Although both TEP and FTRs are key components in the planning and operation of transmission systems in all United States electricity markets, they are distinct from each other in terms of purposes, market practices, and market challenges. Nevertheless, it is worth pointing out their linkages. For instance, although the major economic purpose of expanding transmission capacity is to facilitate cost-reducing electricity trade, it also allows ISO/RTOs to distribute additional FTRs. On the other hand, if FTR revenue insufficiency is a problem because of transmission outages, this insufficiency can provide an incentive for ISO/RTOs and transmission asset owners to improve the scheduling and efficiency of transmission maintenance in order to mitigate the problem. Merchant transmission owners can also elect to use awarded FTRs as an income source to cover the cost of new transmission links, rather than receiving a FERC-regulated return on investment.

We identified six challenges for TEP and two for FTRs; their prioritization ranking based on stakeholder feedback is shown in Figure 10. The poll results place the most importance upon enhancing the current TEP process by considering long-run economic, technology, and policy uncertainty, as well as reactions from both the supply and demand sides of the market.

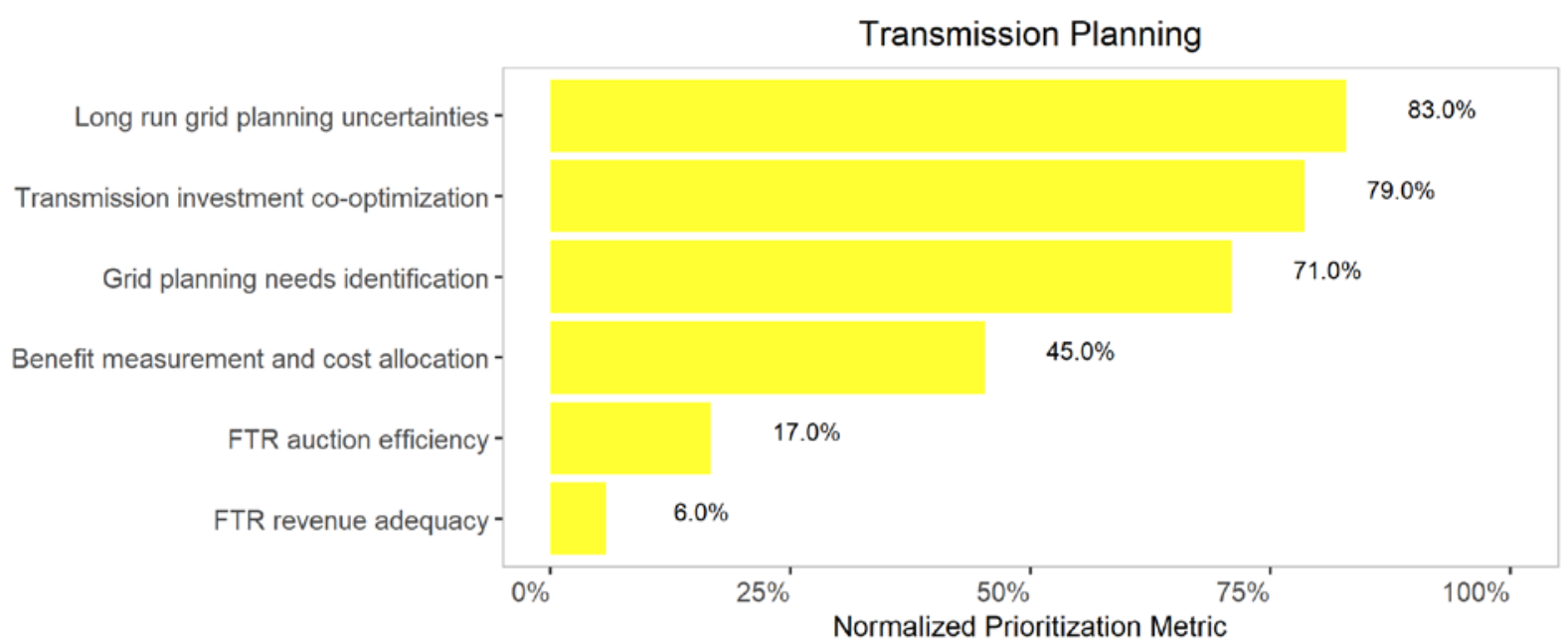

Figure 10. Priority ranking of market challenges related to transmission planning from the ISO/RTO stakeholder meeting

The rest of this section is divided into two subsections, one centered around TEP and one concerning FTRs. Each subsection, following the general structure of this report, is divided into two parts: (1) reviewing current market practice; and (2) assessing challenges and key issues identified from the literature. Compared to other topic areas, the evolution of market rules regarding TEP and FTR is currently progressing relatively slowly. Therefore, our discussion of recent market initiatives and proposals is incorporated into the second part of each subsection devoted to related key topics identified from the literature. 


\subsection{Transmission Expansion Planning}

\subsubsection{Current Market Practice for Transmission Expansion Planning}

Most ISO/RTOs in the United States plan transmission expansion in annual or longer cycles, and within each cycle, ISO/RTOs follow a mostly similar procedure, as detailed in Figure 11, with some limited differences.

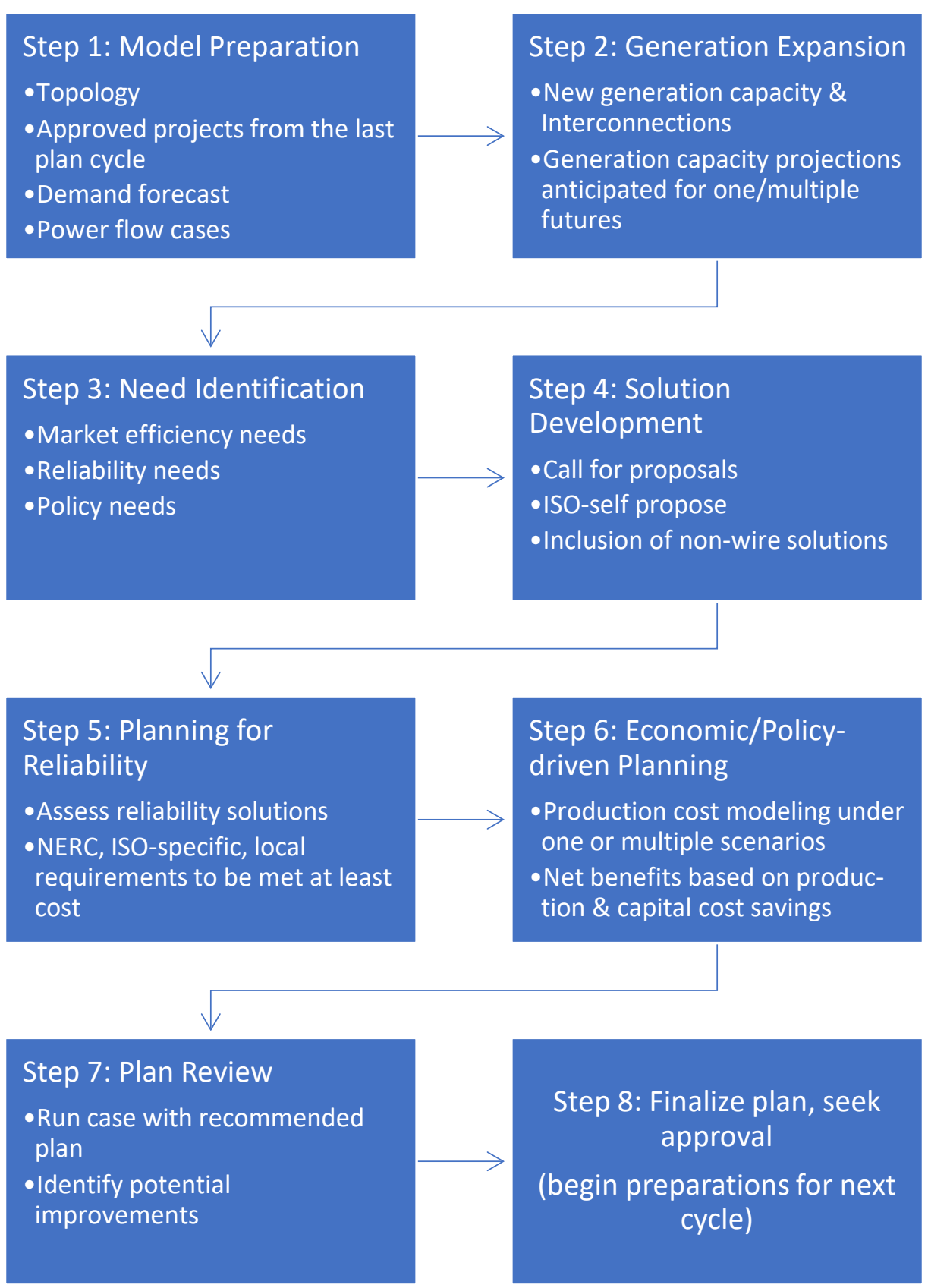

Figure 11. General TEP cycle for ISO/RTOs 
The TEP processes followed by most ISO/RTOs have several common features:

- Need-oriented. The initial steps of transmission planning address the identification of potential needs. These commonly fall into three categories: economic drivers (reduced congestion), improved reliability (such as reducing risk of violating requirements from NERC), and policy goals (especially renewable integration).

- Limited proactivity. When planning for transmission expansion in each cycle, ISO/RTOs do not attempt to fully analyze how potential changes in network configurations could affect the location and type of future investments in generation and other resources; that is, ISO/RTOs do not engage in full transmission-generation co-optimization. However, ISO/RTOs do anticipate actions by generation investors in subsequent planning cycles by considering the generation resources in the development queue, but do not consider how that queue might change as a result of grid reinforcement (NYISO 2020f). Instead of assuming a fixed generation build-out scenario, some ISO/RTOs also anticipate changes in resource investment by employing a generation expansion planning (GEP) tool before conducting any solution assessment (MISO 2021, SPP 2020). Thus, such a GEP is used for anticipating generation investment due to all other factors (resource quality, fuel prices, load growth, etc.), but not potential transmission solution recommendations in the current planning cycle.

- Individual project-based heuristics. In ISO/RTO planning practice, analyses are usually based on heuristics that consider the net benefits of individual projects one at a time. Consequently, the performance evaluation of one reinforcement usually assumes the absence of other reinforcements. However, it is certainly possible, and indeed likely, that the benefit/reliability improvements from different transmission investments will depend on each other, and the optimal portfolio of investments may differ from recommendations made on a project-by-project basis.

Although ISO/RTOs follow the same general process in TEP, actual practices differ in their details, including planning frequency, horizon, and cost allocation methodology. Table 18 summarizes the current practice of TEP in the United States, and contrasts approaches used by different U.S. ISOs. 
Table 18. Current TEP practices of ISO/RTOs

\begin{tabular}{|c|c|c|c|c|c|c|}
\hline $\begin{array}{c}\text { ISO } \\
\text { (Source) }\end{array}$ & Name & $\begin{array}{c}\text { Frequen- } \\
\text { cy }\end{array}$ & $\begin{array}{c}\text { Cycle } \\
\text { (months) }\end{array}$ & \begin{tabular}{|c|}
$\begin{array}{c}\text { Horizon } \\
\text { (years) }\end{array}$ \\
\end{tabular} & ISO-Specific Features & Cost Allocation Rules \\
\hline $\begin{array}{l}\text { PJM (PJM } \\
\text { Inter- } \\
\text { connection } \\
\text { 2020d) }\end{array}$ & $\begin{array}{l}\text { Regional } \\
\text { Transmission } \\
\text { Expansion } \\
\text { Plan }\end{array}$ & $\begin{array}{l}\text { Annual } \\
\text { and } \\
\text { biennial }\end{array}$ & $\begin{array}{l}18 \text { (sesqui- } \\
\text { annual) and } \\
24 \\
\text { (biennial) }\end{array}$ & 15 & $\begin{array}{l}\text { Double-cycle planning: near-term }(18- \\
\text { mo cycle, reliability \& economic } \\
\text { planning in parallel); long-term (24-mo } \\
\text { cycle, reliability \& economic planning } \\
\text { in sequence) }\end{array}$ & $\begin{array}{l}\text { (a) Low voltage, reliability: } 100 \% \text { distribution factor } \\
\text { analysis (DFAX); (b) High voltage }(>345 \mathrm{kV} \text {, single } \\
\text { circuit), Reliability: } 50 \% \text { DFAX, } 50 \% \text { peak-load postage } \\
\text { stamp; (c) Low voltage, economic: } 100 \% \text { localization based } \\
\text { on decreased payment; (d) High voltage, economic: } 50 \% \\
\text { peak-load postage stamp, } 50 \% \text { localization (Gaston } 2016)\end{array}$ \\
\hline $\begin{array}{l}\text { NYISO } \\
\text { (NYISO } \\
2020 b)\end{array}$ & $\begin{array}{l}\text { Comprehen- } \\
\text { sive System } \\
\text { Planning } \\
\text { Process } \\
\end{array}$ & Biennial & 24 & $\begin{array}{l}10 \text { and } \\
20\end{array}$ & $\begin{array}{l}\text { Policy-driven and economics-driven } \\
\text { analyses are in parallel. Economic } \\
\text { project evaluation uses a } 20 \text {-year } \\
\text { planning horizon }\end{array}$ & $\begin{array}{l}\text { "Beneficiaries pay" principle, allocate cost pro-rata to } \\
\text { benefit metrics (Chao 2015) }\end{array}$ \\
\hline $\begin{array}{l}\text { ISO-NE } \\
(\text { ISO-NE } \\
2020 b)\end{array}$ & $\begin{array}{l}\text { Regional } \\
\text { System Plan }\end{array}$ & Biennial & NA & 10 & NA & $\begin{array}{l}\text { (a) Regional benefit upgrades (RBU) ( }>115 \mathrm{kV} \text {, reliability } \\
\text { \& economic): allocate cost regionally with peak-load } \\
\text { postage stamp; (b) non-RBU, allocate cost locally; (c) } \\
\text { policy-driven: } 70 \% \text { cost allocated as RBU, } 30 \% \text { cost } \\
\text { allocated pro-rata State policy needs (ISO-NE } 2020 \mathrm{c} \text { ) }\end{array}$ \\
\hline $\begin{array}{l}\text { MISO } \\
(\mathrm{MISO} \\
2020 \mathrm{a})\end{array}$ & $\begin{array}{l}\text { MISO } \\
\text { Transmission } \\
\text { Expansion } \\
\text { Plan }\end{array}$ & Annual & 24 & 15 & $\begin{array}{l}\text { Scenario-weighted economic evaluation; } \\
\text { multi-value projects }\end{array}$ & $\begin{array}{l}\text { (a) Baseline reliability project (BRP) with }>345 \mathrm{kV}: 20 \% \\
\text { postage stamp \& } 80 \% \text { line outage distribution factor } \\
\text { (LODF) analysis; (b BRP }>100 \mathrm{kV} \text { but }<345 \mathrm{kV}, 100 \% \\
\text { LODF analysis; (c) } 20 \% \text { postage stamp \& } 80 \% \\
\text { "beneficiaries pay"; multi-value project: } 100 \% \text { energy load } \\
\text { postage stamp. }\end{array}$ \\
\hline $\begin{array}{l}\text { SPP (SPP } \\
2020)\end{array}$ & $\begin{array}{l}\text { SPP Inte- } \\
\text { grated Trans- } \\
\text { mission } \\
\text { Planning } \\
\end{array}$ & Annual & 24 & 10 & $\begin{array}{l}\text { Scenario-weighted score-based } \\
\text { economic evaluation }\end{array}$ & “Highway/byway” cost allocation (FERC 2010) \\
\hline $\begin{array}{l}\text { CAISO } \\
\text { (CAISO } \\
2019 a)\end{array}$ & $\begin{array}{l}\text { Transmission } \\
\text { Planning } \\
\text { Process }\end{array}$ & Annual & 24 & 10 & $\begin{array}{l}\text { Transmission Economic Assessment } \\
\text { Methodology (CAISO 2017); } \\
\text { "competitive solicitation" for the project } \\
\text { with costs }>\$ 50 \mathrm{M}\end{array}$ & $\begin{array}{l}\text { High-voltage }(>200 \mathrm{kV}) \text { : a hybrid of energy demand } \\
\text { postage stamp and peak demand postage stamp; low- } \\
\text { voltage: cost allocated to local (recently proposed [CAISO } \\
2018 \mathrm{c}]) \text {. }\end{array}$ \\
\hline $\begin{array}{l}\text { ERCOT } \\
(\text { ERCOT } \\
2019 a) \\
\end{array}$ & \begin{tabular}{|l|} 
Regional \\
Transmission \\
Plan
\end{tabular} & $\begin{array}{l}\text { Biennial } \\
\text { and } \\
\text { annual }\end{array}$ & 12 & 6 & $\begin{array}{l}\text { The biennial cycle identifies long-term } \\
\text { needs and reviews solutions on a } 20 \text { - } \\
\text { year horizon }\end{array}$ & Peak demand postage stamp (Fink et al. 2011) \\
\hline
\end{tabular}




\subsubsection{Key Challenges, Research Opportunities, and Findings from the Literature}

Table 19 summarizes the key issues and research needs identified through a literature review, each of which is discussed in the following subsections. Note that only the first four challenges were included in the stakeholder prioritization survey. However, several additional challenges are also included for completeness because they may become a higher priority in the future.

Table 19. Major research questions and opportunities related to TEP for ISO/RTOs

\begin{tabular}{|c|c|c|}
\hline Challenge & Type & Research Questions and Opportunities \\
\hline Long-run uncertainty & $\begin{array}{l}\text { Technical, } \\
\text { economics }\end{array}$ & $\begin{array}{l}\text { How to rank or quantify the importance of uncertain factors that } \\
\text { affect the TEP process and, in particular, factors that could alter } \\
\text { near-term investments? }\end{array}$ \\
\hline $\begin{array}{l}\text { Generation expansion } \\
\text { coordination }\end{array}$ & $\begin{array}{l}\text { Economics, } \\
\text { implementation }\end{array}$ & $\begin{array}{l}\text { How should estimates be made of potential savings in resource } \\
\text { investment costs (or combined investment-production cost } \\
\text { savings) from avoiding/changing generation/storage expansion as } \\
\text { a result of transmission investments? }\end{array}$ \\
\hline $\begin{array}{l}\text { Transmission needs } \\
\text { identification }\end{array}$ & $\begin{array}{l}\text { Economics, } \\
\text { implementation }\end{array}$ & $\begin{array}{l}\text { How to identify beneficial transmission projects that are missed } \\
\text { by traditional needs identification processes? }\end{array}$ \\
\hline $\begin{array}{l}\text { Cost allocation and } \\
\text { benefit measurement }\end{array}$ & $\begin{array}{l}\text { Economics, } \\
\text { implementation }\end{array}$ & $\begin{array}{l}\text { How to allocate the cost of "local" transmission lines if they } \\
\text { provide regional benefits? }\end{array}$ \\
\hline $\begin{array}{l}\text { Interdependence of } \\
\text { values provided by } \\
\text { multiple projects }\end{array}$ & Economics & $\begin{array}{l}\text { Are the benefits from selected individual projects independent } \\
\text { from each other and, therefore, additive? Or should interactions } \\
\text { within portfolios be considered? }\end{array}$ \\
\hline $\begin{array}{l}\text { The benefit/loss of } \\
\text { using reduced hour } \\
\text { set in simulations }\end{array}$ & $\begin{array}{l}\text { Technical, } \\
\text { economics, } \\
\text { implementation }\end{array}$ & $\begin{array}{l}\text { Can ISO/RTOs use a reduced sample of hours/load slices in their } \\
\text { economic/market efficiency TEP process? What is the potential } \\
\text { value/bias of doing so? }\end{array}$ \\
\hline $\begin{array}{l}\text { Value-based } \\
\text { transmission pricing }\end{array}$ & $\begin{array}{l}\text { Technical, } \\
\text { economics, } \\
\text { implementation }\end{array}$ & $\begin{array}{l}\text { How to allocate and recover the cost of reinforcements that are } \\
\text { primarily to serve export markets, or policy objectives for other } \\
\text { ISO/RTOs or regions? }\end{array}$ \\
\hline $\begin{array}{l}\text { Openness of critical } \\
\text { transmission facility } \\
\text { planning }\end{array}$ & $\begin{array}{l}\text { Economic, } \\
\text { implementation }\end{array}$ & $\begin{array}{l}\text { How should the planning of transmission facilities that have } \\
\text { systemwide benefits include public input, and balance local and } \\
\text { systemwide effects? }\end{array}$ \\
\hline $\begin{array}{l}\text { Planning for end-of- } \\
\text { life transmission }\end{array}$ & $\begin{array}{l}\text { Economic, } \\
\text { implementation, } \\
\text { technical }\end{array}$ & $\begin{array}{l}\text { How and when should the end of life and possible replacement of } \\
\text { a transmission line to be determined? }\end{array}$ \\
\hline
\end{tabular}

\subsubsection{Long-Run Uncertainty and Ranking of Uncertainties}

CAISO, MISO, and SPP are the three ISO/RTOs that have used scenario-based economic evaluation for TEP, ${ }^{1}$ while the Western Electricity Coordinating Council and the Bonneville Power Administration have explored its use (Ho et al. 2016; McCalley et al. 2018). To define scenarios, they review the range of uncertain variables that can potentially influence the TEP decisions and consult with experts and stakeholders on the potential magnitudes of their uncertainty. The variables that have been considered by ISO/RTOs are listed in Table 20. Scenario construction using these variables needs to be conducted cautiously because (1) scenarios affect the economic evaluation of individual projects and (2) more

${ }^{1}$ CAISO no longer uses this methodology, and now relies on sensitivity analysis (CAISO 2017). 
scenarios mean more production cost modeling and other simulation needs within the limited time and resources available to planners.

In general, the greater the number of uncertain variables that are considered, the more scenarios that are needed to span the range of potential uncertainties facing the TEPs. However, the number of scenarios that can be considered is limited. The key question is therefore, How can planners rank or otherwise quantify the importance of uncertain factors that affect the TEP process? To put it differently, which variables, if left out of a risk-based planning process, could change near-term grid reinforcement decisions and result in a significant loss of benefits (Xu and Hobbs 2019)?

Table 20. Uncertainties in TEP considered by ISOs

\begin{tabular}{|l|l|}
\hline \multicolumn{1}{|c|}{ Variables } & \multicolumn{1}{c|}{ ISO/RTO } \\
\hline Peak/energy demand growth rates & CAISO, SPP, MISO \\
\hline Natural gas and coal fuel prices & CAISO, SPP, MISO \\
\hline Existence of strategic bidding behavior & CAISO \\
\hline Hydropower availability & CAISO \\
\hline New economic generation entry & CAISO, SPP, MISO \\
\hline Renewable policy/renewable generation capacities and capacity factors & CAISO, SPP, MISO \\
\hline Emission prices, environmental regulations/ $\mathrm{CO}_{2}$ cap & SPP, MISO \\
\hline Conventional-generation retirement & SPP, MISO \\
\hline Storage penetration & SPP \\
\hline Distributed generation/DR/energy efficiency & SPP, MISO \\
\hline Export demand & SPP \\
\hline
\end{tabular}

Sources: CAISO (2004); MISO (2018a); SPP (2018a).

\subsubsection{Generation Expansion Coordination}

There exists a rich literature addressing the question, How should transmission planning interact with generation expansion planning?" There are two general approaches: proactive and reactive TEP (Sauma and Oren 2007). Reactive TEPs treat generation expansion as exogenous and often uncertain information, similar to scenarios of load growth, fuel prices, and policy (Fang and Hill 2003). On the other hand, proactive TEPs treat ISO/RTOs as a leader of the market that anticipates reactions of generation (and other resources) to transmission availability and costs, which depend on the outcome of TEP planning decisions. Proactive TEP can be implemented by iterating between transmission and resource planning models, but in theory full co-optimization using a single combined model will generally yield a better solution (Spyrou et al. 2017). Depending on whether generation companies behave competitively or strategically, academic TEP works can also be categorized into single level or multilevel TEPs (Pozo, Sauma, and Contreras 2013; Spyrou et al. 2017).

Transmission constraints limit not only energy delivery, but also the ability of regions to share ancillary service capacity and coordinate resource adequacy decisions. ${ }^{2,3}$ This is the so-called deliverability problem discussed in sections 2 and 4 . Only by considering these interactions can the ability of transmission and resources to substitute for each other in the energy, ancillary service, and capacity markets be rigorously considered. Therefore, TEP should develop, for instance, ELCC-type metrics that

2 For example, CAISO recently recognized that much of its flexible ramp procured in its Energy Imbalance Market is not deliverable because of within-balancing-area constraints (Xu 2017).

3 As identified by the National Renewable Energy Laboratory (NREL), transmission constraints can have significant impact on the ELCC measurement (EnerNex Corporation 2011). 
can be used to compare grid reinforcements and resource investments in terms of the ability to meet resource adequacy and reliability needs. ${ }^{4}$

However, as noted before, the current cycle-based ISO/RTO TEP process usually means that ISO/RTOs plan reactively on the basis of the investment and retirement decisions made by generators in response to the ISO/RTO's previous transmission expansion plan. This process can result in inefficient plans that fail to appreciate how TEP can improve the efficiency of resource capital investment (Spyrou et al. 2017). In particular, ISO/RTOs can undervalue transmission projects by ignoring the possible cost savings associated with generation expansion deferrals that may be enabled by a strategic TEP process. The degree of inefficiency is no doubt proportionate to the amount of transmission investment under consideration; this means that the need for proactive planning is particularly important if a commitment is made to plan large interregional grid expansions or even a national grid, as envisioned by some lowcarbon studies (McCalley et al. 2017). Thus, a key question is, How should ISO/RTO TEP consider the reaction from generation expansion and how can transmission and resource additions be considered on a level playing field?

\subsubsection{Identify Regional Opportunities Not Identified by Current TEP Need Identification Procedures}

All ISOs conduct need-oriented TEPs by starting with the projected system and identifying reliability/economic needs. ${ }^{5}$ This need identification is problematic in the sense that it can miss possibly high-value long-distance interregional transmission lines, simply because there is no immediately identifiable congestion associated with a particular existing facility. The flaw of the need identification process is one possible cause for the limited number of long-distance interregional transmission lines recommended by the ISO/RTOs. For example, in 2017, MISO-PJM jointly recommended only five short interregional transmission lines in their joint transmission planning coordination, out of a total of 354 recommendations (MISO 2017a). Similarly, in 2017, PJM, ISO-NE, and NYISO made no interregional grid reinforcement recommendations. Another often-unidentified need in planning processes is maintaining the feasibility of FTRs (SPP 2017).

In summary, the question is, What potentially beneficial grid reinforcements are missed by need identification processes that are currently used by RTOS/ISOs? Optimization-based regional TEP planning tools could be useful for addressing this question and could promote interregional TEP (Krishnan et al. 2016; Spyrou et al. 2017).

\subsubsection{Cost Allocation and Benefit Measurement}

Cost allocation is a contentious issue that can be a significant barrier to implementing grid reinforcements even when their overall benefits exceed their costs (Rivier and Olmos, 2020). In general, there are two broad research needs in the area of cost allocation (Lau and Hobbs, 2021).

One is the need for improved methods to credibly estimate the benefits of grid reinforcements, including the distribution of those benefits among regions and intraregional parties over multidecadal horizons. Furthermore, there is a need to characterize the uncertainty of these benefits, given possible economic,

4 The principle of transmission-resource substitution in capacity markets has been recognized in the CAISO Transmission Economic Assessment Methodology, and quantified using simple methods that consider the relative costs of generation construction in different regions (CAISO 2017).

5 CAISO partially solved this problem by not anchoring economic projects and by not describing patterns of projected congestion in the current TEP process; instead, it requests economic study cases in the beginning (CAISO 2019a). 
policy, and technology scenarios over the multidecadal lives of the projects. In practice, the principle of "beneficiary pay" can be difficult to quantify. As one example, transmission upgrades that are paid for by interconnecting generators bring benefits not just to the generators themselves, but also to the customers receiving the electricity as their costs are lowered. As another example, one state may pay for transmission upgrades while other interconnected states receive reliability benefits. These benefits may be diffuse or, in the case of reliability enhancements, very difficult to assess.

A second general need is to reflect those benefit estimates and their uncertainty in flexible cost allocations to ensure that 1) participating regions each receive a fair share of the project benefits, and 2) their share of the benefits will have a high likelihood of substantially exceeding their costs under most scenarios over the life of the project.

A particular issue is that cost allocations for some classes of transmission facilities are assigned locally, even though benefits may be realized by non-local parties, who thereby become free riders. In particular, in most mechanisms used by ISO/RTOs for transmission cost allocation, both the costs and benefits associated with low-voltage-line expansions are only allocated locally, for example, within price zones. However, ISO/RTOs recommend these lines based on benefit-cost ratio tests in which the benefit is calculated on the basis of regional production cost savings. This process creates a dilemma in which ISO/RTOs determine the economic value of low-voltage transmission lines on a regional basis while only allocating the cost locally (Cook 2020). This issue leads to an open research question: How can the cost of "local" transmission lines be fairly allocated if they provide regional benefits? This question is especially important if an internal reinforcement benefits not only its balancing authority but also others. In this case, the question becomes: How can costs be allocated among balancing authorities so that all regions are certain to benefit on net from facilities that lower overall system costs, and are thereby incentivized to support them?

\subsubsection{Interdependence of Transmission Project Benefits}

Individual project-by-project benefit-cost assessment dominates ISO/RTO TEP processes, while academic researchers focus on optimization-based models (Bahiense et al. 2001). The optimization approach is fundamentally different from ISO/RTO practice because the former is focusing on selecting a set of grid reinforcements that jointly provide the most net cost improvement (or satisfy the reliability requirement at minimum cost) (Majidi-Qadikolai and Baldick 2016). In contrast, by conducting assessments on an individual project basis, ISO/RTOs may recommend one line that is the most costeffective among the group of lines that are meeting the same need. Theoretically, the final recommendations from ISO/RTOs' per-project assessment and the academic optimization-based work will be identical if the benefits of candidate facilities are independent of each other; however, this assumption does not hold in general. The most obvious example is parallel flows, in which the introduction of one line could change the power flow pattern in the whole system. Such interdependences among transmission candidates can thus make ISO/RTO recommendations deviate from the theoretical optimum.

The interdependencies of the benefits provided by different lines complicate the benefit-based cost allocations that ISOs, including NYISO, PJM, ISO-NE, SPP, and MISO, adopt in most of their interregional planning activities (MISO 2020c; NYISO 2020d, 7). If the dependencies are significant, it is difficult for an ISO/RTO to trust the benefit metric used in the cost-allocation methodologies, when that metric is based on a single project analysis. In conclusion, it is important to quantify the interdependence among projects to confirm that such interactions do not significantly affect what portfolio of projects would maximize net benefits. 


\subsubsection{The Benefit/Loss of Using Reduced Sets of Hours/Load Slices in Simulations}

ISO/RTO production cost modeling analyses conducted in tandem with TEP usually use full 8,760-hour analyses over a several-year modeling horizon. High temporal resolution is desirable because interannual weather availability, annual average loads and output, and their intra-year patterns are subject to sample error if only 1 year of weather is considered (Bothwell and Hobbs 2017). However, the complexity of full-year or multiple-sample-year analyses hinders other possible improvements of the current TEP process, such as multi-scenario evaluation and generation expansion anticipation or full co-optimization. ${ }^{6}$ Is it possible to conduct planning studies with a reduced set of temporal scenarios so that other improvements to TEP models and processes (such as multiple long-run scenarios) become computationally possible? And how should those scenarios (hours/load slices) be selected to appropriately represent load-VRE correlations and intra- and inter-year variability?

\subsubsection{Value-Based Transmission Pricing}

Transmission lines can be constructed to serve one or more of many different objectives, including enhancing reliability, alleviating congestion, or achieving broader policy goals. For example, as SPP identified, some of the transmission lines can be constructed solely for exporting renewable resources outside of SPP (SPP 2017). Currently, no cost allocation methodology is widely accepted for this type of export-driven grid reinforcement, and this lack of consensus is a barrier to building lines that have an impact on multiple jurisdictions and, ultimately, a barrier to coordinating the development of complementary renewable resources across large regions. Then the question is, How to allocate the cost of the existing/potential transmission lines that are primarily intended to serve export markets, especially across balancing authorities?

\subsubsection{Openness of Critical Transmission Facility Planning}

NERC has requested that transmission owners mitigate the risks surrounding critical assets whose loss would heavily affect the system, and the lists of critical assets are confidential because of security concerns. An effective way to mitigate such risks can be reinforcements of the grid. The confidential nature of these critical lines creates a debate between transmission owners and other stakeholders (Smith 2019): How, if at all, can the planning of critical assets be considered within transparent and competitive ISO/RTO TEP processes? Furthermore, can the planning of wide-impact transmission facilities be efficiently coordinated by several transmission owners and balancing authorities?

\subsubsection{Planning for End-of-Life Transmission}

Many transmission lines in the United States are approaching their end-of-life. Unlike the retirement of power plants, there is no economic incentive for the determination of line retirement, and possible replacement. How can an efficient and transparent process be instituted for determining the end-of-life of transmission facility? And how many years in advance should transmission owners make this decision and announce it to the ISO/RTO? The answers to these questions continue to be discussed among the stakeholders (Heidorn 2020).

6 Notably, because of the large number of contingencies to be considered, ISO/RTOs have long used reduced sets of net load scenarios for reliability-based TEP, in which they identify and use several peak/low demand powerflow cases. But such use of only a few power-flow cases is inappropriate when systems have geographically dispersed variable renewables whose output is imperfectly correlated. 


\subsection{Financial Transmission Rights}

\subsubsection{Current Market Practice for Financial Transmission Rights}

All U.S. ISO/RTOs have implemented FTR mechanisms, first proposed by Hogan (1992), to provide a convenient way for market participants to hedge congestion risk in LMP-based spot markets with tradable financial instruments. ${ }^{7}$ In contrast to physical transmission rights, FTRs, as the name suggests, are purely financial. Table 21 summarizes the current market practice of FTRs.

Table 21. Review of current market practice of FTRs

\begin{tabular}{|c|c|c|c|c|c|}
\hline $\begin{array}{c}\text { ISO/RTO } \\
\text { (Source) }\end{array}$ & Name of FTR & $\begin{array}{c}\text { Auction } \\
\text { Revenue } \\
\text { Right }\end{array}$ & $\begin{array}{c}\text { Available } \\
\text { Types of FTR }\end{array}$ & Auctions & $\begin{array}{c}\text { Revenue } \\
\text { Shortfall } \\
\text { Allocation }\end{array}$ \\
\hline $\begin{array}{l}\text { PJM (PJM } \\
\text { Interconnection } \\
2020 \mathrm{c})\end{array}$ & $\begin{array}{l}\text { Financial } \\
\text { Transmission } \\
\text { Right }\end{array}$ & $\begin{array}{l}\text { Yes, and } \\
\text { self-convert }\end{array}$ & $\begin{array}{l}\text { Obligation and } \\
\text { option }\end{array}$ & $\begin{array}{l}\text { Long-term, annual, } \\
\text { monthly }\end{array}$ & $\begin{array}{l}\text { Haircut, } \\
\text { temporal } \\
\text { smoothing; }\end{array}$ \\
\hline $\begin{array}{l}\text { NYISO } \\
\text { (NYISO } \\
2020 \mathrm{c}) \\
\end{array}$ & $\begin{array}{l}\text { Transmission } \\
\text { Congestion } \\
\text { Contract } \\
\end{array}$ & No & Obligation & $\begin{array}{l}\text { Seasonal (centralized } \\
\text { auction); monthly } \\
\text { (reconfiguration auction) }\end{array}$ & $\begin{array}{l}\text { Allocated to } \\
\text { transmission } \\
\text { owners } \\
\end{array}$ \\
\hline $\begin{array}{l}\text { ISO-NE (ISO- } \\
\text { NE 2018a) }\end{array}$ & $\begin{array}{l}\text { Financial } \\
\text { Transmission } \\
\text { Right }\end{array}$ & Yes & Obligation & Annual, monthly & $\begin{array}{l}\text { Haircut, } \\
\text { allocated to } \\
\text { load }\end{array}$ \\
\hline $\begin{array}{l}\text { MISO (MISO } \\
\text { 2019a) }\end{array}$ & $\begin{array}{l}\text { Financial } \\
\text { Transmission } \\
\text { Right }\end{array}$ & $\begin{array}{l}\text { Yes, and } \\
\text { self-convert }\end{array}$ & $\begin{array}{l}\text { Obligation } \\
\text { (Option to be } \\
\text { available in } \\
\text { future.) }\end{array}$ & $\begin{array}{l}\text { Annual, monthly, } \\
\text { multiperiod monthly } \\
\text { auctions }\end{array}$ & $\begin{array}{l}\text { Paid- } \\
\text { through } \\
\text { uplift }\end{array}$ \\
\hline $\begin{array}{l}\text { SPP (SPP } \\
\text { 2018b) }\end{array}$ & $\begin{array}{l}\text { Transmission } \\
\text { Congestion } \\
\text { Right }\end{array}$ & $\begin{array}{l}\text { Yes, and } \\
\text { self-convert }\end{array}$ & $\begin{array}{l}\text { Obligation and } \\
\text { option }\end{array}$ & Annual, monthly & $\begin{array}{l}\text { Paid- } \\
\text { through } \\
\text { uplift }\end{array}$ \\
\hline $\begin{array}{l}\text { CAISO } \\
\text { (CAISO } \\
\text { 2020a) }\end{array}$ & $\begin{array}{l}\text { Congestion } \\
\text { Revenue Right }\end{array}$ & No & $\begin{array}{l}\text { Obligation and } \\
\text { option }\end{array}$ & Annual, monthly & $\begin{array}{l}\begin{array}{l}\text { Haircut } \\
\text { (payments }\end{array} \\
\text { to affected } \\
\text { FTRs cut) }\end{array}$ \\
\hline $\begin{array}{l}\text { ERCOT } \\
\text { (ERCOT 2014) }\end{array}$ & $\begin{array}{l}\text { Congestion } \\
\text { Revenue Right }\end{array}$ & No & $\begin{array}{l}\text { Obligation and } \\
\text { option }\end{array}$ & Semiannual, monthly & Haircut \\
\hline
\end{tabular}

Figure 12 illustrates how revenues are distributed among participants in FTR trading and settlements, and helps to identify the key issues discussed in the next subsection. Figure 12(a) represents cash flows without FTRs, and Figure 12(b) shows the flows after instituting FTRs.

$7 \quad$ FTRs can be called by different names in different markets; see Table 21. 
(a)

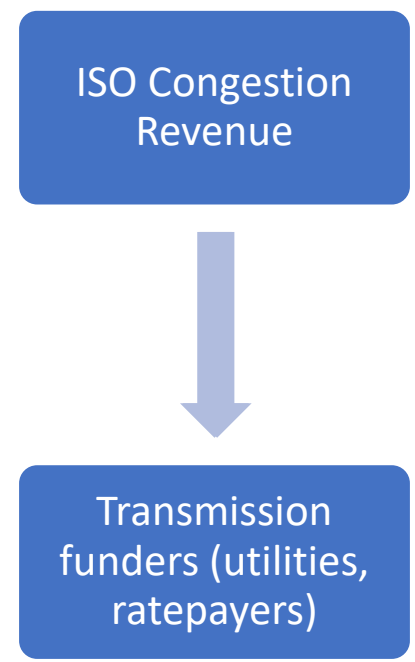

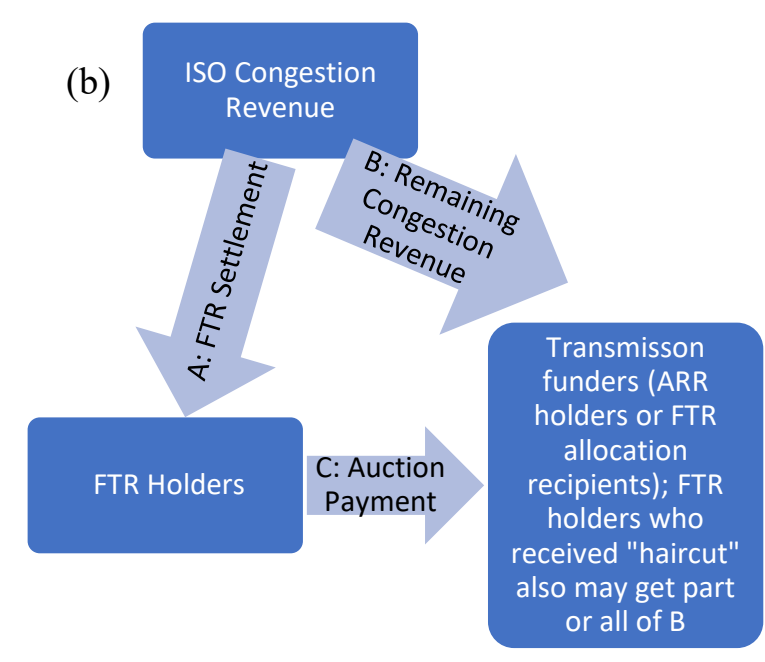

\section{Figure 12. Congestion Revenue Cash Flow (a) without and (b) with FTR markets}

To explain the concept of FTRs, two bookend examples of transmission revenue collection and allocation are provided here. First, in the extreme case without the FTR market, the ISO/RTO ultimately returns all collected congestion revenue to the entities that fund the construction, maintenance, and operation of the transmission grid, such as transmission owners and load. This return is typically done by reducing the ISO/RTO's grid management charges to those entities. Second, at the other extreme, which is the ideal case with an efficient, well-functioning FTR market, the ISO/RTOs first use the congestion revenue to settle FTRs and then, assuming that congestion revenues are sufficient to cover FTR settlements (i.e., FTR revenue adequacy is achieved), ISO/RTOs allocate the remainder of congestion revenues to the entities that fund the transmission system. (If revenues are insufficient to pay off all rights holders at all times, some or all of the remainder may ultimately be used to reimburse FTR holders whose payments had been subjected to "haircuts.")

In FTR markets, the FTR holders either have obtained their rights from free allocations or have bought FTRs from ISO/RTO-operated auctions or in bilateral deals. An efficient auction should, in expectation, result in a convergence between (1) the payment by FTR holders for a right and (2) the settlement that the FTR holder receives from the ISO plus any risk premium (in Figure $12 \mathrm{~b}, \mathrm{C} \geq \mathrm{A}$ in expectation, if the risk premium is positive) ${ }^{8}$ Furthermore, if the congestion revenue is adequate to cover FTR settlements $(\mathrm{B} \geq$ 0 ), the sum of payments received by the transmission owners/funders should be higher than the congestion revenue, again in expectation: $\mathrm{B}+\mathrm{C} \geq \mathrm{B}+\mathrm{A}=$ congestion revenue. In short, with adequate revenue and efficient auctions of FTRs, transmission owners/funders should be better-off because of the FTR market. Finally, to maximize the risk-hedging value of the FTRs, a design goal of FTR systems has been to distribute most of the congestion surplus in the form of FTR payments, that is, A $>$ B. But if B is consistently a significant fraction of total congestion revenues $\mathrm{A}+\mathrm{B}$, then a large portion of congestion risks are going unhedged, which would be an argument for issuing more FTRs.

8 Assuming ISOs also pass the auction payment from FTR holders for unallocated FTRs back to transmission funders. 


\subsubsection{Key Challenges, Research Opportunities, and Findings from the Literature}

Despite the well-defined structures of FTRs in most markets, FTR systems face three significant challenges: revenue inadequacy, auction inefficiency, and rights reconfiguration when changes occur in the needs of market participants or the network. Table 22 summarizes the findings from the literature survey concerning FTR research needs of ISO/RTOs. These short- and medium-term market design challenges are discussed in detail below.

Table 22. Major research questions and opportunities related to FTRs for ISO/RTOs

\begin{tabular}{|l|l|l|}
\hline \multicolumn{1}{|c|}{ Challenge } & \multicolumn{1}{|c|}{ Type } & \multicolumn{1}{c|}{ Research Questions and Opportunities } \\
\hline $\begin{array}{l}\text { FTR revenue inadequacy and } \\
\text { efficient shortfall allocation }\end{array}$ & $\begin{array}{l}\text { Economic, } \\
\text { technical }\end{array}$ & $\begin{array}{l}\text { How to minimize revenue inadequacy? Which FTR } \\
\text { shortfall allocations distort market efficiency the least, } \\
\text { and maximize the hedging value of ISO FTR systems? }\end{array}$ \\
\hline FTR auction inefficiency & Economic & $\begin{array}{l}\text { How should FTR auction efficiency be promoted so that } \\
\text { the transmission funders can be assured of being better } \\
\text { off with ISO-operated FTR markets than without } \\
\text { FTRs? }\end{array}$ \\
\hline FTR rights reconfiguration & Economic & $\begin{array}{l}\text { When hedging needs of market participants change or } \\
\text { the network is altered, how can existing and new rights } \\
\text { be reconfigured to be more compatible with the } \\
\text { changed situation? }\end{array}$ \\
\hline
\end{tabular}

\subsubsection{Congestion Revenue Inadequacy and Shortfall Allocation}

A well-functioning FTR market, as discussed above, along with congestion revenue, both generates enough combined revenue to pay FTR holders and increases revenues for transmission funders relative to a case without FTRs. However, as previously mentioned, congestion revenue is not always adequate, nor are auctions efficient. Suppose the congestion revenue is inadequate to cover FTR payouts (i.e., congestion revenue $<$ A; a FTR shortfall will occur and will need to be recovered from market participants in some way (socialization), since the ISO cannot operate at a deficit. For example, the CAISO recently changed its FTR system to allocate such shortfalls (if any) to FTR holders (i.e., by not fully funding them); consequently, the hedging function of FTR is no longer perfect (CAISO 2018b). Before that modification, CAISO used to allocate the shortfall to the transmission funders and fully fund the FTR holders, which the CAISO market monitors argued was unfair to the transmission funders.

The issue of congestion revenue inadequacy applies to all ISO/RTOs, and it has turned out to be a crucial consideration in the design of FTR and transmission revenue allocation schemes. The source of the inadequacy problem is that adequacy is guaranteed only if the transmission flows corresponding to awarded FTRs satisfy all transmission constraints. However, ISOs have to award FTRs well ahead of time and cannot perfectly predict the network topologies and available transmission capacities. Both ISO/RTOs and academics have acknowledged that the conditions of revenue adequacy can be easily violated because of unexpected line outages, deratings, and transmission switching (Hedman, Oren, and O'Neill 2011). Such violations mean that that congestion revenue is often insufficient for particular hours and particular paths, and sometimes even on an annual basis. ${ }^{9}$ For example, SPP generated only sufficient congestion revenue to account for $92 \%$ of approximately $\$ 375$ million in required transmission congestion rights funding for 2016. This fraction increased somewhat to $94 \%$ in 2017 and 2018, when the

9 Note that violation does not necessarily mean that revenue inadequacy will occur, just that it cannot be ruled out. 
required funding level was roughly $\$ 600$ million. ISO/RTOs have proposed or implemented fixes to mitigate congestion revenue inadequacy and to avoid having to allocate revenue shortfalls. For example, since 2018, CAISO has moved the deadline of its annual transmission outage plan closer to its annual FTR auctions, hoping to use the latest network information for the simultaneous feasibility test (CAISO 2018b). Another approach that ISO/RTOs use is to release available transmission capacity to the auctions gradually, over a period of time, so that they can auction additional FTRs on the basis of more up-to-date information.

On the other hand, ISO/RTOs also need to handle any revenue shortfalls carefully. Among the possible ways to allocate shortfalls are the following (Oren and Hedman 2010):

- Full funding of FTRs by the ISO and uplift of any resulting shortfall to transmission funders or others; this approach was previously used by CAISO.

- Prorating the FTR settlements to cover the shortfall (haircut). Currently, two variants exist: prorate based on the quantity of FTRs owned by each holder or prorate on the basis of an individual flowgate-by-flowgate analysis (PJM and ERCOT use the first, and CAISO has recently adopted the second variant) (Bautista Alderete 2013).

- Full funding of FTRs and allocation of the shortfall to the derated flowgate/transmission line owner (NYISO adopts this approach to provide incentives for efficient scheduling of transmission maintenance).

- Intertemporal smoothing of the congestion revenue accounting; most ISOs have implemented this measure.

However, as mentioned before, none of the above approaches is perfect, and each presents different incentives and risks to market participants.

\subsubsection{Auction Inefficiency}

It was argued above that if there is a risk premium, then what FTR buyers are willing to pay for FTRs will exceed their expected payout (cash flows $\mathrm{C}$ and $\mathrm{A}$, respectively, in Figure 12. But when purchasers of FTRs from an ISO-run auction pay an amount $\mathrm{C}$ for the FTRs they buy that is lower than the expected payout $\mathrm{A}$, this is termed auction inefficiency. As a result, the transmission owners/consumers are paying out more in congestion revenue than they receive in auction revenues.

This inefficiency has also been identified as a problem since FTRs were first introduced in ISO/RTO markets (Bartholomew et al. 2003). It remains an important issue to stakeholders and market monitors. For example, CAISO provided a monthly ratio of auction revenue to FTR payouts (C/A), which shows that even with the fixes added in 2019 (i.e., CAISO Tariff Amendment tracks A \& B), that ratio is still about $85 \%$ on average, showing that some auction inefficiency remains (Bautista Alderete 2020). Such an inefficiency has also been recognized by other ISO/RTOs, e.g., by PJM, where the ratio of $(\mathrm{B}+\mathrm{C}) /(\mathrm{A}+\mathrm{B})$ (again, these terms are defined in Figure 12) has been only about $74.5 \%$ from 2012 to 2017. This ratio has sometimes been even lower (as low as 50\%) because PJM decided in 2017 to allocate FTR shortfalls due to revenue inadequacy to the transmission funders (Monitoring Analytics 2020a).

Several factors contribute to auction inefficiency. First, it is possible that the transmission owners/funders, such as LSEs, lack price discovery capabilities, so that speculation can be dependably profitable. However, this situation is expected to diminish in the long run, with traders working for LSEs becoming more familiar with the system. The second factor is the regulatory auction bid/offer limits set by ISO/RTOs. ISO/RTOs usually set such restrictions on the basis of credit requirements (for FTR buyers) or expected peak usage of the transmission services (for LSEs). Note that, even with perfect 
congestion forecasts, that is, traders knowing exactly what price differences will occur in the DA market, artificial constraints will cause them to deviate from bidding the correct price (Deng et al. 2010). ${ }^{10}$ Other factors, including exercise of market power through gaming and weak incentives for regulated utilities to engage in risk management, could also contribute to auction inefficiency.

ISOs have taken actions to improve auction efficiency. For example, in 2019, CAISO started to limit the volume of its FTR trading by reducing the types of purchasable FTRs. For instance, FTR traders can no longer trade source-to-source FTRs; the revenue/payments associated with such FTRs automatically goes to transmission funders. This fix could potentially improve the auction efficiency by reducing gaming opportunities, but the effect is still uncertain. Such fixes can also reduce the hedging value of FTRs, and ultimately reduce the efficiency of the market as a whole; it has been argued that the market efficiencypromoting benefits of FTRs are well in excess of the costs to ratepayers of auction inefficiency (London Economics 2020). The NYISO system attempts to address the root of the auction inefficiency problem by placing responsibility for congestion revenue inadequacy on the owners of transmission facilities whose maintenance or deratings cause the inadequacy; this approach is reported to have incentivized transmission owners to reduce maintenance outage lengths and to improve outage scheduling.

\subsubsection{Rights Reconfiguration}

Allocated and auctioned FTRs often have multi-year lifetimes, but the grid topology and needs of rights holders may change and make existing rights obsolete or infeasible. For instance, rights holders may have different needs during peak versus off-peak periods, or during weekends versus weekdays, but their rights might apply 24/7. As variable renewable penetration increases, these needs may evolve as well. Adjusting the definition of rights and creating more categories may be desirable to accommodate new or changed needs, but is not simple, given the existence of long-lived rights that would have to be accommodated by the procedures that allocate revised rights.

As another example, network models or the physical networks themselves may change, resulting in retirement of a source or sink of existing FTRs. ISO network models are usually updated several times a year, and pricing locations can be removed and added during this process. These pricing location changes can affect FTRs. The question then arises about how or whether the affected FTRs should be reassigned when one of their locations is retired.

As an example of the complications, an FTR from A to B will become invalid when the ISO removes A from its network. Should the ISO retire the FTR from A to B? If so, what happens if retiring the FTR makes the other cleared FTRs infeasible? Should the ISO reassign the FTR as C to B? If so, how should C be determined? ISO-NE, for example, uses the latter reassignment process today but the process is complicated and not scalable. It may also be inefficient.

Research could consider the benefits of alternative definitions of FTRs, in terms of periods covered, and the issue of optimal reconfiguration given the existence of existing rights and changes in the network.

10 Note that these limits are useful. First, the credit requirement is necessary against the default risk of FTR holders, that is, the GreenHat FTR default in PJM (www.utilitydive.com/news/pjm-naive-about-greenhats-ftr-defaultrisks-report/551341/). Second, the LSE's expected usage of transmission services is an input to some mechanisms for free allocation of FTRs. 


\subsection{Conclusion}

This report provides an overview and prioritization of current market design challenges and research opportunities faced by the seven U.S. ISO/RTOs that are likely to appear over the next 2- to 10-year horizon. These challenges and opportunities fall within six high-level market design topic areas, which are discussed in each subsection of this report. This discussion includes the current status of relevant and recent ISO/RTO market design initiatives, as well as major challenges and research opportunities in wholesale market design that could benefit from development and application of analytical tools to support improved market procedures, based on theoretical considerations, industry reports, academic literature, technical capabilities of the project team, and ISO/RTO inputs.

The specific market design challenges and opportunities discussed in this report were identified through a review of ISO/RTOs publications, industry reports, and the academic literature. The project team then solicited feedback during an April 2020 workshop on ISO and RTO R\&D Prioritization, which included representatives from North American ISO/RTOs as well as other stakeholders. In addition, we conducted an interactive polling exercise with representatives from all seven U.S. ISO/RTOs to prioritize the six different high-level topic areas of market design, as well as specific market design challenges and opportunities within each of these six topic areas. According to the prioritization ranking feedback from ISO/RTO participants, several key themes in market design challenges and research needs have emerged, as detailed in Figure 13. These market challenge cross-rankings are calculated as the product of overall topic ranking and challenge ranking within each topic (both in percentage terms).

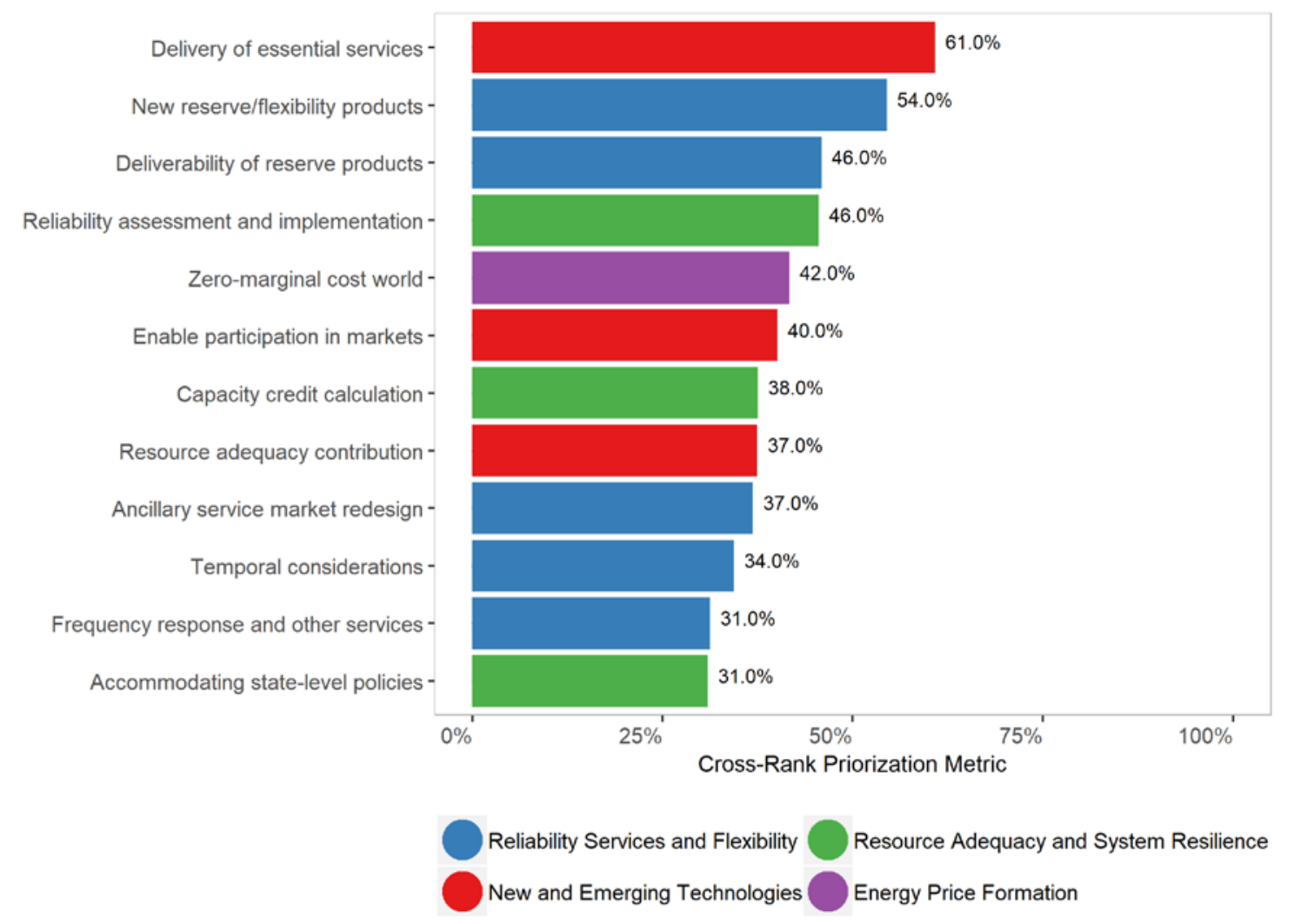

Figure 13. Composite cross-ranking of the 12 highest-priority market challenges and research opportunities across all six major topic areas from the ISO/RTO stakeholder meeting 
With rapid growth of emerging technologies, including battery storage and hybrid resources, new types of VRE like offshore wind, DERs, and demand-side flexibility - all technologies with very different operational characteristics from conventional thermal generation modes - the ability of current wholesale electricity market structures to ensure both long-term and operational reliability is unclear. The deployment of these new technologies results in changes in ERS requirements, but such technologies also have often-underutilized capabilities to provide many of these services themselves. Market rule changes could enable these technologies to participate in providing the full range of ERS. Furthermore, the development of new methods to accurately calculate the resource adequacy contribution of these emerging technologies would be invaluable in the context of long-term planning processes.

From a system perspective, two additional high-priority challenges were identified by system operators. First, at an operational level, a primary identified priority is ensuring that system resources are appropriately incentivized to provide the grid services and operational flexibility needed to maintain system reliability in an economically efficient manner. Specifically, development of market products for new reliability services, deliverability of capacity products, adjustments to existing ERS, and potential implementation of multi-day markets for energy-limited resources are topics that all require further assessment. Second, a key challenge over longer time horizons is providing efficient incentives to ensure revenue sufficiency for the resources needed to guarantee long-term reliability, while also providing efficient price signals for market exit when appropriate. This challenge will become even more pronounced in systems increasingly characterized by zero-marginal-cost resources. Well-designed energy price formation mechanisms, especially scarcity and shortage pricing, possibly combined with additional resource adequacy constructs, are critical for generator cost recovery in power systems with high penetrations of zero-marginal cost resources. More advanced calculation methods for determining both system reliability requirements and technologies' individual resource adequacy contributions are also needed to ensure long-term resource adequacy. Furthermore, it is important to consider both proactive market design changes, to develop supportive frameworks for anticipated power systems of the future, and reactive changes in cases where grid evolution outpaces market design updates.

While identified as lower near-term priorities by ISO/RTO polling participants, challenges also exist in transmission-distribution coordination because of more active consumer participation at the distribution level of the power grid. Moreover, there are a number of market challenges and research opportunities related to transmission planning and FTRs. For transmission-distribution coordination, enabling DERs to participate in wholesale markets for electricity and other grid services and improving ISO/RTO situational awareness of DERs are two primary challenges. In the transmission planning area, incorporating long-term uncertainties and developing methods to co-optimize transmission and generation decisions in the planning process were identified as the highest-priority challenges. Research in these areas will also contribute to addressing challenges and opportunities in the other topic areas that were prioritized by the workshop participants. For example, efficient transmission planning is a crucial component of guaranteeing system reliability, enabling local operational flexibility, and facilitating the integration of emerging resources.

This report is focused specifically on key design challenges for the wholesale electricity market and associated research opportunities for the U.S. ISO/RTOs, based on ISO/RTO inputs. Per that feedback, the scope includes issues relevant between 2 and 10 years from now. However, the power system will continue to evolve, and technology advances and changes in the policy environment may create additional challenges over longer time horizons. Research areas have been identified to improve both power system operation and planning to meet the emerging system and market needs, to develop new market design mechanisms to accommodate these changes, and to assess the impacts of different implementations. 
Future work could explore a broader set of challenges and time scales than is documented in this report. These could include longer-term issues such as inter-regional transmission expansion coordination requirements to accommodate very high VRE penetration levels and the role of improved VRE and load forecasts in such futures, as well as additional considerations such as broader industry and regulatory perspectives.

We conclude that collaboration between the research community and system operators, as well as other market participants and relevant stakeholders, is critical to address market design challenges on the pathway towards a clean, reliable, resilient, and affordable electricity system. 


\subsection{References}

Abani, A.O., N. Haryg1 V. Rious, and M. Saguan. 2018. "The Impact of Investors' Risk Aversion on the Performances of Capacity Remuneration Mechanisms.” Energy Policy 112 (January): 84-97. https://doi.org/10.1016/j.enpol.2017.10.008.

Abdul-Rahman, K., J. Wu, E. Haq, and P. Ristanovic. 2011. "Considerations of Reactive Power/Voltage Control in CAISO Market Operations." In 2011 IEEE Power and Energy Society General Meeting, 1-6. https://doi.org/10.1109/PES.2011.6039559.

AEMO (Australian Energy Market Operator Limited). 2020. Renewable Energy Integration Stage 1 Report. AEMOL, April. https://aemo.com.au/-/media/files/majorpublications/ris/2020/renewable-integration-study-stage-1.pdf.

Aggarwal, S., S. Corneli, E. Gimon, R. Gramlich, M. Hogan, R. Orvis, and B. Pierpont. 2019. Wholesale Electricity Market Design for Rapid Decarbonization. San Francisco, CA: Energy Innovation, April. https://energyinnovation.org/wp-content/uploads/2019/07/Wholesale-Electricity-MarketDesign-For-Rapid-Decarbonization.pdf.

Ambec, S., and C. Crampes. 2019. "Decarbonizing Electricity Generation with Intermittent Sources of Energy." Journal of the Association of Environmental and Resource Economists 6 (6): 1105-34. https://doi.org/10.1086/705536.

Arroyo, J.M., and F.D. Galiana. 2005. "Energy and Reserve Pricing in Security and Network-Constrained Electricity Markets.” IEEE Transactions on Power Systems 20 (2): 634-43. https://doi.org/10.1109/TPWRS.2005.846221.

Bahiense, L., G.C. Oliveira, M. Pereira, and S. Granville. 2001. "A Mixed Integer Disjunctive Model for Transmission Network Expansion.” IEEE Transactions on Power Systems 16 (3): 560-65. https://doi.org/10.1109/59.932295.

Bahramirad, S., A. Khodaei, and R. Masiello. 2016. "Distribution Markets." IEEE Power and Energy Magazine 14(2): 102-6. https://doi.org/10.1109/mpe.2016.2543121.

Bartholomew, E.S., A.S. Siddiqui, C. Marnay, and S.S. Oren. 2003. "The New York Transmission Congestion Contract Market: Is It Truly Working Efficiently?” The Electricity Journal 16 (9): 14-24. https://doi.org/10.1016/j.tej.2003.09.006.

Bartlett, J. 2019. Reducing Risk in Merchant Wind and Solar Projects through Financial Hedges. Working Paper 19-06. Resources for the Future. https://media.rff.org/documents/WP_1906_Bartlett.pdf.

Bautista Alderete, G. 2013. "FTRs and Revenue Adequacy." In Financial Transmission Rights: Analysis, Experiences and Prospects, edited by Juan Rosellón and Tarjei Kristiansen, 253-70. London: Springer London. https://doi.org/10.1007/978-1-4471-4787-9_10. 2020. "Congestion Revenue Rights Performance Update." California ISO, Market Surveillance Committee Meeting General Session, Folsom, CA, March 13. http://www.caiso.com/Documents/CongestionRevenueRightsPerformanceUpdate-PresentationMar13_2020.pdf.

Beiter, P.C., J.K. Lau, J.E. Novacheck, Q. Yu, G.W. Stephen, J.L. Jorgenson, W.D. Musial, and E.J. Lantz. 2020. The Potential Impact of Offshore Wind Energy on a Future Power System in the U.S. Northeast, NREL/TP-5000-74191, 1596257. Golden, CO: National Renewable Energy Laboratory. https://doi.org/10.2172/1596257.

Bhagwat, P.C., A. Marcheselli, J.C. Richstein, E.J.L. Chappin, and L.J. De Vries. 2017. “An Analysis of a Forward Capacity Market with Long-Term Contracts.” Energy Policy 111: 255-67. 
Bidwell, M. 2005. "Reliability Options: A Market-Oriented Approach to Long-Term Adequacy." The Electricity Journal 18 (5): 11-25.

Biggar, D.R., and M.R. Hesamzadeh. 2014. The Economics of Electricity Markets, 1st ed. Chichester, West Sussex, United Kingdom: Wiley-IEEE Press. dx.doi.org/10.1002/9781118775745.

Bothwell, C., and B.F. Hobbs. 2017. "Crediting Wind and Solar Renewables in Electricity Capacity Markets: The Effects of Alternative Definitions upon Market Efficiency." The Energy Journal 38 (01). https://doi.org/10.5547/01956574.38.SI1.cbot.

Botterud, A., and H. Auer. 2020. "Resource Adequacy with Increasing Shares of Wind and Solar Power: A Comparison of European and U.S. Electricity Market Designs.” Economics of Energy \& Environmental Policy 9 (2): 71. https://doi.org/10.5547/2160-5890.9.1.abot.

Briggs, R.J., and A. Kleit. 2013. "Resource Adequacy Reliability and the Impacts of Capacity Subsidies in Competitive Electricity Markets.” Energy Economics 40 (November): 297-305. https://doi.org/10.1016/j.eneco.2013.07.009.

Brown, D.P. 2018. "The Effect of Subsidized Entry on Capacity Auctions and the Long-Run Resource Adequacy of Electricity Markets.” Energy Economics 70 (February): 205-32. https://doi.org/10.1016/j.eneco.2018.01.002.

Butner, M., B.D. Noll, J. Gundlach, B. Unel, and A. Zevin. 2020. Carbon Pricing in Wholesale Electricity Markets: An Economic and Legal Guide. Institute for Policy Integrity, New York University School of Law. https://policyintegrity.org/publications/detail/carbon-pricing-inwholesale-electricity-markets.

Byers, C., and A. Botterud. 2019. "Additional Capacity Value from Synergy of Variable Renewable Energy and Energy Storage.” IEEE Transactions on Sustainable Energy, 11(2): 1106-9. https://doi.org/10.1109/TSTE.2019.2940421.

Byers, C., T. Levin, and A. Botterud. 2018. "Capacity Market Design and Renewable Energy: Performance Incentives, Qualifying Capacity, and Demand Curves." The Electricity Journal 31 (1): 65-74. https://doi.org/10.1016/j.tej.2018.01.006.

CAISO (California Independent System Operator). 2004. Transmission Economic Assessment Methodology. Folsom, CA: CAISO. www.caiso.com/Documents/TransmissionEconomicAssessmentMethodology.pdf. . 2017. Transmission Economic Assessment Methodology (Draft). Folsom, CA: CAISO. https://www.caiso.com/Documents/DraftTransmissionEconomicAssessmentMethodology.pdf. 2018a. Resource Adequacy Enhancements Initiative. http://www.caiso.com/StakeholderProcesses/Resource-Adequacy-Enhancements. . 2018b. Tariff Amendments to Increase Efficiency of Congestion Revenue Rights Auctions (Track $B)$. Folsom, CA: CAISO. 2018c. Transmission Access Charge Structure Enhancements. Folsom, CA: CAISO. http://www.caiso.com/InitiativeDocuments/DraftFinalProposalTransmissionAccessChargeStructureEnhancements.pdf. 2018d. EIM Greenhouse Gas Enhancements 3rd Revised Draft Final Proposal. Folsom, CA: CAISO. 2018e. 2017 Annual Report on Market Issues \& Performance. Folsom, CA: CAISO. http://www.caiso.com/Documents/2017AnnualReportonMarketIssuesandPerformance.pdf. 2018f. Participation of Distributed Energy Resource Aggregations in Markets Operated by Regional Transmission Organizations and Independent System Operators. Folsom, CA: CAISO https://www.caiso.com/Documents/Jun26_2018_Post-TechnicalConferenceCommentsParticipation_DERA_MarketsOperated_RTOISO_RM18-9.pdf. 
2019a. Business Practice Manual: Transmission Planning Process. Folsom, CA: CAISO. https://bpmcm.caiso.com/Pages/BPMDetails.aspx?BPM=Transmission+Planning+Process. 2019b. CAISO, Market Disruption - RTM Failure and Suspension, Operating Procedure 2710, Version 4.4. Folsom, CA: CAISO. www.caiso.com/Documents/2710.pdf.

2019c. "Comments of The Department of Market Monitoring of The California Independent System Operator Corporation on Assigned Commissioner and Administrative Law Judge's Ruling Initiating Procurement Track and Seeking Comment on Potential Reliability Issues." Folsom, CA: CAISO. http://www.caiso.mobi/Documents/CPUC-

DMMCommentsonRulingInitiatingProcurementTrackandSeekingCommentonPotentialReliability Issues-Jul232019.pdf.

2020a. "CAISO Congestion Revenue BPM Version 25." Folsom, CA: CAISO.

https://bpmcm.caiso.com/Pages/BPMDetails.aspx?BPM=Congestion\%20Revenue\%20Rights.

- 2020b. "Maximum Import Capability Stabilization and Multi-Year Allocation: Second Revised Straw Proposal." Folsom, CA: CAISO.

http://www.caiso.com/InitiativeDocuments/SecondRevisedStrawProposalMaximumImportCapabilityStabilizationandMultiYearAllocation.pdf.

2020c. "Day-Ahead Market Enhancements: Straw Proposal.” Folsom, CA: CAISO.

http://www.caiso.com/InitiativeDocuments/StrawProposal-Day-AheadMarketEnhancements.pdf . 2020d. Business Practice Manual for Reliability Requirements. Folsom, CA: CAISO.

https://bpmcm.caiso.com/BPM\%20Document\%20Library/Reliability\%20Requirements/BPM\%2 0for\%20Reliability\%20Requirements\%20Version\%2049_redline.pdf.

2020e. Resource Adequacy Enhancements, Fifth Revised Straw Proposal. Folsom, CA: CAISO. http://www.caiso.com/InitiativeDocuments/FifthRevisedStrawProposal-

ResourceAdequacyEnhancements.pdf.

- 2020f. Preliminary Root Cause Analysis, Mid-August 2020 Heat Storm. Folsom, CA: CAISO.

October. http://www.caiso.com/Documents/Preliminary-Root-Cause-Analysis-Rotating-OutagesAugust-2020.pdf

Cappers, P., J. MacDonald, C. Goldman, and O. Ma. 2013. "An Assessment of Market and Policy Barriers for Demand Response Providing Ancillary Services in U.S. Electricity Markets." Energy Policy 62 (November): 1031-39. https://doi.org/10.1016/j.enpol.2013.08.003.

Chao, H. 2015. "NYISO Transmission Planning and Cost Allocation." Presentation to the Harvard Electricity Policy Group 81st Plenary Session, Palm Beach, FL, December. https://hepg.hks.harvard.edu/files/hepg/files/panel_1_chao.pdf?m=1523368172.

Chaurey, A., and G. Katsigiannakis. 2020. "Will FERC's BSM Orders Inhibit Renewable and Battery Development in New York?” ICF International Inc. https://www.icf.com/insights/energy/fercbsm-orders.

Chen, Y., P. Gribik, and J. Gardner. 2014. "Incorporating Post Zonal Reserve Deployment Transmission Constraints into Energy and Ancillary Service Co-Optimization." IEEE Transactions on Power Systems 29 (2): 537-49. https://doi.org/10.1109/TPWRS.2013.2284791.

Chernyakhovskiy, I. (ORCID:0000000284917814), S. Koebrich, V. Gevorgian, and J.M. Cochran. 2019. Grid-Friendly Renewable Energy: Solar and Wind Participation in Automatic Generation Control Systems, NREL/TP-6A20-73866. Golden, CO: National Renewable Energy Laboratory. https://doi.org/10.2172/1543130.

Cobos, N.G., J.M. Arroyo, and A. Street. 2018. "Least-Cost Reserve Offer Deliverability in Day-Ahead Generation Scheduling Under Wind Uncertainty and Generation and Network Outages." IEEE Transactions on Smart Grid 9 (4): 3430-42. https://doi.org/10.1109/TSG.2016.2632622. 
Conejo, A.J., and R. Sioshansi. 2018. "Rethinking Restructured Electricity Market Design: Lessons Learned and Future Needs.” International Journal of Electrical Power \& Energy Systems 98 (June): 520-30. https://doi.org/10.1016/j.ijepes.2017.12.014.

Cook, A.D. 2020. "Another Rejection for MISO Cost Allocation Plan," RTO Insider, Potomac, MD, March 24. https://rtoinsider.com/another-rejection-miso-cost-allocation-plan-158477/.

Cook, J.J., K. Ardani, E. O'Shaughnessy, B. Smith, and R. Margolis. 2018. Expanding PV Value: Lessons Learned from Utility-Led Distributed Energy Resource Aggregation in the United States, NREL/TP-6A20-71984. Golden, CO: National Renewable Energy Laboratory. https://www.nrel.gov/docs/fy19osti/71984.pdf.

Corneli, S., E. Gimon, and B. Pierpont. 2019. Wholesale Electricity Market Design for Rapid Decarbonization: Long-Term Markets, Working with Short-Term Energy Markets. San Francisco, CA: Energy Innovation, June. https://energyinnovation.org/wpcontent/uploads/2019/06/Wholesale-Electricity-Market-Design-For-Rapid-DecarbonizationLong-Term-Markets-Working-WIth-Short-Term-Energy-Markets.pdf.

CPUC (California Public Utilities Commission). 2020. "D.20-06-028 Decision Adopting Resource Adequacy Import Requirements." CPUC.

Cramton, P. 2017. "Electricity Market Design.” Oxford Review of Economic Policy 33 (4): 589-612. https://doi.org/10.1093/oxrep/grx041.

Cramton, P., and A. Ockenfels. 2012. "Economics and Design of Capacity Markets for the Power Sector." Papers of Peter Cramton. University of Maryland, Department of Economics - Peter Cramton. https://econpapers.repec.org/paper/pccpccumd/12cocap.htm.

Cramton, P., A. Ockenfels, and S. Stoft. 2013. "Capacity Market Fundamentals." Economics of Energy and Environmental Policy 2 (2). http://dx.doi.org/10.5547/2160-5890.2.2.2

Cramton, P., and S. Stoft. 2008. "Forward Reliability Markets: Less Risk, Less Market Power, More Efficiency." Utilities Policy 16 (3): 194-201.

Dai, C., Y. Chen, F. Wang, J. Wan, and L. Wu. 2019. "A Configuration-Component-Based Hybrid Model for Combined-Cycle Units in MISO Day-Ahead Market.” IEEE Transactions on Power Systems 34 (2): 883-96. https://doi.org/10.1109/TPWRS.2018.2872927.

De Maere d'Aertrycke, G., A. Ehrenmann, and Y. Smeers. 2017. "Investment with Incomplete Markets for Risk: The Need for Long-Term Contracts." Energy Policy 105: 571-83.

Deng, S-J., S. Oren, and A. P. Meliopoulos. 2010. "The Inherent Inefficiency of Simultaneously Feasible Financial Transmission Rights Auctions.” Energy Economics 32 (4): 779-85. https://doi.org/10.1016/j.eneco.2010.01.010.

Deng, S.-J., and S.S. Oren. 2006. "Electricity Derivatives and Risk Management." Energy 31 (6-7): 94053.

Denholm, P.L., and R. Margolis. 2018. "The Potential for Energy Storage to Provide Peaking Capacity in California Under Increased Penetration of Solar Photovoltaics," NREL/TP-6A20-70905. Golden, CO: National Renewable Energy Laboratory. https://doi.org/10.2172/1427348.

Denholm, P.L., Y. Sun, and T.T. Mai. 2019. “An Introduction to Grid Services: Concepts, Technical Requirements, and Provision from Wind," NREL/TP-6A20-72578. Golden, CO: National Renewable Energy Laboratory. https://doi.org/10.2172/1493402.

Denholm, P.L., J. Nunemaker, P. Gagnon, and W. Cole. 2020. "The Potential for Battery Energy Storage to Provide Peaking Capacity in the United States.” Renewable Energy 151: 1269-1277.

Du, P., N.V. Mago, W. Li, S. Sharma, Q. Hu, and T. Ding. 2020. "New Ancillary Service Market for ERCOT.” IEEE Access 8: 178391-401. https://doi.org/10.1109/ACCESS.2020.3027722. 
Dupuy, M., and C. Linvill. 2019. "Implementing Demand Response 2.0: Progress toward Full Potential in the United States." The Electricity Journal, Special Issue: Energy Optimization is the Key to Affordable, Reliable Decarbonization, 32 (7): 106622. https://doi.org/10.1016/j.tej.2019.106622.

Edmunds, C., S. Galloway, I. Elders, W. Bukhsh, and R. Telford. 2020. "Design of a DSO-TSO Balancing Market Coordination Scheme for Decentralised Energy.” Transmission Distribution IET Generation 14 (5): 707-18. https://doi.org/10.1049/iet-gtd.2019.0865.

EIA (Energy Information Administration). 2019a. "Early November Cold Weather Prompts Fuel Switching in PJM and MISO." Today in Energy, December 2. https://www.eia.gov/todayinenergy/detail.php?id=42136. 2019b. "Extreme Cold in the Midwest Led to High Power Demand and Record Natural Gas Demand." Today in Energy, February 26. https://www.eia.gov/todayinenergy/detail.php?id=38472.

—. 2020. "Form EIA-860: 2019ER.” Electricity, September 15. https://www.eia.gov/electricity/data/eia860/.

- 2021. "Wholesale U.S. electricity prices were generally lower and less volatile in 2020 than 2019." Today in Energy, January 8.

https://www.eia.gov/todayinenergy/detail.php?id=46396\#: :text=As\%20a\%20result\%20of\%20th ese,first $\% 20$ half $\% 20$ of $\% 20$ the $\% 20$ year.

Ela, E., and M. O’Malley. 2016. "Scheduling and Pricing for Expected Ramp Capability in Real-Time Power Markets.” IEEE Transactions on Power Systems 31 (3): 1681-91. https://doi.org/10.1109/TPWRS.2015.2461535.

Ela, E., M. Milligan, and B. Kirby. 2011. Operating Reserves and Variable Generation, NREL/TP-550051978. Golden, CO: National Renewable Energy Laboratory. https://www.nrel.gov/docs/fy11osti/51978.pdf.

Ela, E., V. Gevorgian, A. Tuohy, B. Kirby, M. Milligan, and M. O’Malley. 2014. "Market Designs for the Primary Frequency Response Ancillary Service_-Part I: Motivation and Design." IEEE Transactions on Power Systems 29 (1): 421-31. https://doi.org/10.1109/TPWRS.2013.2264942.

Ela, E., M. Milligan, A. Bloom, A. Botterud, A. Townsend, and T. Levin. 2014. Evolution of Wholesale Electricity Market Design with Increasing Levels of Renewable Generation, NREL/TP-5D0061765. Golden, CO: National Renewable Energy Laboratory. https://www.nrel.gov/docs/fy14osti/61765.pdf.

EnerNex Corporation. 2011. Eastern Wind Integration and Transmission Study, SR-5500-47078. Golden, CO: National Renewable Energy Laboratory. https://www.nrel.gov/docs/fy11osti/47078.pdf.

EPRI (Electric Power Research Institute). 2016. Wholesale Electricity Market Design Initiatives in the United States: Survey and Research Needs, Technical Update. Palo Alto, CA: EPRI, November 7. https://www.epri.com/research/products/000000003002009273.

- 2019a. Ancillary Services in the United States: Technical Requirements, Market Designs and Price Trends, 3002015670. Palo Alto, CA: EPRI.

-2019b. Flexibility Assessment for the California ISO: Evaluating Flexibility Needs and Systemwide Feasible Installed Flexible Capacity, 3002013725. Palo Alto, CA: EPRI. http://membercenter.epri.com/abstracts/Pages/ProductAbstract.aspx?ProductId=00000000300201 3725 .

2019c. Independent System Operator and Regional Transmission Organization Price Formation Working Group White Paper: Current Practice and Research Gaps in Alternative (Fast-Start) Price Formation Modeling, Technical Update 3002013724. Palo Alto, CA: EPRI. https://www.epri.com/research/products/3002013724. 
2020. Power System Supply Resilience: The Need for Definitions and Metrics in DecisionMaking, Technical Update 3002014963. Palo Alto, CA: EPRI.

- 2021. Exploring the Impacts of Extreme Events, Natural Gas Fuel and Other Contingencies on Resource Adequacy. Technical Update 3002019300. Palo Alto, CA: EPRI

ERCOT (Electric Reliability Council of Texas). 2014. ERCOT Market Education: Congestion Revenue Rights. http://www.ercot.com/content/wcm/training_courses/53/crr_february2014.pdf.

- 2018a. "Creation of Primary Frequency Response Service Product and Revisions to Responsive Reserve," Nodal Protocol Revision Request No. 863, January 1.

http://www.ercot.com/content/wcm/key_documents_lists/144694/863NPRR-

01_Creation_of_Primary_Frequency_Response_Service_Product_and_Revisions_to_Responsive _Reserve_010118.doc.

2018b. Emerging Grid Issues Briefing. November 8.

http://www.ercot.com/content/wcm/lists/144928/LegislativeandPUCTBriefing-

EmergingGridIssues-FINAL.pdf.

2019a. ERCOT Planning Guide, Section 3: Regional Planning. Austin, TX.

www.ercot.com/content/wcm/current_guides/53526/03-121219.doc.

2019b. Strategic Plan 2019-2023.

http://www.ercot.com/content/wcm/lists/144926/ERCOT_Strategic_Plan_2019-2023.pdf.

. 2019c. Distributed Energy Resources (DERs) in ERCOT, January.

http://www.ercot.com/content/wcm/lists/164134/DER_OnePager_2019_FINAL.pdf.

- 2020a. Preliminary Seasonal Assessment of Resource Adequacy for the ERCOT Region (SARA)

Fall 2020, May 13. http:/www.ercot.com/content/wcm/lists/197378/SARA-

PreliminaryFall2020.pdf.

- 2020b. Creation of ERCOT Contingency Reserve Service and Revisions to Responsive Reserve, NPRR 863, July 23. http://www.ercot.com/mktrules/issues/NPRR863.

- 2020c. Methodology for Setting Maximum Shadow Prices for Network and Power Balance Constraints, December 8. http://www.ercot.com/mktrules/issues/OBDRR020

- 2021. Market Prices, Historical RTM Load Zone and Hub Prices, accessed March 10, 2021. http://www.ercot.com/mktinfo/prices.

Fan, L., and Guan, Y. 2016. "An Edge-based Formulation for Combined-Cycle Units." IEEE Transactions on Power Systems, 31 (3): 1809-1819.

Fan, L., Pan, K., \& Guan, Y. 2019. “A Strengthened Mixed-integer Linear Programming Formulation for Combined-cycle Units.” European Journal of Operational Research, 275 (3): 865-881.

Fang, R., and D.J. Hill. 2003. "A New Strategy for Transmission Expansion in Competitive Electricity Markets." IEEE Transactions on Power Systems 18 (1): 374-80. https://doi.org/10.1109/TPWRS.2002.807083.

Farmer, M., and R. Gramlich. 2020. Whether to FRRExit: Information States Need on the Costs and Benefits of Departing the PJM Capacity Construct. Miles Farmer PLLC and Grid Strategies LLC.

FERC (Federal Energy Regulatory Commission). 2010. Order Accepting Tariff Revisions: SPP Highway/Byway Methodology. Washington, DC: FERC.

2011. Order 755: Frequency Regulation Compensation in the Organized Wholesale Power

Market. Final Rule 137 FERC 61,064. Washington, DC: FERC. https://ferc.gov/sites/default/files/2020-06/OrderNo.755.pdf.

2013. Centralized Capacity Market Design Elements, Commission Staff Report ADI 3-7-000.

Washington, DC: FERC. https://www.ferc.gov/CalendarFiles/20130826142258-

Staff\%20Paper.pdf. 
2016a. Order 825: Settlement Intervals and Shortage Pricing in Markets Operated by Regional Transmission Organizations and Independent System Operators. Docket No. RM15-24-000. Washington, DC: FERC.

2016b. Order 831: Offer Caps in Markets Operated by Regional Transmission Organizations and Independent System Operators. Washington, DC: FERC.

2016c. Fast-Start Pricing in Markets Operated by Regional Transmission Organizations and Independent System Operators. Docket No. RM17-3-000. Washington, DC: FERC. https:/www.ferc.gov/whats-new/comm-meet/2016/121516/E-2.pdf.

.2018a. Order 841: Electric Storage Participation in Markets Operated by Regional Transmission Organizations and Independent System Operators. Washington, DC: FERC. https://ferc.gov/sites/default/files/2020-06/Order-841.pdf.

2018b. Order 844: Uplift Cost Allocation and Transparency in Markets Operated by Regional Transmission Organizations and Independent System Operators. Washington, DC: FERC. https://www.federalregister.gov/documents/2018/04/25/2018-08609/uplift-cost-allocation-andtransparency-in-markets-operated-by-regional-transmission-organizations.

2019a. 2019 Assessment of Demand Response and Advanced Metering, Staff Report.

Washington, DC: FERC. https://www.ferc.gov/sites/default/files/2020-04/DR-AMReport2019_0.pdf.

. 2019b. "FERC Directs PJM to Expand Minimum Offer Price Rule," News Release, December 19. https://www.ferc.gov/news-events/news/ferc-directs-pjm-expand-minimum-offer-price-rule0 .

2020a. "FERC Approves Market Rules to Protect Competition, Supplies in NYISO," News Release, February 20. https://www.ferc.gov/news-events/news/ferc-approves-market-rulesprotect-competition-supplies-nyiso.

2020b. Energy Primer: A Handbook of Energy Market Basics. Washington, DC: FERC. https://www.ferc.gov/sites/default/files/2020-06/energy-primer-2020.pdf. 2020c. Order 2222: Participation of Distributed Energy Resource Aggregations in Markets Operated by Regional Transmission Organizations and Independent System Operators. Washington, DC: FERC. https://www.ferc.gov/sites/default/files/2020-09/E-1_0.pdf. . 2020d. "Carbon Pricing in Organized Wholesale Electricity Markets." Washington, DC: FERC. https://www.ferc.gov/media/ad20-14-000-0.

Fink, S., K. Porter, C. Mudd, and J. Rogers. 2011. A Survey of Transmission Cost Allocation Methodologies for Regional Transmission Organizations, NREL/SR-5500-49880. Golden, CO: National Renewable Energy Laboratory. https://www.nrel.gov/docs/fy11osti/49880.pdf.

Garcia, M., and R. Baldick. 2019. "Real-Time Co-Optimization: Interdependent Reserve Types for Primary Frequency Response." In Proceedings of the Tenth ACM International Conference on Future Energy Systems, 550-55. Phoenix, AZ: Association for Computing Machinery. https://doi.org/10.1145/3307772.3335319.

Gaston, V. 2016. Cost Allocation and Cost Recovery Educational Session. PJM Transmission Replacement Processes Senior Task Force. PSEG Services Corporation. https://pjm.com//media/committees-groups/task-forces/trpstf/20160603/20160603-item-04-education-module-6cost-allocation-and-recovery.ashx.

Gerard, H., E. Rivero, and D. Six. 2016. Basic Schemes for TSO-DSO Coordination and Ancillary Services Provision, Technical Report D1.3. http://smartnet-project.eu/wpcontent/uploads/2016/12/D1.3_20161202_V1.0.pdf. 
Giacomoni, A. 2018. "FERC Docket EL18-34-000 Fast-Start Resources.” Presented at PJM Interconnection, December 18. https://www.pjm.com/-/media/committees-groups/taskforces/epfstf/20180118/20180118-fast-start-pricing.ashx.

Glazer, C., J. Morrison, P. Breakman, A. Clements, and L. Schwartz. 2017. The Future of CentrallyOrganized Wholesale Electricity Markets, Future Electric Utility Regulation Series. Berkeley, CA: Lawrence Berkeley National Laboratory. https://emp.lbl.gov/publications/future-centrallyorganized-wholesale.

Goggin, M., and R. Gramlich. 2020. A Moving Target: An Update on the Consumer Impacts of FERC Interference with State Policies in the PJM Region. Grid Strategies LLC. https://gridprogress.files.wordpress.com/2020/05/a-moving-target-paper.pdf.

Gorman, W., A. Mills, M. Bolinger, R. Wiser, N.G Singhal, E. Ela, and E. O’Shaughnessy. 2020.

"Motivations and Options for Deploying Hybrid Generator-plus-Battery Projects within the Bulk Power System." The Electricity Journal 33 (5): 106739.

Gramlich, R., and M. Hogan. 2019. Wholesale Electricity Market Design for Rapid Decarbonization: A Decentralized Markets Approach. San Francisco, CA: Energy Innovation. June. https://energyinnovation.org/wp-content/uploads/2019/06/Wholesale-Electricity-Market-DesignFor-Rapid-Decarbonization-A-Decentralized-Markets-Approach.pdf.

Gramlich, R., and J.F. Wilson. 2018. Maintaining Resource Adequacy in PJM While Accommodating State Policies: A Proposal for the Resource-Specific FRR Alternative. Prepared for Sierra Club, Natural Resources Defense Council, District of Columbia Office of the People's Council, and American Council on Renewable Energy by Grid Strategies LLC and Wilson Energy Economics, July 27. https://gridprogress.files.wordpress.com/2018/09/frr-rs-proposal-07-27-18-final.pdf.

Gramlich, R., M. Goggin, and J. Burwen. 2019. Enabling Versatility: Allowing Hybrid Resources to Deliver Their Full Value to Customers. Grid Strategies LLC and Energy Storage Association.

Gribik, P.R., D. Chatterjee, and N. Navid. 2012. "Potential New Products and Models to Improve an RTO's Ability to Manage Uncertainty." In 2012 IEEE Power and Energy Society General Meeting, 1-5. https://doi.org/10.1109/PESGM.2012.6345119.

Gribik, P. R., W.W. Hogan, and S.L. Pope. 2007. Market-Clearing Electricity Prices and Energy Uplift. http://www.lmpmarketdesign.com/papers/Gribik_Hogan_Pope_Price_Uplift_123107.pdf.

Grübel, J., T. Kleinert, V. Krebs, G. Orlinskaya, L. Schewe, M. Schmidt, and J. Thürauf. 2020. "On Electricity Market Equilibria with Storage: Modeling, Uniqueness, and a Distributed ADMM." Computers \& Operations Research 114 (February): 104783. https://doi.org/10.1016/j.cor.2019.104783.

Heath, B., and A.L. Figueroa-Acevedo. 2018. "Potential Capacity Contribution of Renewables at Higher Penetration Levels on MISO System.” In 2018 IEEE International Conference on Probabilistic Methods Applied to Power Systems (PMAPS), 1-6. https://doi.org/10.1109/PMAPS.2018.8440442.

Hedman, K. W., S.S. Oren, and R.P. O’Neill. 2011. "Optimal Transmission Switching: Economic Efficiency and Market Implications.” Journal of Regulatory Economics 40 (2): 111-40. https://doi.org/10.1007/s11149-011-9158-z.

Heidorn, R. 2020. "Stakeholders Seek TO 'Engagement' on End-of-Life Tx.” RTO Insider, March 25. https://rtoinsider.com/stakeholders-seek-engagement-end-of-life-transmission-158633/.

Hibbard, P.J., and C. Wu. 2019. Fuel and Energy Security in New York State: An Assessment of Winter Operational Risks for a Power System in Transition, Final Report. Boston, MA: Analysis Group. https://www.nyiso.com/documents/20142/9312827/Analysis\%20Group\%20Fuel\%20Security\%2 0Final\%20Report\%2020191111\%20Text.pdf/cbecabaf-806b-d554-ad32-12cfd5a86d9e. 
Hibbard, P., T. Schatzki, and S. Bolthrunis. 2017. Capacity Resource Performance in NYISO Markets: An Assessment of Wholesale Market Options.

https://www.analysisgroup.com/globalassets/uploadedfiles/content/insights/publishing/analysis_g roup_draft_capacity_resource_performance.pdf

Ho, J., B.F. Hobbs, P. Donohoo-Vallett, Q. Xu, S. Kasina, S.W. Park, and Y. Ouyang. 2016. Planning Transmission for Uncertainty: Applications and Lessons for the Western Interconnection, Final

Report. Prepared for Western Electricity Coordinating Council by The Johns Hopkins University, Baltimore, MD. www.wecc.org/Reliability/Planning-for-Uncertainty-Final-Report.pdf.

Hobbs, B.F., M.C. Hu, J.G. Inon, S.E. Stoft, and M. P. Bhavaraju. 2007. "A Dynamic Analysis of a Demand Curve-Based Capacity Market Proposal: The PJM Reliability Pricing Model.” IEEE Transactions on Power Systems 22 (1): 3-14. https://doi.org/10.1109/Tpwrs.2006.887954.

Hogan, W. W. 1992. "Contract Networks for Electric Power Transmission.” Journal of Regulatory Economics 4: 211-42.

- 2018. "Electricity Market Design and the Green Agenda." Presented at the 41st IAEE International Conference, Plenary Session: Electricity Market Design, Groningen, the Netherlands, June 12.

Hogan, W., and ERCOT Staff. 2013. "Back Cast of Interim Solution B+ to Improve Real-Time Scarcity Pricing." White Paper. ERCOT.

http://www.ercot.com/content/gridinfo/resource/2014/mktanalysis/White_Paper_Back_Cast_of_I nterim_Solution_B+_to_Improve_Re.pdf.

Hogan, W. W., and S. L. Pope. 2019 . PJM Reserve Markets: Operating Reserve Demand Curve Enhancements. Harvard University and FTI Consulting Inc., March 21. https://scholar.harvard.edu/whogan/files/hogan_pope_pjm_report_032119.pdf

Holttinen, H., M. O’Malley, D. Flynn, M. Milligan, and J. C. Smith. 2014. "Recommended Practices for Wind Integration Studies.” In 2014 IEEE PES General Meeting|Conference Exposition, 1-5. https://doi.org/10.1109/PESGM.2014.6939402.

Horger, T. 2019. "Fuel Security Senior Task Force Summary.” Presentation. December 19. https://pjm.com/-/media/committees-groups/committees/mrc/20191219/20191219-item-07-1fsstf-summary-presentation.ashx.

Hua, B., D.A. Schiro, T. Zheng, R. Baldick, and E. Litvinov. 2019. "Pricing in Multi-Interval Real-Time Markets." IEEE Transactions on Power Systems 34 (4): 2696-2705. https://doi.org/10.1109/TPWRS.2019.2891541.

Huang, S., Q. Wu, S.S. Oren, R. Li, and Z. Liu. 2015. "Distribution Locational Marginal Pricing Through Quadratic Programming for Congestion Management in Distribution Networks." IEEE

Transactions on Power Systems 30 (4): 2170-78. https://doi.org/10.1109/TPWRS.2014.2359977.

ISO-NE (Independent System Operator-New England). 2017. Revisions to Implement Full Integration of Demand Response: ER17-2164-000. Electronic Filing. https://www.iso-ne.com/staticassets/documents/2017/07/prd_implement_full_integration.pdf.

—. 2018a. ISO New England Manual for Financial Transmission Rights. Manual 06, October 4. https://www.iso-ne.com/staticassets/documents/2018/10/manual_06_financial_transmission_rights_rev11_20181004.pdf. 2018b. Operational Fuel-Security Analysis. January 17. https://www.iso-ne.com/staticassets/documents/2018/01/20180117_operational_fuel-security_analysis.pdf. 2019. Energy-Security Improvements. ISO Discussion Paper, Version 1, April. https://www.isone.com/staticassets/documents/2019/04/a00_iso_discussion_paper_energy_security_improvements.pdf. 
2020a. ISO-NE Regional Electricity Outlook 2020. https://www.iso-ne.com/staticassets/documents/2020/02/2020_reo.pdf.

. 2020b. "Regional System Plan and Related Analyses." https://www.iso-ne.com/systemplanning/system-plans-studies/rsp/.

—. 2020c. "Section II: OpenAccess Transmission Tariff," ER20-450-000.

- n.d. "Competitive Auctions with Sponsored Policy Resources (CASPR) Key Project.". https://www.iso-ne.com/committees/key-projects/implemented/caspr.

Jain, P. 2019. "Ancillary Services Shortage Pricing.” Marketing Issues Working Group, October 18. https://www.nyiso.com/documents/20142/8783504/Ancillary\%20Services\%20Shortage\%20Prici ng\%20analysis_10_18_2019\%20MIWG_final.pdf/2efb4d65-1fec-611a-77fc-43f08a869d9e.

Johnson, S.C., J.D. Rhodes, and M.E. Webber. 2020. "Understanding the Impact of Non-Synchronous Wind and Solar Generation on Grid Stability and Identifying Mitigation Pathways." Applied Energy 262 (March): 114492. https://doi.org/10.1016/j.apenergy.2020.114492.

Keane, A., M. Milligan, C. J. Dent, B. Hasche, C. D’Annunzio, K. Dragoon, H. Holttinen, N. Samaan, L. Soder, and M. O'Malley. 2011. "Capacity Value of Wind Power." IEEE Transactions on Power Systems 26 (2): 564-72. https://doi.org/10.1109/TPWRS.2010.2062543.

Kirschen, D.S., and G. Strbac. 2004. Fundamentals of Power System Economics. Wiley. https://www.wiley.com/en-us/Fundamentals+of+Power+System+Economics-p-9780470020586.

Klem, A., and G. Stephen. 2019. "Capacity Valuation of Demand Response in the Presence of Variable Generation through Monte Carlo Analysis." In 2019 IEEE Power Energy Society Innovative Smart Grid Technologies Conference (ISGT), 1-5. https://doi.org/10.1109/ISGT.2019.8791619.

Kotha, M. 2019. Capacity Zones Formation and Demand Curves Lesson 4: Capacity Zones and Demand Curves. ISO New England, October. https://www.iso-ne.com/staticassets/documents/2019/10/20191021-fcm101-lesson-4-capacity-zones-demandcurves_PRINT.pdf.

Kovanen, I., J. Rose, H. Pande, and G. Katsigiannakis. 2020. "The Potential Impacts of FERC's PJM Minimum Offer Price Rule Order.” https://www.icf.com/insights/energy/impacts-ferc-pjmminimum-offer-price? success $=$ true \& video $=$ dac8cc6009724998bbb659a6c0513990.

Kraan, O., G.J. Kramer, I. Nikolic, E. Chappin, and V. Koning. 2019. "Why Fully Liberalised Electricity Markets Will Fail to Meet Deep Decarbonisation Targets Even with Strong Carbon Pricing." Energy Policy 131 (August): 99-110. https://doi.org/10.1016/j.enpol.2019.04.016.

Krishnan, V., J. Ho, B.F. Hobbs, A.L. Liu, J.D. McCalley, M. Shahidehpour, and Q.P. Zheng. 2016. “CoOptimization of Electricity Transmission and Generation Resources for Planning and Policy Analysis: Review of Concepts and Modeling Approaches.” Energy Systems 7 (2): 297-332. https://doi.org/10.1007/s12667-015-0158-4.

Kristov, L. 2017. "Modernizing Transmission-distribution Interface Coordination for a High-DER Future." Presentation at Energy Advisory Committee Meeting, March 29. https://www.energy.gov/sites/prod/files/2017/04/f34/2_TD\%20Interface\%20Panel\%20-\%20Lorenzo\%20Kristov\%2C\%20CAISO.pdf.

Kyle, W. 2018. Flexible Ramping Product Uncertainty Calculation and Implementation Issues. CAISO, April 18. https://www.caiso.com/Documents/FlexibleRampingProductUncertaintyCalculationImplementati onIssues.pdf.

Lambert, E., Morais, H., Reis, F., Alves, R., Taylor, G., Souvent, A., and Suljanovic, N. 2018. "Practices and Architectures for TSO-DSO Data Exchange: European Landscape." In 2018 IEEE PES Innovative Smart Grid Technologies Conference Europe (ISGT-Europe), October, 1-6. 
Lau, J., and B.F. Hobbs. 2021. R\&D Recommendations for Transmission Grid Economic Analysis and Planning, Grid of the Future 2021 White Papers, Prepared for the Office of Electricity Delivery and Energy Reliability, National Electricity Division, U.S. Department of Energy, Draft.

Lawrence, M., and J. Vrins. 2019. Distributed Energy Resources: What DERs Are, Why They Matter, and How They Interact with Markets. MISO DERs Level 100 Workshop. Enerdynamics. https://cdn.misoenergy.org/20190321 DER 100 Workshop329253.pdf.

Le Cadre, H., I. Mezghani, and A. Papavasiliou. 2019. "A Game-Theoretic Analysis of TransmissionDistribution System Operator Coordination.” European Journal of Operational Research 274 (1): 317-39. https://doi.org/10.1016/j.ejor.2018.09.043.

Leslie, G., D.I. Stern, A. Shanker, and M.T. Hogan. 2020. "Designing Electricity Markets for High Penetrations of Zero or Low Marginal Cost Intermittent Energy Sources.” SSRN Scholarly Paper ID 3601485. Social Science Research Network, Rochester, NY. https://doi.org/10.2139/ssrn.3601485.

Levin, T., J. Kwon, and A. Botterud. 2019. "The Long-Term Impacts of Carbon and Variable Renewable Energy Policies on Electricity Markets.” Energy Policy 131 (August): 53-71. https://doi.org/10.1016/j.enpol.2019.02.070.

Lew, D., D. Bartlett, A. Groom, P. Jorgensen, J. O'Sullivan, R. Quint, B. Rew, B. Rockwell, S. Sharma, and D. Stenclik. 2019. "Secrets of Successful Integration: Operating Experience with High Levels of Variable, Inverter-Based Generation." IEEE Power and Energy Magazine 17 (6): 24-34. https://doi.org/10.1109/MPE.2019.2930855.

Li, W., P. Du, and N. Lu. 2018. "Design of a New Primary Frequency Control Market for Hosting Frequency Response Reserve Offers from Both Generators and Loads." IEEE Transactions on Smart Grid 9 (5): 4883-92. https://doi.org/10.1109/TSG.2017.2674518.

Liu, J., H. Cheng, P. Zeng, L. Yao, C. Shang, and Y. Tian. 2018. "Decentralized Stochastic Optimization Based Planning of Integrated Transmission and Distribution Networks with Distributed Generation Penetration.” Applied Energy 220 (June): 800-813. https://doi.org/10.1016/j.apenergy.2018.03.016.

Liu, Y. 2017. "Demand Response and Energy Efficiency in the Capacity Resource Procurement: Case Studies of Forward Capacity Markets in ISO New England, PJM and Great Britain.” Energy Policy 100: 271-82.

London Economics. 2020. Review of PJM's Auction Revenue Rights and Financial Transmission Rights. Sponsored by PJM Interconnection. https://pjm.com/-/media/committees-groups/taskforces/afmtf/postings/lei-review-of-pjm-arrs-and-ftrs-report.ashx.

Loutan, C., and V. Gevorgian. 2020. Avangrid Renewables Tule Wind Farm Demonstration of Capability to Provide Essential Grid Services. CAISO, Avangrid Renewables, National Renewable Energy Laboratory, General Electric.

Loutan, C., P. Klauer, S. Chowdhury, S. Hall, M. Morjaria, V. Chadliev, N. Milam, C. Milan, and V. Gevorgian. 2017. Demonstration of Essential Reliability Services by a 300-MW Solar Photovoltaic Power Plant, NREL/TP-5D00-67799. Golden, CO: National Renewable Energy Laboratory. https://doi.org/10.2172/1349211.

Mai, T., J. Bistline, Y. Sun, W. Cole, C. Marcy, C. Namovicz, and D. Young. 2018. "The Role of Input Assumptions and Model Structures in Projections of Variable Renewable Energy: A Multi-Model Perspective of the U.S. Electricity System.” Energy Economics 76 (October): 313-24. https://doi.org/10.1016/j.eneco.2018.10.019.

Majidi-Qadikolai, M., and R. Baldick. 2016. "Integration of N-1 Contingency Analysis with Systematic Transmission Capacity Expansion Planning: ERCOT Case Study." IEEE Transactions on Power Systems 31 (3): 2234-45. https://doi.org/10.1109/tpwrs.2015.2443101. 
Mayorga Gonzalez, D., J. Hachenberger, J. Hinker, F. Rewald, U. Häger, C. Rehtanz, and J. Myrzik. 2018. "Determination of the Time-Dependent Flexibility of Active Distribution Networks to Control Their TSO-DSO Interconnection Power Flow.” In 2018 Power Systems Computation Conference (PSCC), 1-8. https://doi.org/10.23919/PSCC.2018.8442865.

Mays, J., D.P. Morton, and R.P. O’Neill. 2019. “Asymmetric Risk and Fuel Neutrality in Electricity Capacity Markets.” Nature Energy 4 (11): 948-56. https://doi.org/10.1038/s41560-019-0476-1.

McCalley, J.D., P. Maloney, P. Liu, B.F. Hobbs, and Q. Xu. 2018. TIP 330: Co-Optimization and Anticipative Planning Methods for Bulk Transmission and Resource Planning under Long-Run Uncertainties, Technology Innovation Project, Closing Project Brief. Bonneville Power Administration, Portland, OR. www.bpa.gov/Doing\%20Business/TechnologyInnovation/CPBProjectBriefs/TX-CPB-3302018.pdf.

McCalley, J., J. Caspary, C. Clack, W. Galli, M. Marquis, D. Osborn, A. Orths, J. Sharp, V. Silva, and P. Zeng. 2017. "Wide-area planning of electric infrastructure: Assessing investment options for lowcarbon futures." IEEE Power and Energy Magazine 15 (6): 83-93.

Meng, L., J. Zafar, S.K. Khadem, A. Collinson, K.C. Murchie, F. Coffele, and G.M. Burt. 2020. "Fast Frequency Response from Energy Storage Systems-A Review of Grid Standards, Projects and Technical Issues." IEEE Transactions on Smart Grid 11 (2): 1566-81. https://doi.org/10.1109/TSG.2019.2940173.

Mezghani, I., A. Papavasiliou, and H. Le Cadre. 2018. "A Generalized Nash Equilibrium Analysis of Electric Power Transmission-Distribution Coordination." In Proceedings of the Ninth International Conference on Future Energy Systems, 526-31. Karlsruhe, Germany: Association of Computing Machinery. https://doi.org/10.1145/3208903.3214346.

Milligan, M. 2018. "Sources of Grid Reliability Services.” The Electricity Journal 31 (9): 1-7. https://doi.org/10.1016/j.tej.2018.10.002.

Milligan, M., B.A. Frew, K. Clark, and A.P. Bloom. 2017. Marginal Cost Pricing in a World without Perfect Competition: Implications for Electricity Markets with High Shares of Low Marginal Cost Resources, NREL/TP-6A20-69076. Golden, CO: National Renewable Energy Laboratory. https://www.nrel.gov/docs/fy18osti/69076.pdf.

Milligan, M., B. Frew, E. Ibanez, J. Kiviluoma, H. Holttinen, and L. Soder. 2017. “Capacity Value Assessments of Wind Power." Wiley Interdisciplinary Reviews-Energy and Environment 6 (1). https://doi.org/10.1002/wene.226.

Milligan, M., B.A. Frew, A. Bloom, E. Ela, A. Botterud, A. Townsend, and T. Levin. 2016. "Wholesale Electricity Market Design with Increasing Levels of Renewable Generation: Revenue Sufficiency and Long-Term Reliability.” The Electricity Journal 29 (2): 26-38.

Mills, A.D., and P. Rodriguez. 2019. Drivers of the Resource Adequacy Contribution of Solar and Storage for Florida Municipal Utilities. Berkeley, CA: Lawrence Berkeley National Laboratory.

MISO (Midcontinent Independent System Operator). 2013. Compensation for Restoration Energy Whitepaper. Prepared by MISO Emergency Preparedness and Power System Restoration Working Group, May 29.

https://cdn.misoenergy.org/Compensation\%20for\%20Restoration\%20Energy\%20Whitepaper333 792.pdf.

2016. Ramp Capability Product Development IR048. https://www.misoenergy.org/stakeholderengagement/issue-tracking/ramp-capability-product-development.

. 2017a. MTEP 17 Report. Carmel, IN: MISO.

https://www.misoenergy.org/planning/planning/previous-mtepreports $/ \# t=10 \& p=0 \& \mathrm{~s}=$ FileName $\& \mathrm{sd}=$ desc. 
2017b. "Automatic Generation Control (AGC) Enhancement for Fast-Ramping Resources Study." https://www.misoenergy.org/stakeholder-engagement/issue-tracking/automaticgeneration-control-agc-enhancement-for-fast-ramping-resources/

. 2018a. "MTEP 19 Futures Development Workshop.” Carmel, IN: MISO. March 20.

https://cdn.misoenergy.org/20180320\%20MTEP19\%20Futures\%20Workshop\%20Presentation15 0635.pdf.

2018b. Short Term Capacity Reserve Evaluation, March 31.

https://cdn.misoenergy.org/20180412\%20MSC\%20Item\%2008\%20STCR\%20Evaluation\%20Pa per170646.pdf.

. 2018c. MISO Enhanced Combined Cycle Model White Paper I-Research and Development Report.

https://cdn.misoenergy.org/20180209\%20ECCTT\%20White\%20Paper\%201\%20Research\%20\& \%20Development\%20Report118729.pdf.

—. 2018d. Enhanced Combined Cycle Model White Paper 2 - Conceptual Design. https://cdn.misoenergy.org/20180914\%20ECCTT\%20White\%20Paper\%202\%20Conceptual\%20 Design_20180823273208.pdf. 2019a. MISO BPM 004: FTR and ARR. https://cdn.misoenergy.org/BPM\%20004\%20-\%20FTR\%20and\%20ARR49548.zip. 2019b. MISO Forward: Deliverability and Value in a 3D Future MIISO. https://cdn.misoenergy.org/MISO\%20FORWARD324749.pdf.

- 2019c. ELMP III White Paper I: R\&D Report and Design Recommendation on Short-Term Enhancements. https://cdn.misoenergy.org/20190117\%20MSC\%20Item\%2005\%20ELMP\%20III\%20Whitepaper 315878.pdf.

2019d. DER 300 Workshop. April 9. https://cdn.misoenergy.org/20190424 DER 300 Combined Slides336066.pdf.

2019e. DER 300 Michigan, Post-Workshop Summary. October.

https://cdn.misoenergy.org/20191001 MISO DER 300 in Michigan Participant

Summary394023.pdf.

2019f. Aligning Resource Availability and Need. December.

https://cdn.misoenergy.org/Aligning\%20Resource\%20Availability $\% 20$ and $\% 20 \mathrm{Need} \% 20(\mathrm{RAN}) 4$ 10587.pdf.

2020a. Business Practices Manual: Transmission Planning. Carmel, IN: MISO. https://cdn.misoenergy.org/BPM\%20021\%20-\%20Transmission\%20Pricing49590.zip.

- 2020b. MISO and DER: Framing and Discussion Document. Technical Report. Carmel, IN: MISO. https://cdn.misoenergy.org/DER Framing Report 2019397951.pdf.

2020c. MISO Regional and Interregional Cost Allocation. Reference Document, August 12.

Carmel, IN: MISO.

https://cdn.misoenergy.org/MISO\%20Regional\%20and\%20Interregional\%20Cost\%20Allocation \%20Reference90295.pdf.

- 2020d. Resource Adequacy Business Practice Manual. Carmel, IN: MISO. https://www.misoenergy.org/legal/business-practice-manuals/. 2021. Business Practice Manual 20 Transmission Planning, Version 23. Carmel, IN: MISO. https://www.misoenergy.org/legal/business-practice-manuals/, 4.4.2.2.1.1 Resource Forecasting, p. 107. 
MISO Market Subcommittee. 2018. Multi-Day Financial Commitments. Market Roadmap ID:31, February 8. https://cdn.misoenergy.org/20180208\%20MSC\%20Item\%2006\%20MultiDay\%20Commitment122381.pdf.

MJB\&A (M.J. Bradley \& Associates), LLC. 2020. FERC Order on Minimum Offer Price Rule in PJM Markets, MJB\&A Summary. January 3. Concord, MA: MJB\&A. https://www.mjbradley.com/sites/default/files/MJBA-Summary_FERC-PJM-MOPR-Order.pdf.

Monitoring Analytics. 2020a. 2019 State of the Market Report for PJM. https://www.monitoringanalytics.com/reports/PJM_State_of the Market/2019.shtml. 2020b. Potential Impacts of the MOPR Order: The Independent Market Monitor for PJM, March.

https://www.monitoringanalytics.com/reports/Reports/2020/IMM_Potential_Impacts_of_the_MO PR_Order_20200320.pdf.

More than Smart. 2017. Coordination of Transmission and Distribution Operations in a High Distributed Energy Resource Electric Grid. Prepared by staff of CAISO, PG\&E, SCE, and SDG\&E with support from More Than Smart. https:/www.caiso.com/Documents/MoreThanSmartReportCoordinatingTransmission_DistributionGridOperations.pdf.

Murphy, S., J. Apt, J. Moura, and F. Sowell. 2018. "Resource Adequacy Risks to the Bulk Power System in North America." Applied Energy 212 (February): 1360-76. https://doi.org/10.1016/j.apenergy.2017.12.097.

Murphy, S., L. Lavin, and J. Apt. 2020. "Resource Adequacy Implications of Temperature-Dependent Electric Generator Availability." Applied Energy 262: 114424.

Muzhikyan, A., L. Walter, S. Benner, and A. Giacomoni. 2019. "Limited Energy Capability Resource Duration Requirement for Participation in PJM Capacity Market.” In 2019 IEEE Power Energy Society Innovative Smart Grid Technologies Conference (ISGT), 1-5. https://doi.org/10.1109/ISGT.2019.8791630.

Navid, N., and G. Rosenwald. 2012. "Market Solutions for Managing Ramp Flexibility with High Penetration of Renewable Resource." IEEE Transactions on Sustainable Energy 3 (4): 784-90. https://doi.org/10.1109/TSTE.2012.2203615.

NERC (North American Electric Reliability Corporation). 2011. Methods to Model and Calculate Capacity Contributions of Variable Generation for Resource Adequacy Planning. Princeton, NJ: NERC. March. https://www.nerc.com/files/ivgtf1-2.pdf. 2020a. 2020 Long-Term Reliability Assessment. December. https://www.nerc.com/pa/RAPA/ra/Reliability\%20Assessments\%20DL/NERC_LTRA_2020.pdf. 2020b. Ensuring Energy Adequacy with Energy-Constrained Resources. Page 92. December. https://www.nerc.com/comm/RSTC/AgendaHighlightsandMinutes/RSTC_Meeting_Agenda_Pac kage_Dec_16 2020_ATTENDEE.pdf\#search=Energy-Constrained\%20Resources.

Newberry, D., D. Pollitt, R. Ritz, and W. Strielkowski. 2017. "Market Design for a High-renewables European Electricity System." Renewable and Sustainable Energy Reviews 91: 695-707.

Newell, S.A., and P. Ruiz. 2019. "Market Design for Winter Energy Security in New England," Responses to ISO-NE Proposal. The Brattle Group, April. https:/www.iso-ne.com/staticassets/documents/2019/04/a3a_nextera_presentation_responses_to_iso_proposal.pdf.

Newell, S.A., J.M. Hagerty, J.P. Pfeifenberger, B. Zhou, E. Shorin, P. Fitz, S.H. Gang, P.S. Daou, and J. Wroble. 2018. PJM Cost of New Entry Combustion Turbines and Combined-Cycle Plants with June 1, 2022 Online Date. Prepared for PJM Interconnection, LLC, by The Brattle Group and Sargent \& Lundy, April 19. https://www.pjm.com/ /media/committeesgroups/committees/mic/20180425-special/20180425-pjm-2018-cost-of-new-entry-study.ashx. 
Newell, S.A., J.M. Hagerty, K. Spees, J.P. Pfeifenberger, Q. Liao, C. D. Ungate, and J. Wroble. 2014. Cost of New Entry Estimates for Combustion Turbine and Combined Cycle Plants in PJM with June 1, 2018 Online Date. Prepared for PJM Interconnection, LLC, by The Brattle Group and Sargent \& Lundy, May 18.

http://www.ercot.com/content/wcm/lists/114801/Cost_of_New_Entry_Estimates_for_Combustio n_Turbine_and_Combined_Cycle_Plants_in_PJM.pdf.

Newell, S.A., D.L. Oates, J.P. Pfeifenberger, K. Spees, J.M. Hagerty, J.I. Pedtke, and M. Witkin. 2018. Fourth Review of PJM's Variable Resource Requirement Curve. The Brattle Group. https://www.pjm.com/-/media/library/reports-notices/special-reports/2018/20180420-pjm-2018variable-resource-requirement-curve-study.ashx?la=en.

Newell, S.A., K. Spees, J.P. Pfeifenberger, I. Karkatsouli, N. Wintermantel, and K. Carden. 2014. Estimating the Economically Optimal Reserve Margin in ERCOT. Prepared for ERCOT by The Brattle Group and Astrape Consulting, January 31.

http://www.ercot.com/content/wcm/lists/114801/Estimating_the_Economically_Optimal_Reserve _Margin_in_ERCOT_Revised.pdf.

Newell, S.A., R. Carroll, A. Kaluzhny, K. Spees, K. Carden, N. Wintermantel, and A. Krasny. 2018. Estimation of the Market Equilibrium and Economically Optimal Reserve Margins for the ERCOT Region, 2018 Update. Prepared for ERCOT by The Brattle Group, December $\mathrm{https}$ //brattlefiles.blob.core.windows.net/files/15258_estimation_of_the_market_equilibrium_and _economically_optimal_reserve_margins_for_the_ercot_region.pdf.

Nicholson, E. 2019. "Procuring Flexibility in Wholesale Electricity Markets." Current Sustainable/Renewable Energy Reports 6 (3): 100-106. https://doi.org/10.1007/s40518-01900133-4.

Nicholson, E., and A. Quinn. 2019. "Wholesale Electricity Markets in the United States: Identifying Future Challenges Facing Commercial Energy." IEEE Power and Energy Magazine 17 (1): 6772. https://doi.org/10.1109/MPE.2018.2872304.

NYISO (New York Independent System Operator). 2017a. Distributed Energy Resources Roadmap for New York's Wholesale Electricity Markets, A Report by the New York Independent System Operator, January. https:/www.nyiso.com/documents/20142/1391862/Distributed Energy Resources Roadmap.pdf/ec0b3b64-4de2-73e0-ffef-49a4b8b1b3ca. . 2017b. Distributed Energy Resources Market Design Concept Proposal, A Report by the New York Independent System Operator, January. https://www.nyiso.com/documents/20142/1391862/Distributed-Energy-Resources-2017-MarketDesign-Concept-Proposal.pdf/122a815f-b767-e67f-0a8f-323e5489c2b1. . 2019a. Management Response to the Analysis Group's Report Fuel and Energy Security in New York State: An Assessment of Winter Operational Risks for a Power System in Transition. NYISO, November.

https://www.nyiso.com/documents/20142/9312827/NYISO\%20Management\%20Response\%20to \%20Analysis\%20Group\%20Fuel\%20and\%20Energy\%20Security\%20Study.pdf/56513957-ba430555-c475-30fe4a4c079a. .2019b. Enabling Technologies for Distributed Energy Resources. https:/www.nyiso.com/documents/20142/8922912/Enabling\%20Technologies\%20for\%20DER \%20Study\%20Report.pdf/58b44121-6711-985a-a137-c8007cd7edfc. 2019c. Reliability and Market Considerations for a Grid in Transition. NYISO. December 20 https://www.nyiso.com/documents/20142/2224547/Reliability-and-Market-Considerations-for-aGrid-in-Transition-20191220\%20Final.pdf/61a69b2e-0ca3-f18c-cc39-88a793469d50. 
2020a. 2020-2024 Strategic Plan: The New York Independent System Operator. NYISO. https://www.nyiso.com/documents/20142/2225883/2020-Strategic-Plan.pdf/e282579c-9988-3ff65164-dfea1abfbc13?t=1576765917219.

2020b. Comprehensive System Planning Process. NYISO. https://www.nyiso.com/en/cspp.

2020c. NYISO Manual 03: Transmission Congestion Contracts Manual. Rensselaer, NY: NYISO

TCC Market Operations, February.

https://www.nyiso.com/documents/20142/2923301/tcc_mnl.pdf/cc3f4273-3e2f-b969-550a$01 \mathrm{c} 2587 \mathrm{a} 70 \mathrm{~d} 6$.

2020d. OATT Section 31.5.7. NYISO OATT, November 25.

https://nyisoviewer.etariff.biz/ViewerDocLibrary/MasterTariffs/9FullTariffNYISOOATT.pdf. 2020e. Manual 4: Installed Capacity Manual. Rensselaer, NY: NYISO Capacity Market

Products, June 5. https://www.nyiso.com/documents/20142/2923301/icap_mnl.pdf/234db95c9a91-66fe-7306-2900ef905338.

_. 2020f. 2020 Load and Capacity Data ("Gold Book"). NYISO.

www.nyiso.com/documents/20142/2226333/2020-Gold-Book-Final-Public.pdf/9ff426ab-e32528bc-97cf-106d792593a1?t=1588251915775.

O’Neill, R.P., E.B. Fisher, B.F. Hobbs, and R. Baldick. 2008. “Towards a Complete Real-Time Electricity Market Design.” Journal of Regulatory Economics 34 (3): 220-50. https://doi.org/10.1007/s11149-008-9062-3.

O’Neill, R.P., P.M. Sotkiewicz, B.F. Hobbs, M.H. Rothkopf, and W.R. Stewart. 2005. "Efficient MarketClearing Prices in Markets with Nonconvexities." European Journal of Operational Research 164 (1): 269-85. https://doi.org/10.1016/j.ejor.2003.12.011.

Oren, S.S., and K.W. Hedman. 2010. "Revenue Adequacy, Shortfall Allocation and Transmission Performance Incentives in FTR/FGR Markets." In 2010 IREP Symposium Bulk Power System Dynamics and Control-VIII (IREP), Aug. 1-6, Rio de Janeiro, Brazil: IEEE. https://doi.org/10.1109/IREP.2010.5563297.

Papavasiliou, A., and I. Mezghani. 2018. "Coordination Schemes for the Integration of Transmission and Distribution System Operations.” In 2018 Power Systems Computation Conference (PSCC), 1-7. https://doi.org/10.23919/PSCC.2018.8443022.

Park, B., Z. Zhou, A. Botterud, and P. Thimmapuram. 2020. "Probabilistic Zonal Reserve Requirements for Improved Energy Deliverability with Wind Power." IEEE Transactions on Power Systems, 35 (6): 4324-34. https://doi.org/10.1109/TPWRS.2020.2992763.

Parks, K. 2019. "Declining Capacity Credit for Energy Storage and Demand Response with Increased Penetration." IEEE Transactions on Power Systems 34 (6): 4542-46. https://doi.org/10.1109/TPWRS.2019.2915805.

Rocha-Garrido, P. 2020. "Effective Load Carrying Capability (ELCC)." February 24. https://www.pjm.com/-/media/committees-groups/committees/mic/2020/20200224-capacitymarket/20200224-item-02-effective-load-carrying-capability-elcc.ashx.

Patterson, A.T. 2019. "Impact of Carbon Pricing on Potential Expanded Buyer-Side Mitigation in the NYISO Markets.” Concord, MA: The NorthBridge Group, November. https://policyintegrity.org/documents/NorthBridge_NY_BSM_Carbon_Price_Study.pdf.

Pfeifenberger, J.P., S.A. Newell, K. Spees, A. Murray, and I. Karkatsouli. 2014. Third Triennial Review of PJM's Variable Resource Requirement Curve. Prepared for PJM by The Brattle Group, May 15. http://citeseerx.ist.psu.edu/viewdoc/download?doi=10.1.1.487.4798\&rep=rep1\&type=pdf.

Pfeifenberger, J.P, K. Spees, K. Carden, and N. Wintermantel. 2013. Resource Adequacy Requirements: Reliability and Economic Implications. The Brattle Group. https://www.ferc.gov/legal/staffreports/2014/02-07-14-consultant-report.pdf. 
Pickering, S., I. Rostkowski, S. Foley, M. Huebsch, Z. Claes, D. Ticknor, J. McCalley, J. Okullo, B. Heath, and A. Figueroa-Acevedo. 2019. "Power System Resource Adequacy Evaluation under Increasing Renewables for the Midwestern US." In 2019 North American Power Symposium (NAPS), 1-6. https://doi.org/10.1109/NAPS46351.2019.9000346.

PJM Energy Price Formation Senior Task Force. 2018. "Price Formation.” PJM, December 14https://www.pjm.com/-/media/committees-groups/task-forces/epfstf/20181214/20181214-item04-price-formation-paper.ashx.

PJM Interconnection. 2017a. Demand Response Strategy. PJM Interconnection, June 28. https://www.pjm.com/ /media/library/reports-notices/demand-response/20170628-pjm-demandresponse-strategy.ashx.

2017b. Advancing Zero Emissions Objectives through PJM's Energy Markets: A Review of Carbon-Pricing Frameworks. PJM Interconnection.

https://www.pjm.com/ /media/library/reports-notices/special-reports/20170502-advancing-zeroemission-objectives-through-pjms-energy-markets.ashx.

2018a. Capacity Repricing or in the Alternative MOPR-Ex Proposal: Tariff Revisions to Address Impacts of State Public Policies on the PJM Capacity Market. Before the FERC, Docket No. ER18___000, PJM Interconnection, LLC, April 9. https://www.pjm.com/directory/etariff/FercDockets/3576/20180409-er18-1314-000.pdf. . 2018b. "Capacity Reform Filing." Before the FERC, October 2. https://www.pjm.com//media/documents/ferc/filings/2018/20181002-capacity-reform-filing-w0172181x8DF47.ashx. 2018c. Fuel Security Analysis: A PJM Resilience Initiative. December 17. PJM Interconnection. https://www.pjm.com/-/media/library/reports-notices/fuel-security/2018-fuel-securityanalysis.ashx?la=en.

- 2019a. PJM Manual 20: PJM Resource Adequacy Analysis, Revision 10, Effective Date March 21, 2019. Resource Adequacy Planning, PJM. https://www.pjm.com//media/documents/manuals/m20.ashx.

2019b. "PJM W-DER Draft Proposal Summary." Re-post of January 26, 2018, Education Session, June 10. https://www.pjm.com/-/media/committeesgroups/subcommittees/ders/20190610/20190610-item-07-pjm-w-der-draft-proposalsummary.ashx.

.2019c. "Economic Dispatch and Border Adjustment Options." Carbon Pricing Senior Task Force, August 26. https://www.pjm.com/-/media/committees-groups/taskforces/cpstf/20190826/20190826-item-03-economic-dispatch-and-border-adjustments.ashx. 2019d. "Modeling Generation Senior Task Force Update \& Recommendation." Presented at the Modeling Generation Senior Task Force Meeting, PJM Interconnection, November 14. 2020a. "PJM Study of Carbon Pricing \& Potential Leakage Mitigation Mechanisms." Presented at the Carbon Pricing Senior Task Force, PJM Interconnection, January 14. https://www.pjm.com/-/media/committees-groups/task-forces/epfstf/20180118/20180118-faststart-pricing.ashx.

2020b. PJM Manual 18: PJM Capacity Market, Revision 46, Effective Date November 19, 2020. Capacity Market \& Demand Response Operations, PJM. https://www.pjm.com//media/documents/manuals/m18.ashx. 2020c PJM Manual 06: Financial Transmission Rights, Revision 25, Effective Date July 23, 2020. Market Simulation Department, PJM. https://www.pjm.com//media/documents/manuals/m06.ashx. 
2020d PJM Manual 14B: PJM Region Transmission Planning Process, Revision 48, Effective Date October 1, 2020. Transmission Planning Department, PJM. https://www.pjm.com/$/$ media/documents/manuals/m14b.ashx.

Pozo, D., E.E. Sauma, and J. Contreras. 2013. "A Three-Level Static MILP Model for Generation and Transmission Expansion Planning.” IEEE Transactions on Power Systems 28 (1): 202-10. https://doi.org/10.1109/tpwrs.2012.2204073.

Rachunok, B., A. Staid, J. Watson, D. L. Woodruff, and D. Yang. 2018. "Stochastic Unit Commitment Performance Considering Monte Carlo Wind Power Scenarios." In 2018 IEEE International Conference on Probabilistic Methods Applied to Power Systems (PMAPS), Boise, ID, 1-6.

Rahimi, F., and F. Albuyeh. 2016. "Applying Lessons Learned from Transmission Open Access to Distribution and Grid-Edge Transactive Energy Systems." In 2016 IEEE Power Energy Society Innovative Smart Grid Technologies Conference (ISGT), 1-5. https://doi.org/10.1109/ISGT.2016.7781236.

Rebello, E., D. Watson, and M. Rodgers. 2020. "Ancillary Services from Wind Turbines: Automatic Generation Control (AGC) from a Single Type 4 Turbine.” Wind Energy Science 5 (1): 225-36. https://doi.org/10.5194/wes-5-225-2020.

Rebours, Y.G., D.S. Kirschen, M. Trotignon, and S. Rossignol. 2007. "A Survey of Frequency and Voltage Control Ancillary Services-Part I: Technical Features." IEEE Transactions on Power Systems 22 (1): 350-57. https://doi.org/10.1109/TPWRS.2006.888963.

Riaz, S., and P. Mancarella. 2019. "On Feasibility and Flexibility Operating Regions of Virtual Power Plants and TSO/DSO Interfaces.” In 2019 IEEE Milan PowerTech, 1-6. https://doi.org/10.1109/PTC.2019.8810638.

Riesz, J., J. Gilmore, and I. Macgill. 2016. "Assessing the Viability of Energy-Only Markets with 100\% Renewables: An Australian National Electricity Market Case Study." Economics of Energy \& Environmental Policy 5 (1): 105-30. https://doi.org/10.2307/26189401.

Rivier, M., and L. Olmos. 2020. "Cost allocation issues in transmission network investment." In Transmission Network Investment in Liberalized Power Markets (pp. 135-170). Springer, Cham.

Sakti, A., A. Botterud, and F. O'Sullivan. 2018. "Review of Wholesale Markets and Regulations for Advanced Energy Storage Services in the United States: Current Status and Path Forward." Energy Policy 120 (September): 569-79. https://doi.org/10.1016/j.enpol.2018.06.001.

Salon, C., O. Huet, and F. Blanc. 2013. "How DSO Could Facilitate System Optimization in New Market Mechanisms for Distributed Resources.” In 22nd International Conference and Exhibition on Electricity Distribution (CIRED 2013), 1-4. https://doi.org/10.1049/cp.2013.0914.

Saraf, N., K. McIntyre, J. Dumas, and S. Santoso. 2009. "The Annual Black Start Service Selection Analysis of ERCOT Grid.” IEEE Transactions on Power Systems 24 (4): 1867-74. https://doi.org/10.1109/TPWRS.2009.2030290.

Sauma, E.E., and S.S. Oren. 2007. "Economic Criteria for Planning Transmission Investment in Restructured Electricity Markets.” IEEE Transactions on Power Systems 22 (4): 1394-1405. https://doi.org/10.1109/TPWRS.2007.907149.

Schäfer, S., and L. Altvater. 2019. "On the Functioning of a Capacity Market with an Increasing Share of Renewable Energy.” Journal of Regulatory Economics 56 (1): 59-84.

Schmalensee, R. 2019. “On the Efficiency of Competitive Energy Storage.” SSRN Scholarly Paper ID 3405058. Rochester, NY: Social Science Research Network. https://doi.org/10.2139/ssrn.3405058.

Sebastian, M., J. Marti, and P. Lang. 2008. "Evolution of DSO Control Centre Tool in Order to Maximize the Value of Aggregated Distributed Generation in Smart Grid." In CIRED Seminar 2008: SmartGrids for Distribution, 1-4. https://doi.org/10.1049/ic:20080408. 
Shahmohammadi, A., R. Sioshansi, A.J. Conejo, and S. Afsharnia. 2018. "Market Equilibria and Interactions between Strategic Generation, Wind, and Storage." Applied Energy 220 (June): 87692. https://doi.org/10.1016/j.apenergy.2017.10.035.

Siddiqui, A.S., R. Sioshansi, and A.J. Conejo. 2019. "Merchant Storage Investment in a Restructured Electricity Industry.” The Energy Journal 40 (4). https://doi.org/10.5547/01956574.40.4.asid.

Silva, J., J. Sumaili, R.J. Bessa, L. Seca, M.A. Matos, V. Miranda, M. Caujolle, B. Goncer, and M.Sebastian-Viana. 2018. "Estimating the Active and Reactive Power Flexibility Area at the TSO-DSO Interface." IEEE Transactions on Power Systems 33 (5): 4741-50. https://doi.org/10.1109/TPWRS.2018.2805765.

Singhal, N.G., N. Li, and K.W. Hedman. 2018. "A Reserve Response Set Model for Systems with Stochastic Resources.” IEEE Transactions on Power Systems 33 (4): 4038-49. https://doi.org/10.1109/TPWRS.2017.2776202.

Sioshansi, R., S.H. Madaeni, and P. Denholm. 2013. "A Dynamic Programming Approach to Estimate the Capacity Value of Energy Storage.” IEEE Transactions on Power Systems 29 (1): 395-403.

Smith, C. 2019. "Stakeholders Say Critical Tx Planning PJM's Responsibility." RTO Insider, November 28. https://rtoinsider.com/critical-tx-planning-pjm-responsibility-146692/.

Soder, L., and M. Amelin. 2008. "A Review of Different Methodologies Used for Calculation of Wind Power Capacity Credit.” In 2008 IEEE Power and Energy Society General Meeting - Conversion and Delivery of Electrical Energy in the 21st Century, 1-5. https://doi.org/10.1109/PES.2008.4596666.

SPP (Southwest Power Pool). 2017. 2017 Strategic Plan Revised Initiatives. Strategic Planning Committee. Little Rock, AR: SPP. https://spp.org/documents/55101/2017\%20strategic\%20plan $\% 20-\% 20$ revised $\% 20$ initiatives.pdf.

- 2018a. 2019 Integrated Transmission Planning Scope. Little Rock, AR: SPP Engineering. October 16. https://www.spp.org/documents/60005/2019\%20itp\%20scope.pdf. 2018b. SPP Congestion Hedging FAQ. May 7. https://www.spp.org/documents/39277/tcr\%20markets\%20frequently\%20asked\%20questions.pdf

- 2018c. An Evolutionary Approach to Advancing Technologies. Operations Engineering, SPP, October 16. https://www.spp.org/documents/56322/an evolutionary approach to advancing technologies v2.pdf.

2018d. Resource Adequacy Workbook Instruction Manual. SPP Engineering, October 1. https://www.spp.org/documents/45078/resource\%20adequacy\%20workbook\%20instruction\%20 manual_10-01-2018.pdf.

- 2019b. Holistic Integrated Tariff Team Report: Preparing for a Reliable and Cost-Effective Future. Little Rock, AR: SPP. https://www.spp.org/documents/60323/hitt\%20report.pdf. 2019c. 2019 ELCC Wind Study Report. SPP Resource Adequacy, August 13. https://www.spp.org/documents/60434/2019\%20elcc\%20wind\%20study\%20report.pdf. 2019d. 2019 ELCC Solar Study Report. SPP Resource Adequacy. https://www.spp.org/Documents/60747/2019\%20ELCC\%20Solar\%20Study\%20Report.docx. 2020, Integrated Transmission Planning Manual Version 2.8. https://spp.org/Documents/60911/itp\%20manual\%20version\%202.8.docx,

SPP Market Design. 2020. SIR18 HITT R3C Multi-Day Market. March 18. https://www.spp.org/documents/61834/sir18_hittr3cmultidaymarket_sppbod.pdf.

SPP Market Monitoring Unit. 2019. Self-Committing in SPP Markets: Overview, Impacts, and Recommendations. Market Monitoring Unit, SPP, December. https://spp.org/documents/61118/spp\%20mmu\%20self-commit\%20whitepaper.pdf. 
Spyrou, E., J.L. Ho, B.F. Hobbs, R.M. Johnson, and J.D. McCalley. 2017. "What Are the Benefits of CoOptimizing Transmission and Generation Investment? Eastern Interconnection Case Study." IEEE Transactions on Power Systems 32 (6): 4265-77. https://doi.org/10.1109/tpwrs.2017.2660249.

Stoft, S. 2002. Power System Economics: Designing Markets for Electricity. Wiley. https://www.wiley.com/en$\mathrm{gb} /$ Power+System+Economics\%3A+Designing+Markets+for+Electricity-p-9780471150404.

Tierney, S., and P. Hibbard. 2019. "Clean Energy in New York State: The Role and Economic Impacts of a Carbon Price in NYISO's Wholesale Electricity Markets.” White Paper, Analysis Group, October. https://www.analysisgroup.com/Insights/publishing/clean-energy-in-new-york-state-therole-and-economic-impacts-of-a-carbon-price-in-nyisos-wholesale-electricity-markets/.

Tuohy, A. 2016. "The Evolution of Ancillary Services to Facilitate Integration of Variable Renewable and Distributed Energy Resources: A Survey of Some Changes to the Ancillary Services and Ancillary Service Markets.” Technical Update, EPRI. https://www.epri.com/research/products/000000003002008987.

Tuohy, A., and E. Lannoye. 2014. "Metrics for Quantifying Flexibility in Power System Planning." Technical Paper Series. Power System Transformation, EPRI. https://www.epri.com/research/products/3002004243.

Vázquez, C., M. Rivier, and I.J. Pérez-Arriaga. 2002. "A Market Approach to Long-Term Security of Supply.” IEEE Transactions on Power Systems 17 (2): 349-57.

Wang, B., and B.F. Hobbs. 2016. "Real-Time Markets for Flexiramp: A Stochastic Unit CommitmentBased Analysis." IEEE Transactions on Power Systems 31 (2): 846-60. https://doi.org/10.1109/TPWRS.2015.2411268.

Wang, C., T. Peng, P. B. Luh, P. Gribik, and L. Zhang. 2013. "The Subgradient Simplex Cutting Plane Method for Extended Locational Marginal Prices." IEEE Transactions on Power Systems 28 (3): 2758-67. https://doi.org/10.1109/TPWRS.2013.2243173.

Wang, F., and K.W. Hedman. 2015. "Dynamic Reserve Zones for Day-Ahead Unit Commitment with Renewable Resources." IEEE Transactions on Power Systems 30 (2): 612-20. https://doi.org/10.1109/TPWRS.2014.2328605.

Wiser, R.H., A. Mills, J. Seel, T. Levin, and A. Botterud. 2017. Impacts of Variable Renewable Energy on Bulk Power System Assets, Pricing, and Costs. Berkeley, CA: Lawrence Berkeley National Laboratory. https://doi.org/10.2172/1411668.

Xu, L. 2017. Discussion on Flexible Ramping Product. Market Surveillance Committee Meeting, CASIO, Folsom, CA. https://www.caiso.com/Documents/Discussion_FlexibleRampingProduct.pdf.

$\mathrm{Xu}$, Q., and B.F. Hobbs. 2019. "Value of Model Enhancements: Quantifying the Benefit of Improved Transmission Planning Models." IET Generation, Transmission \& Distribution 13 (13): 2836-45.

Ye, H., and Z. Li. 2018. "Deliverable Robust Ramping Products in Real-Time Markets." IEEE Transactions on Power Systems 33 (1): 5-18. https://doi.org/10.1109/TPWRS.2017.2688972.

Zhao, F., T.X. Zheng, and E. Litvinov. 2018. "Constructing Demand Curves in Forward Capacity Market." IEEE Transactions on Power Systems 33 (1): 525-35. https://doi.org/10.1109/Tpwrs.2017.2686785.

Zhao, J., T. Zheng, and E. Litvinov. 2020. "A Multi-Period Market Design for Markets with Intertemporal Constraints.” IEEE Transactions on Power Systems 35 (4): 3015-25. https://doi.org/10.1109/TPWRS.2019.2963022.

Zipf, M., and D. Möst. 2016. "Cooperation of TSO and DSO to Provide Ancillary Services.” In 2016 13th International Conference on the European Energy Market (EEM), 1-6. https://doi.org/10.1109/EEM.2016.7521273. 


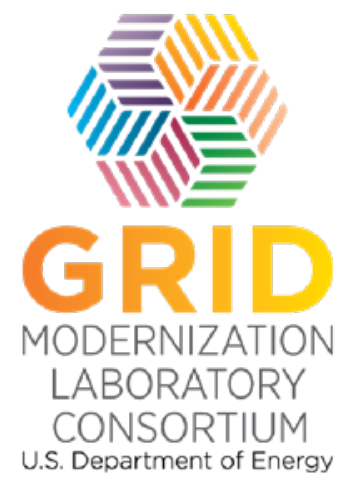

National Renewable Energy Laboratory 15103 Denver West Parkway

Golden, CO 80401

303-275-3000 - www.nrel.gov 